MARCELO ROSSI

\title{
DESENVOLVIMENTO DO PROCESSO DE CULTIVO DE Escherichia coli RR1
}

\author{
Dissertação apresentada à Escola \\ Politécnica da Universidade de \\ São Paulo para obtenção do \\ título de Mestre em Engenharia.
}

São Paulo

2001 
Rossi, Marcelo

Desenvolvimento do processo de cultivo de Escherichia coli RR1. São Paulo, 2001. $100 p$

Dissertação (Mestrado) - Escola Politécnica da Universidade de São Paulo. Departamento de Engenharia Química.

1. Escherichia coli 2. Síntese de hormônio de crescimento humano (hGH) 3. Meio de cultivo 4. Proteína recombinante I. Universidade de São Paulo. Escola Politécnica. Departamento de Engenharia Química. II. t 


\section{Agradecimentos}

À professora Beatriz, por sua orientação e conselhos, necessários para a realização deste trabalho.

Ao Dr. Paulo Bartolini, Maria Tereza e Regina, do IPEN/CNEN, pela participação no desenvolvimento do projeto de $\mathrm{hGH}$, pelas contribuições e sugestões para a realização deste trabalho.

Aos professores Maria Candida, Aldo e Andreas, pelo apoio técnico, estímulo e convívio ao longo do trabalho.

Aos amigos, Celso, Sandra, Renata, Elis, Daniela, Olavo, Patrícia, Grace, Thomaz, Juliana, Luciana, Maria Elisa, Bruno, Gisele, Rosaina, não só pela contribuição para realização do presente trabalho, mas pelo companheirismo e amizade durante o Mestrado.

Aos funcionários Orlinda, Euclides, Andréa, Valter e Vanessa, pelo importante apoio técnico durante o preparo dos ensaios.

Aos funcionários da secretaria (Elizete, Graça, Sônia e Alexandre) e da biblioteca (Maria Lúcia, Maria, Cris Villela e Marília), pela presteza no atendimento.

A todos aqueles que, direta ou indiretamente, contribuíram para a realização desta dissertação.

À CAPES, pela concessão da bolsa de Mestrado. 


\section{SUMÁRIO}

Lista de Abreviaturas

Lista de Tabelas

Lista de Figuras

Resumo

Abstract

1) INTRODUÇÃO

2) REVISÃO BIBLIOGRÁFICA 3

2.1) Metabolismo da Escherichia coli $\quad 7$

2.2) Sistema de expressão 11

2.3) Produção do hormônio de crescimento humano (hGH) em Escherichia coli 14

2.4) Considerações sobre o meio de cultivo 16

2.4.1) Suplementação do meio de cultivo durante o crescimento $\begin{array}{ll}\text { de cepas auxotróficas } & 17\end{array}$

2.4.2) Suplementação do meio de cultivo com aminoácidos precursores da proteína alvo

3) MATERIAIS E MÉTODOS 22

3.1) Meios de Cultivo 22

3.1.1) Meio TYE 22

3.1.2) Meio 2XTY 22

3.1.3) Meio para inóculo 23

3.1.4) Meio para biorreator 23

3.2) Soluções 23

3.2.1) Solução de Micronutrientes 1

3.2.2) Solução de Micronutrientes 2

3.2.3) Solução de Aminoácidos 24

3.2.4) Solução de Antibióticos $\quad 24$

3.2.5) Soluções para alimentação dos ensaios descontínuos alimentados 24 
3.3) Microrganismo 25

3.4) Preparo do pré-inóculo e do inóculo 25

3.5) Cultivos em biorreator 26

3.6) Esterilizações 26

$\begin{array}{ll}3.7) \text { Procedimentos analíticos } & 27\end{array}$

3.7.1) Determinação da concentração celular $(X) \quad 27$

3.7.2) Determinação de acetato 28

3.7.3) Determinação da concentração de hGH 28

3.7.4) Determinação da vazões de entrada de ar no biorreator 29

3.7.5) Determinações das frações molares de $\mathrm{O}_{2}$ e $\mathrm{CO}_{2}$ no gás de exaustão do biorreator $\quad 29$

3.8) Determinação da velocidade específica de respiração $\left(Q_{02}\right)$

3.9) Tratamento dos Dados Experimentais 30

3.9.1) Cálculo das velocidades específicas 31

3.9.2) Fator de conversão substrato a células 32

3.9.3) Produtividade em células 32

3.10) Exemplo de cálculo para obtenção das concentrações de acetato 32

3.11) Processo descontínuo alimentado 34

3.11.1) Processo descontínuo alimentado por pulsos 34

3.11.2) Processo descontínuo alimentado por vazão exponencial 35

4) RESULTADOS E DISCUSSÃO 37

4.1) Ensaios em incubador rotativo $\quad 37$

4.2) Ensaios em biorreator $\quad 47$

4.3) Ensaios descontínuos-alimentados $\quad 67$

4.4) Indução por choque térmico 80

4.5) Balanço gasoso

5) CONCLUSÕES 88

6) ANEXO I 90

REFERÊNCIAS BIBLIOGRÁFICAS

Apêndices 


\section{Lista de Abreviaturas}

acetil-CoA acetil-coenzima A

AMPc $=\mathrm{cAMP}=$ adenosina 3 ', 5' monofosfato cíclico

ATP adenosina trifosfato

BMS Biomassa seca

CAT cloranfenicol acetil transferase

CNEN Comissão Nacional de Energia Nuclear

CoA coenzima A

DNA ácido desoxirribonuclêico

EMP Via de Entner-Meyers-Parnas (Via Glicolítica)

FAD flavina adenina dinucleotídeo (forma oxidada)

$\mathrm{FADH}_{2}$ flavina adenina dinucleotídeo (forma reduzida)

hGH hormônio de crescimento humano

HMF hexose monofosfato (via de consumo de glicose)

IPEN Instituto de Pesquisas em Energia Nuclear

LEB Laboratório de Engenharia Bioquímica

NAD nicotidamina adenina dinucleotídeo (forma oxidada)

$\mathrm{NADH}$ nicotidamina adenina dinucleotídeo (forma reduzida) 


$\begin{array}{ll}\text { OD } & \text { tensão de oxigênio dissolvido } \\ \text { PPP } & \text { Via de Pentose Fosfato } \\ \text { RNA } & \text { ácido ribonuclêico } \\ \text { RNAm } & \text { RNA mensageiro } \\ \text { TCA } & \text { ciclo dos ácidos tricarboxílicos ou ciclo de Krebs } \\ \text { TPP } & \text { tiamina pirofosfato } \\ \text { Vvm } & \text { volume de ar por volume de meio por minuto. }\end{array}$

\section{Listas de Símbolos}

$\mu$ $=\mu_{\mathrm{x}}=$ velocidade específica de crescimento $\quad\left(\mathrm{h}^{-1}\right)$

$\mu_{\text {máx }}$ velocidade específica máxima de crescimento $\left(\mathrm{h}^{-1}\right)$

$\mu_{\mathrm{s}} \quad$ velocidade específica de consumo de glicose $\left(\mathrm{g} \mathrm{g}^{-1} \mathrm{~h}^{-1}\right)$

$\mu_{\mathrm{s} \text { máx }} \quad$ velocidade específica máxima de consumo de glicose $\left(\mathrm{g} \mathrm{g}^{-1} \mathrm{~h}^{-1}\right)$

$\mu_{\mathrm{Ac}} \quad$ velocidade específica de formação (ou síntese) de acetato $\left(\mathrm{mg} \mathrm{g}^{-1} \mathrm{~h}^{-1}\right)$

$\mu_{\mathrm{Ac} \text { máx }} \quad$ velocidade específica máxima de formação de acetato $\left(\mathrm{mg} \mathrm{g}^{-1} \mathrm{~h}^{-1}\right)$

$\mathrm{Y}_{\mathrm{X} / \mathrm{G}} \quad$ fator de conversão substrato à células $\quad\left(\mathrm{g} \mathrm{g}^{-1}\right)$

Qo2 velocidade específica de consumo de oxigênio $\left(\mathrm{mmol} \mathrm{g}^{-1} \mathrm{~h}^{-1}\right)$

Qo2 máx velocidade específica máxima de consumo de oxigênio $\left(\mathrm{mmol} \mathrm{g}^{-1} \mathrm{~h}^{-1}\right)$ 


$\begin{array}{ll}\mathrm{Q}_{\mathrm{CO} 2} & \text { velocidade específica de formação de } \mathrm{CO}_{2}\left(\mathrm{mmol} \mathrm{g}^{-1} \mathrm{~h}^{-1}\right) \\ \mathrm{P}_{\mathrm{x}} & \text { produtividade em células }\left(\mathrm{g} \mathrm{L}^{-1} \mathrm{~h}^{-1}\right) \\ \mathrm{t}_{\mathrm{f}} & \text { tempo de cultivo decorrido para exaustão da glicose (h) } \\ \mathrm{T} & \text { tempo total de ensaio }(\mathrm{h}) \\ \mathrm{X}_{0} & \text { concentração celular inicial }\left(\mathrm{g} \mathrm{L}^{-1}\right) \\ \mathrm{X}_{\mathrm{f}} & \text { concentração inicial de glicose } \quad\left(\mathrm{g} \mathrm{L}^{-1}\right) \\ \mathrm{G}_{0} & \\ \mathrm{G}_{\mathrm{f}} & \text { concentração final de glicose }\left(\mathrm{g} \mathrm{L}^{-1}\right) \\ \mathrm{C}_{\mathrm{T}} & \text { concentração total de ácido acético } \quad\left(\mathrm{g} \mathrm{Lol} \mathrm{L}^{-1}\right)\end{array}$




\section{Lista de Tabelas}

Tabela 3.11.2.1 Variáveis utilizadas no cálculo da alimentação exponencial e seus respectivos valores

Tabela 4.1.1

Resumo das características dos ensaios realizados em incubador rotativo

Tabela 4.1.2 Resumo dos parâmetros dos ensaios realizados em incubador rotativo

Tabela 4.2.1 Descrição dos ensaios realizados no primeiro conjunto

Tabela 4.2.2

Parâmetros dos ensaios em biorreator realizados no primeiro conjunto

Tabela 4.2.3 Descrição dos ensaios realizados no segundo conjunto

Tabela 4.2.4

Parâmetros dos ensaios em biorreator realizados no segundo conjunto

Tabela 4.3.1 Características dos ensaios descontínuos-alimentados

Tabela 4.3.2 Parâmetros dos ensaios realizados na forma descontínuaalimentada

Tabela 4.5.1

Resultados obtidos com o balanço gasoso para os ensaios descontínuos e descontínuos-alimentados

Tabela A1 Valores experimentais do ensaio S1

Tabela A2

Valores experimentais do ensaio S2

Tabela A3

Valores experimentais do ensaio S3

Tabela A4 Valores experimentais do ensaio S4

Tabela A5 Valores experimentais do ensaio S5

Tabela A6 Valores experimentais do ensaio S6

Tabela A7 Valores experimentais do ensaio S7

Tabela A8 Valores experimentais do ensaio S8

Tabela A9 Valores experimentais do ensaio S9 
Tabela A12 Valores experimentais do ensaio d2 …................................ A6

Tabela A13 Valores experimentais do ensaio d3 …................................ A7

Tabela A14 Valores experimentais do ensaio d4 …............................. A7

Tabela A15 Valores experimentais do ensaio d5 ................................ A8

Tabela A16 Valores experimentais do ensaio d6 .................................... A9

Tabela A17 Valores experimentais do ensaio d7 ................................... A10

Tabela A18 Valores experimentais do ensaio d8 f.................................. A11

Tabela A19 Valores experimentais do ensaio d9 ................................. A12

Tabela A20 Valores experimentais do ensaio d10 ….............................. A13

Tabela A21 Valores experimentais do ensaio da-1 ............................... A14



Tabela A23 Valores experimentais do ensaio da-3 f.............................. A16

Tabela B1 Valores de tensão de oxigênio dissolvido para os ensaios d3 e $\mathrm{d} 4$ e para os ensaios d9 e d10 ............................................... B1

Valores experimentais e ajustados de velocidade específica de

Tabela B2 respiração (consumo de oxigênio) para os ensaios da-1, da-2 e da-3 


\section{Lista de Figuras}

Figura 2.1.1 Resumo das reações catalisadas pelo complexo de piruvato desidrogenase, onde L refere-se ao grupamento lipoíla e E1 corresponde a enzima piruvato desidrogenase, E2 a dihidrolipoil transacetilase e E3 a ihidrolipoil desidrogenase. A coenzima TPP é a tiamina pirufosfato

Figura 2.1.2 Relações entre as principais vias de catabolismo e o TCA (ciclo de Krebs). A via de glicose-6-fosfato a piruvato é a via glicolítica (ou via EMP) e a via de pentose-fosfato (PPP), que desvia no 6-fosfogluconato, unem-se novamente no fosfogliceraldeído. Em aerobiose, os elétrons do NADH e FADH2 são transferidos à cadeia de transporte de elétrons com a formação de ATP; mas em anaerobiose, o NADH é reoxidado por um aceptor orgânico de elétrons (B), gerado durante o catabolismo

Figura 4.1.1 Concentrações celulares dos ensaios S1 $\left(30{ }^{\circ} \mathrm{C}\right)$ e $\mathrm{S} 2\left(37^{\circ} \mathrm{C}\right) . . \quad 40$

Figura 4.1.2 Concentrações de glicose dos ensaios S1 $\left(30{ }^{\circ} \mathrm{C}\right)$ e $\mathrm{S} 2\left(37^{\circ} \mathrm{C}\right) . \quad 40$

Figura 4.1.3 Concentrações celular e de glicose para os ensaios S3 e S4 ... $\quad 42$

Figura 4.1.4 Concentrações celular e de glicose para os ensaios S5, S6 e S7

Figura 4.1.5 Concentrações celular e de glicose para os ensaios S9 e S10. Comparação entre as velocidades dos dois ensaios

Figura 4.2.1 Ensaio d2: (a) Concentrações celular e de glicose; (b) Concentração e perfil da velocidade específica de síntese de acetato

Figura 4.2.3 Ensaio d3: (a) Perfis das concentrações celular e de glicose; (b) velocidades específicas de crescimento e de consumo de glicose 
Figura 4.2.4 Ensaio d4: (a) Perfis das concentrações celular e de glicose; (b) velocidades específicas de crescimento e de consumo de glicose

Figura 4.2.5 Ensaio d5: (a) Perfis das concentrações celular e de glicose: (b) velocidades específicas de crescimento e de consumo de glicose; (c) concentração e velocidade específica de formação de acetato

Figura 4.2.6 Variações da concentração de oxigênio dissolvido para os ensaio d3 e d4 durante o tempo de cultivo

Figura 4.2.7 Ensaio d6: (a) Concentrações celular e de glicose; (b) velocidades específicas de crescimento e de consumo de glicose

Figura 4.2.8 Ensaio d7: (a) Concentração celular e de glicose; (b) velocidade específica de crescimento; (c) concentração e velocidade específica de formação de acetato

Figura 4.2.9 Ensaio d8: (a) Concentrações celular e de glicose; (b) velocidade específica de crescimento; (c) concentração e velocidade específica de formação de acetato

Figura 4.2.10 Ensaio d9: (a) concentrações celular e de glicose; (b) velocidades específicas de crescimento e de consumo de glicose; (c) concentração e velocidade específica de formação de acetato

Figura 4.2.11 Ensaio d10: (a) Concentrações celular e de glicose; (b) velocidades específicas de crescimento e de consumo de glicose; (c) concentração e velocidade específica de formação de acetato

Figura 4.2.12 Variações das concentrações de oxigênio dissolvido para os ensaios d9 e d10 durante o tempo de cultivo 
Figura 4.2.13 Ensaio da-1: (a) concentrações celular e de glicose mostrando o instante de cada pulso; (b) as velocidades específicas de crescimento e de consumo de glicose

Figura 4.2.14 Ensaio da-1: (a) concentração de acetato produzido pelo microrganismo; (b) velocidades específicas de crescimento e de formação de acetato

Figura 4.2.15 Perfil da variação da concentração de oxigênio dissolvido para o ensaio da-1

Figura 4.2.16 Ensaio da-2: (a) concentrações celular e de glicose na fase descontínua e no pulso; (b) velocidades específicas de crescimento e de consumo de glicose

Figura 4.2.17 Ensaio da-2: (a) concentração de acetato produzido pelo microrganismo; (b) velocidade específica de crescimento e de formação de acetato

Figura 4.2.18 Perfil da variação da concentração de oxigênio dissolvido para o ensaio da-2

Figura 4.2.19 Ensaio da-3: (a) concentrações celular e de glicose; (b) velocidades específicas de crescimento e de consumo de glicose

Figura 4.2.20 Ensaio da-3: (a) concentração de acetato produzido; (b) velocidades específicas de crescimento e de formação de acetato

Figura 4.2.21 Perfil da variação da concentração de oxigênio dissolvido para o ensaio da-3

Figura 4.4.1.1 Cromatograma de uma amostra padrão de hGH e seu tempo de retenção

Figura 4.4.1.2 Cromatograma da amostra 0 submetida ao choque osmótico para avaliação da quantidade de hGH 
Figura 4.4.1.3 Cromatograma da amostra 3 horas e submetida ao choque osmótico para avaliação da quantidade de hGH

Figura 4.5.1 Velocidade específica de consumo de oxigênio (QO2) em função do tempo para o ensaio da-1

Figura 4.5.2 Velocidade específica de consumo de oxigênio em função do tempo para o ensaio da-2

Figura 4.5.3 Velocidade específica de consumo de oxigênio em função do tempo para o ensaio da-3 


\section{Resumo}

No presente trabalho, cultivou-se o microrganismo Escherichia coli RR1, contendo o vetor que carrega o gene estrutural para a síntese do hormônio de crescimento humano (hGH) (baseado no promotor $\mathrm{p}_{\mathrm{L}}$ e $\mathrm{p}_{\mathrm{R}}$ do fago $\lambda$ sob controle do repressor termosensível cI857) em processos descontínuo e descontínuo-alimentado realizados em biorreatores com capacidade útil de 2 e $4 \mathrm{~L}$. Tal cepa é auxotrófica com relação aos aminoácidos 1-leucina e 1-prolina e à tiamina (vitamina B1).

Nos cultivos descontínuos com concentrações menores de extrato de levedura e bactotriptona em relação ao meio denominado basal, a concentração celular foi baixa, atingindo 2,4 g.L. $\mathrm{L}^{-1}$, com fator de conversão glicose à células de $0,25 \mathrm{~g} . \mathrm{g}^{-1}$. Em cultivos descontínuos com aumento (em relação ao meio basal) da concentração de extrato de levedura e de bactotriptona e com adição de l-prolina, a concentração celular alcançou valores da ordem de 5,9 g. $\mathrm{L}^{-1}$ e fator de conversão glicose à células de $0,48 \mathrm{~g} . \mathrm{g}^{-1}$, simultaneamente à maior formação de acetato $\left(2,5 \mathrm{~g} . \mathrm{L}^{-1}\right)$, este último prejudicial ao processo. Contudo, este resultado de crescimento celular não se repetiu devido a mudança do lote de células utilizado entre o primeiro e o segundo conjunto de ensaios.

Os cultivos descontínuos-alimentados foram realizados com diferentes formas de alimentação bem como diferentes composições de solução de alimentação. Uma alimentação contínua com velocidade exponencial e composição semelhante à do meio, pareceu ser a mais favorável, levando à concentração celular final de 9,2 g.L $L^{-1}$ e fator de conversão glicose a células, na fase descontínua-alimentada, de $0,36 \mathrm{~g} \cdot \mathrm{g}^{-1}$.

Os ensaios com indução térmica não foram eficientes provavelmente devido à problemas na detecção das concentração de glicose existente no instante inicial da ativação da síntese do hGH. Esta glicose presente pode ter prejudicado a formação do hGH por conseqüência do processo fermentativo causado pelo aumento da temperatura e pela presença de elevada concentração de nutrientes complexos.

O meio de cultivo utilizado possivelmente não supriu as necessidades metabólicas da célula para a síntese do hormônio de crescimento humano e em nenhum dos cultivos com indução térmica houve a produção de hGH. 


\section{ABSTRACT}

In the present work, the host Escherichia coli RR1, having the vector with the structural gene for human growth hormone $(\mathrm{hGH})$ synthesis, based on $\mathrm{p}_{\mathrm{L}}$ or $\mathrm{p}_{\mathrm{R}}$ promoters from bacteriophage $\lambda$ under the control of the thermosensitive repressor cI857, was cultivated in batch and fed-batch cultures in bioreactors with working volumes of 2 and 4 L. This host has amino acids (1-leucine and 1-proline) and thiamine (Vitamin B1) auxotrophy.

Batch cultures under low yeast extract and bacto-tryptone concentrations (relative to the basal medium) resulted in a low biomass yield $\left(2.4\right.$ g. $\left.\mathrm{L}^{-1}\right)$ and cell yield on glucose $\left(0.25 \mathrm{~g} . \mathrm{g}^{-1}\right)$. Increasing these concentrations and adding 1 -proline to the medium led to higher biomass formation (5.9 g.. $\left.\mathrm{L}^{-1}\right)$, cell yield on glucose $\left(0.48 \mathrm{~g} . \mathrm{g}^{-1}\right)$ and acetate high levels $\left(2.5\right.$ g.. $\left.\mathrm{L}^{-1}\right)$, which were harmful to the process. However, these results of cellular growth were not reproducible due to different cell stocks applied.

The fed-batch cultures were performed under different feeding strategies and different nutrients concentrations of the feeding solution. A continuous exponential feeding rate with growth medium-like composition seemed to be the most favorable, reaching final cellular concentration of $9.2 \mathrm{~g} . \mathrm{L}^{-1}$ and yield on glucose on fed-batch mode of $0.36 \mathrm{~g} \cdot \mathrm{g}^{-1}$.

The heat-shock runs were not efficient probably due to problems in detection of glucose concentration existing on initial instant of hGH activation synthesis. Glucose interferes with the hGH synthesis because the fermentation caused by temperature shift and presence of high complex nutrients concentration.

The culture medium used, probably was not able to supply cell metabolic needs for the human growth hormone synthesis and in no other temperature-induced experiment the hGH production was observed. 


\section{Introdução}

Microrganismos geneticamente modificados são utilizados industrialmente para a produção de hormônios, antibióticos, enzimas e proteínas em geral. Na produção de moléculas heterólogas, não somente o desenvolvimento das cepas que carregam os genes exógenos torna-se uma etapa importante, como também o desenvolvimento do processo de produção. Neste sentido, o estudo das condições adequadas de cultivo em reator é um requisito essencial para a viabilidade do processo.

Por muitos anos, a bactéria Escherichia coli tem sido o procarioto predominante nos estudos utilizando técnicas de biologia molecular e DNA recombinante, e devido ao vasto conhecimento acumulado sobre ela, tem sido o microrganismo hospedeiro mais utilizado para a expressão de produtos recombinantes. DONOVAN et al. (1996) comentam o desenvolvimento de promotores que permitem acionar a síntese de moléculas-alvo de forma bem regulada através da modificação de condições do processo em questão. Tais condições incluem: presença de moléculas específicas, variações de temperatura, de pH e de oxigênio dissolvido (OD).

Um importante enfoque para a otimização da produção de uma proteína recombinante, durante um cultivo de E. coli, tem sido atingir simultaneamente alta concentração celular e produção específica da proteína-alvo. A concentração da fonte de carbono, ou de outros nutrientes necessários, é controlada empregando-se diferentes estratégias de cultivo, de modo a limitar sua concentração (controle da velocidade específica $(\mu))$ e minimizar a produção de certos produtos de fermentação, como o acetato. 
Este composto é prejudicial à produção de proteínas heterólogas e é o principal produto das vias fermentativas de E. coli (SUAREZ et al., 1998; SUAREZ, 1997; BAUER et al., 1990; JENSEN, CARLSEN, 1990).

O Dr. Paolo Bartolini, do Departamento de Aplicação de Técnicas Nucleares em Ciências Biológicas (IPEN-CNEN), vem desenvolvendo o processo para a obtenção do hormônio de crescimento humano (hGH) - através de um projeto apoiado pelo Programa de Inovação Tecnológica em Pequenas Empresas - em E. coli RR1 (contendo o vetor phGH) a vários anos. Recentemente, o Laboratório de Engenharia Bioquímica (LEB) do Departamento de Engenharia Química da EPUSP o tem auxiliado neste desenvolvimento na forma de um mestrado.

O presente trabalho teve como objetivo estudar:

i) a cinética de crescimento deste microrganismo em meios de cultivo com diferentes concentrações de nutrientes de composição complexa. Tais variações visaram obter um aumento da massa celular;

ii) a implicação da composição do meio na síntese da molécula de hGH.

Embora neste trabalho não tenha ocorrido tal síntese, o IPEN obteve resultados de produção de hGH em um meio de cultivo mais complexo em relação ao utilizado neste trabalho. 


\section{Revisão Bibliográfica}

$\mathrm{Na}$ literatura encontram-se várias trabalhos utilizando Escherichia coli, desde a aplicação de compostos obtidos por clonagem, como as enzimas alimentares específicas ( p. ex.; dismutase superóxido cobre/zinco do fruto mamão papaya (LIN et al.,1998), sacarose sintetase de feijão (NAKAI; TONOUCHI, 1997) ); enzimas de outros microrganismos para síntese de alguns compostos (como a endoglucanase do Tricoderma reesei), a utilização do gene luc da luciferase (para a detecção da presença de pequenas quantidades de benzenos, toluenos e outros compostos aromáticos em águas residuárias), e principalmente aplicações na área farmacêutica, como na produção de hormônios.

BERMEJO et al. (1998) fez uso de genes de Clostridium acetobutilicum, sob controle do promotor thl, para a produção de acetona em E. coli por redução do acetato metabolizado. Observou-se um aumento da concentração de acetona da ordem de $150 \%$ em cultivos descontínuos-alimentados, demonstrando a habilidade da célula em obter solventes a partir de glicose como fonte de carbono e energia.

Também como exemplo do uso de genes clonados, LEE; KIM (1998), fazendo uso do gene que codifica a síntese de estafiloquinase (sak) em Staphylococcus aureus, inserido em um vetor pKK-ompA sob controle do promotor tac em E. coli JM 109, expressou esta enzima no espaço periplásmico, obtendo uma concentração de $15 \mu \mathrm{g} \mathrm{mL}{ }^{-1}$ e de $5 \mu \mathrm{g} \mathrm{mL} \mathrm{L}^{-1}$ no meio extracelular.

UI; OKAGIMA (1997) obtiveram 2,3 butanodiol clonando genes de três enzimas de Klebsiella pneumoniae em E. coli com glicose como fonte de carbono. O maior rendimento alcançado, em meso-butanodiol, foi de $27 \%$ (w/w ou $10,7 \mathrm{~g} \mathrm{~L}^{-1}$ ) em relação à glicose 
inicial (4\%) e a concentração máxima obtida, em 2,3-butanodiol, foi de $17,7 \mathrm{~g} \mathrm{~L}^{-1}$ com glicose inicial de $10 \%$.

Exemplos do uso de E. coli na agricultura também são encontrados: CALDWELL et al. (1998) mapearam e clonaram os genes de duas enzimas ascorbato peroxidase citossólica do feijão (SOY APx1 e SOY APx2), para estudos das diferenças entre estas enzimas encontradas nos nódulos das raízes da planta de feijão. Estudos posteriores determinaram a quantidade e seqüência de aminoácidos de cada espécie enzimática.

NAKAI; TONOUCHI (1997), trabalhando com fragmentos de DNA para codificar a enzima sacarose sintetase da vagem do feijão mung (nativo da Índia) em vetor pET, e utilizando a cepa E. coli BL21(DE3) como hospedeiro, obteve alto nível de expressão. Testes executados posteriormente mostraram que a atividade da enzima recombinante é muito próxima à da enzima nativa, porém com uma tendência maior de sintetizar sacarose.

Usos em diagnósticos e propósitos terapêuticos também são exemplos do manejo de E. coli com expressão heteróloga. ASTURIAS (1997) promoveu a expressão da proteína denominada profilina, habitualmente usada no tratamento de pacientes alérgicos a pólen e a alguns tipos de alimentos, em E. coli BL21(DE3), obtendo $45 \mathrm{mg} \mathrm{L}^{-1}$ de produto já purificado. A proteína recombinante mostrou boa reatividade quando comparada à natural.

Aminoácidos são também sintetizados por meio da inserção de genes heterólogos. GALKIN; KULAKOVA (1997) utilizaram vetores contendo genes de várias desidrogenases envolvidas na síntese de aminoácidos a partir da conversão de $\alpha$-cetoácidos como fonte de carbono, obtendo-se rendimentos da ordem de $80 \%$. 
LI, S. et al. (1997) obtiveram trombopoietina humana com um rendimento de $12 \%$ das proteínas totais da $E$. coli $\left(2 \mathrm{mg} \mathrm{g}^{-1}\right.$ de célula úmida) usando o promotor tac. A proteína foi obtida quase que totalmente na forma de corpos de inclusão.

HAUGHT; DAVIS (1998) utilizaram a cepa E. coli D31 para sintetizar um peptídeo antimicrobiano denominado $\mathrm{P} 2$, sob forma de proteína de fusão, juntamente com a proquimosina bovina. Esta proteína sérica foi escolhida por causa da completa insolubilidade em E. coli (pois formava corpos de inclusão), promovendo uma proteção contra os efeitos tóxicos do peptídeo P2. O rendimento alcançou o valor de $16 \%$ das proteínas totais celulares.

JANG et al. (1998) obteve hormônio de crescimento bovino em um teor de $35 \%$ das proteínas totais da célula de E. coli BL21 (DE3). Neste caso, a transcrição do gene do hormônio recombinante foi induzida por IPTG e a temperatura de cultivo elevada para $40{ }^{\circ} \mathrm{C}$. Embora sob forma de inclusão, o hormônio recombinante mostrou ter atividade semelhante ao hormônio natural. SAKAKIBARA; UEMURA (1997), usando o mesmo sistema (E.coli BL21(DE3) com indução do promotor lac) estudaram uma enzima placentária denominada frutose-6-fosfato,2quinase/frutose-2,6-bifosfatase isolada da placenta humana, que depois de purificada mostrou ter atividade de $75-80 \mathrm{mU} \mathrm{mg}^{-1}$. Outro exemplo é o trabalho de PANDA et al. (1999), que teve por objetivo maximizar a produtividade do hormônio de crescimento ovino (r-oGH) em E. coli M15 por meio de cultivos descontínuos e descontínuos-alimentados de alta concentração celular e sob indução de IPTG, tendo obtido a formação de corpos de inclusão. Com este processo alcançou-se, em 16 horas de cultivo descontínuo-alimentado, 3,2 g L L $^{-1}$ de r-oGH com uma densidade celular óptica de 124 (produtividade de $0,2 \mathrm{~g} \mathrm{~L}^{-1} \mathrm{~h}^{-1}$ ). A alimentação de nutrientes 
(glicose e extrato de levedura) durante a fase descontínua alimentada mostrou que o componente extrato de levedura colaborou para manter alto o rendimento específico de proteínas na célula, e por conseguinte, um alto rendimento da molécula alvo.

Todavia, o uso de IPTG para indução de sistemas que utilizam bactérias recombinantes (transformadas) voltados à síntese de produtos terapêuticos ou farmacêuticos pode gerar problemas no processo de purificação desses produtos. Para eliminar esse problema, alguns trabalhos são elaborados utilizando o sistema de indução do operon lac sob controle do promotor de choque térmico $\lambda \mathrm{p}_{\mathrm{L}}$.

LIM; JUNG (1998), investigando as conseqüências da velocidade específica de síntese do interferon- $\gamma$ na melhoria da sua produtividade, efetuaram estudos com a $E$. coli N4830-1, contendo o promotor $\lambda \mathrm{p}_{\mathrm{L}}$ para indução térmica. Com meio semi-definido, obtiveram uma produção de $7,43 \mathrm{~g} \mathrm{~L}^{-1}$ de interferon- $\gamma$ e uma concentração celular de 43,6 g $\mathrm{L}^{-1}$ em cultivos descontínuos-alimentados, uma concentração de interferon 23 vezes maior do que em cultivos descontínuos.

SCHMIDT et al. (1999) estudaram a síntese de insulina pelo uso de E. coli BL21 contendo um vetor sob ação de "choque térmico", em meio sintético e em meio complexo. Utilizando um sistema híbrido de indução (operon lac sob controle do promotor $\lambda \mathrm{p}_{\mathrm{L}}$ ) e cultivos em alta concentração celular, relataram um rendimento de $30 \%$ das proteínas totais no meio complexo e $21 \%$ em meio sintético e uma concentração de 4,5 g insulina $\mathrm{L}^{-1}$ para o meio sintético.

Utilizando a cepa $E$. coli $\mathrm{W} 3110$ carregando o vetor pAPH1 (que contém o gene estrutural do hGH) sob controle do promotor pho A, CHANG et al. (1987) sintetizaram o 
hormônio em meio sintético, obtendo um rendimento de 6 a $10 \%$ das proteínas totais (aproximadamente 20 a $25 \mu \mathrm{g} / \mathrm{mL} \mathrm{A}_{550}$ ). Investigaram também a eficiência de expressão de dois outros vetores, phGH4L e phGH4R, diferentes somente na direção de transcrição do fragmento de DNA, obtendo as concentrações de 15,4 e $7,9 \mu \mathrm{g} / \mathrm{ml} / \mathrm{A}_{550}$, respectivamente, demonstrando a influência da leitura do DNA na síntese do produto-alvo.

GUPTA et al. (1999) estudaram o aumento no rendimento da expressão de proteínas heterólogas fazendo uso do gene da T7 RNApolimerase sob controle do promotor $\lambda \mathrm{p}_{\mathrm{L}}$ para síntese de $\beta$-galactosidase . Com concentrações celulares da ordem de $5,2 \mathrm{~g} \mathrm{~L}{ }^{-1}$, atingiu-se uma concentração final de produto de $0,95 \mathrm{~g} \mathrm{~L}^{-1}$ de $\beta$-galactosidase.

\subsection{Metabolismo da Escherichia coli}

O microrganismo utilizado neste trabalho é a $E$. coli RR1, derivada da cepa E. coli HB101 havendo como diferença básica entre elas o gene rec $A^{+}$. Este microrganismo (E. coli RR1) também possui outras características, como impossibilidade de metabolizar galactose, xilose e manitol e possivelmente lactose, e requerendo uma suplementação do meio de crescimento com os aminoácidos leucina e prolina, e de tiamina (vitamina B1), características herdadas da cepa HB101.

O aminoácido leucina é obtido por um conjunto de reações através do metabolismo primário da bactéria, ligados principalmente à família do piruvato. A leucina é obtida por síntese de compostos cetônicos, resultando 2 moléculas de acetil-CoA (VOET; VOET, 1995). O aminoácido 1-prolina é sintetizado a partir da família do $\alpha$-cetoglutarato presente no ciclo dos ácidos carboxílicos (TCA). A 1-prolina presente no meio de crescimento é transportada para o interior celular por um sistema simporte (sistema enzimático que 
permite o transporte de moléculas simultaneamente à íons em um sentido unidirecional), juntamente com íons $\mathrm{Na}^{+}$ou $\mathrm{H}^{+}$, sendo utilizada basicamente para síntese de proteínas e atuação em algum tipo de regulação do metabolismo central (INGRAHAM et al., 1983).

A deficiência da cepa RR1 em prolina está ligada ao gene proA, responsável pela síntese da enzima $\gamma$-glutamil semialdeído desidrogenase, e no caso da leucina, ligada ao gene leuB, responsável pela enzima $\beta$-isopropilmalato desidrogenase (MOAT; FOSTER, 1995).



Figura 2.1.1 - Resumo das reações catalisadas pelo complexo de piruvato desidrogenase, onde L refere-se ao grupamento lipoíla e $\mathrm{E}_{1}$ corresponde a enzima piruvato desidrogenase, $\mathrm{E}_{2}$ à dihidrolipoil transacetilase e $\mathrm{E}_{3}$ à dihidrolipoil desidrogenase. O coenzima TPP é a tiamina pirofosfato. (STRYER, 1995)

A tiamina (Figura 2.1.1) está envolvida na hidrogenação e descarboxilação do piruvato a acetil-CoA por ação do complexo piruvato-desidrogenase (um complexo de 5 enzimas e grupos prostéticos composto por FAD, CoA, NAD e lipoato). A tiamina compõe também a coenzima tiamina-pirofosfato (TPP) que faz parte da catálise da descarboxilação 
do piruvato a acetaldeído, principalmente em fermentações alcóolicas. A falta de tiamina pode causar incapacidade de oxidação do piruvato sob condições aeróbias de cultivo, ou parcial oxidação deste, levando a célula a desviar parte do fluxo proveniente do catabolismo das hexoses para a obtenção de oxaloacetato e malato, principalmente (LEHNINGER, 1993).

A tiamina (sob forma de TPP) é também utilizada pela transcetolase para estabilizar compostos obtidos da enzima que sintetiza xilose-5 fosfato, formados na via da hexosemonofosfato (HMF).

Como parte das coenzimas NADH são obtidas pela oxidação do piruvato a acetilCoA, um baixo fluxo de elétrons proveniente da cadeia respiratória prejudica este processo, diminuindo a concentração de NADH e leva a célula a direcionar seu metabolismo para a fermentação (Figura 2.1.2), promovendo um maior acúmulo dos produtos de fermentação (ou fermentação ácido mista).

Para que não haja acúmulo de produtos intermediários antes do piruvato, o controle do consumo das hexoses é feito provavelmente pela ação de controles regulatórios encontrados nas vias glicolítica e pentose-fosfato e, sendo o complexo piruvatodescarboxilase deficiente, o fluxo da via glicolítica (principal via de biossíntese e de geração de energia) é predominantemente dirigido para as vias das quais as enzimas lactato desidrogenase e piruvato-formiato liase fazem parte, gerando metabólitos como formiato e lactato que são produtos de fermentação ácido-mista (STRYER, 1995; WHITE, 1995). 


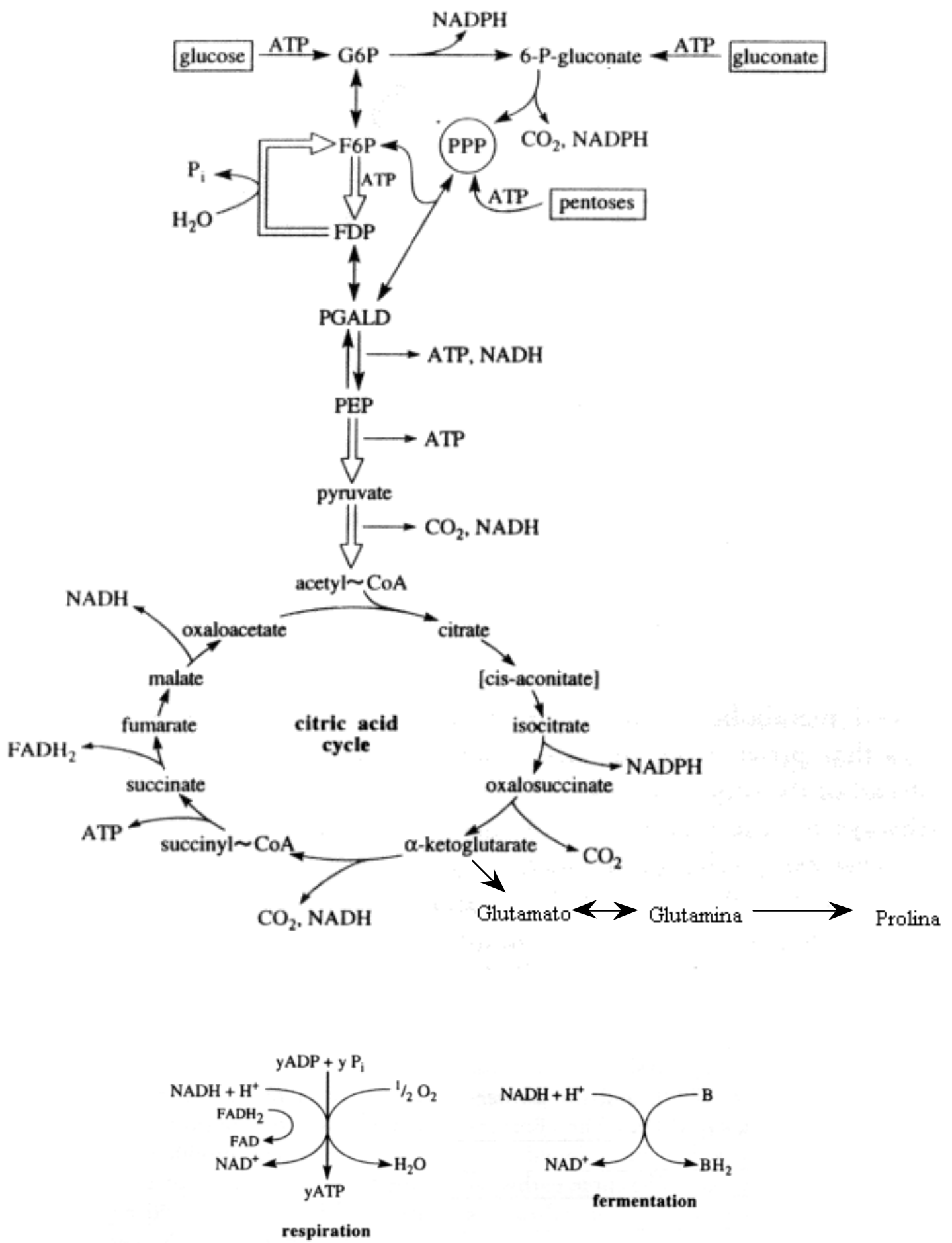

Figura 2.1.2 - Relações entre as principais vias de catabolismo e o TCA (ciclo de Krebs). A via de glicose-6 fosfato a piruvato é a via glicolítica (ou via EMP) e a via de pentose-fosfato (PPP), que desvia no 6-fosfogluconato, unem-se novamente no fosfogliceraldeído. Em aerobiose, os elétrons do $\mathrm{NADH}_{\text {e }} \mathrm{FADH}_{2}$ são transferidos à cadeia de transporte de elétrons com a formação de ATP, mas em anaerobiose, o NADH é reoxidado por um aceptor orgânico de elétrons (B), gerado durante o catabolismo. (WHITE, 1995). 
É interessante ressaltar que todas as enzimas envolvidas na conversão de piruvato em produtos de fermentação são sintetizadas a partir das hexoses em crescimento aeróbio, com exceção do complexo formiato-hidrogênio-liase (este em crescimento anaeróbio). Todavia, tal complexo encontra-se nestes casos sob forma inativa, dependendo de uma modificação pós-traducional (modificação realizada na molécula da proteína depois de formado o polipeptídeo, diminuindo a sua atividade ou função, p. ex., dentro da célula) para passar à forma ativa, o que pode ocorrer devido a mudança de potencial de óxido-redução ou por um aumento da concentração de piruvato no citoplasma (KNAPPE, 1987).

\subsection{Sistema de expressão:}

O sistema de expressão do microrganismo E. coli RR1 utilizado no presente trabalho está baseado no controle exercido pelo promotor $\lambda p_{L} p_{R}$, que inicia a transcrição de um determinado gene estrutural (neste estudo o gene estrutural do hGH) presente em um vetor denominado pCR23 quando é submetido à um aumento de temperatura (choque térmico) . A transcrição é iniciada quando a temperatura atinge valores em torno de 42-45 ${ }^{\circ} \mathrm{C}$, quando então a regulação negativa exercida pelo repressor $\lambda \mathrm{cI}$ é inativada, fazendo com que a RNApolimerase possa então reconhecer e transcrever os genes que codificam a síntese do hGH. O repressor $\lambda$ cI é codificado em um vetor co-residente (LOVE et. al., 1996) de baixo número de cópias denominado pRK248cIts, que então regula o promotor $\lambda \mathrm{p}_{\mathrm{L}}$ presente no vetor $\mathrm{pRC} 23$. Sendo este último um derivado do vetor $\mathrm{pBR} 322 \mathrm{e}$, portanto um vetor multicópias, este está presente em maior número que o vetor pRK248cIts, ocorrendo uma expressão basal da molécula de interesse, pois não existe quantidade 
suficiente de repressores $\lambda$ cI para que haja uma regulação negativa eficiente na síntese do hormônio.

A síntese do hGH (ou outra molécula de interesse) se dá quando, uma vez elevada a temperatura, o repressor $\lambda c I$ presente no vetor pRK248cIts é inativado e a transcrição da RNApolimerase sob controle do promotor $\lambda \mathrm{p}_{\mathrm{L}}$ é efetivada. Em seguida, o RNAm formado realiza uma tradução (formação de polipeptídeos a partir de genes contidos em um RNAm) sobre os genes contidos no vetor pRC23, sintetizando a molécula alvo a partir dos genes estruturais lá inseridos. Para o IPEN tal vetor recebe a denominação de $\mathrm{p} \lambda \mathrm{p}_{\mathrm{L}} \mathrm{hGH}$ (CROWL, 1986).

KILIKIAN (1998) utilizou um outro sistema de expressão - o operon lac controlado por indução química (IPTG ou lactose), tendo usado E. coli BL21(DE3)plysS para a expressão da proteína heteróloga troponina $\mathrm{C}(\mathrm{TnC})$. Com este sistema foram estudados a cinética de crescimento celular, a melhor composição do meio de cultivo, a cinética para obtenção do produto alvo, bem como o emprego de IPTG (indutor gratuito, não é metabolizado pela célula) e lactose (indutor e fonte de carbono e energia).

O sistema operon lac presente na bactéria E. coli BL21(DE3)plysS é constituído por um operador $(l a c O)$, um promotor (lac $P$ ), um repressor (lac $I$ ) e por uma proteína ativada por catabolismo (CAP), que liga-se ao complexo cAMP/CAP. Quando um indutor está presente, este liga-se ao repressor lac, induzindo uma mudança conformacional que permite ao repressor desligar-se do DNA. Então a RNApolimerase está livre para mover-se ao longo do DNA e, assim sendo, o RNA do produto de interesse (heterólogo ou não) pode ser transcrito, iniciando a sua expressão. Quando as concentrações de glicose na célula são altas, moléculas denominadas AMP cíclico (cAMP) têm sua formação inibida e, quanto 
menor a concentração de glicose, mais cAMP é formada. Esta última liga-se ao sítio ativo da proteína CAP, ativando a transcrição dos genes envolvidos no operon lac pela RNApolimerase, talvez pelo aumento da afinidade do sítio pela enzima. Este fenômeno é conhecido por repressão catabólica. Para que ocorra tal expressão, deve haver a presença de um indutor químico, como por exemplo, lactose ou IPTG.

A temperatura ótima de crescimento de E. coli $\left(37-39{ }^{\circ} \mathrm{C}\right)$ coincide com a temperatura ótima de indução do operon lac. O uso de temperaturas menores reduz alterações metabólicas indesejáveis, como a síntese de proteases ou 'heat shock proteins", aumentando o rendimento do produto-alvo, e ainda, contribui para aumentar a solubilidade, isto é, reduz a formação de corpos de inclusão. A redução da temperatura melhora ainda a capacidade de excreção da proteína, contribuindo para a conformação adequada e redução da lise celular (DONOVAN et al., 1996).

Em E. coli o produto recombinante é freqüentemente armazenado no citoplasma. Contudo na literatura, encontramos casos de proteínas que são endereçadas ao espaço periplásmico, e mais raramente ainda, moléculas que são excretadas para o meio extracelular. No espaço periplásmico, onde a degradação por ação das proteases é menos severa, encontram-se apenas $4 \%$ de um total de 3000 proteínas diferentes. A armazenamento do hGH sintetizado pela cepa RR1 usada como hospedeiro neste trabalho dá-se no espaço periplásmico. 


\subsection{Produção do hormônio de crescimento humano (hGH) em Escherichia}

$$
\text { coli }
$$

O hGH, também conhecido como somatotropina, é um polipeptídeo pituitário com grande aplicação biológica, incluindo síntese de proteínas, proliferação de algumas células e sintomas voltados ao metabolismo associado à idade (KOSTYO; ISAKSSON, 1977). Este hormônio consiste de 191 aminoácidos ligados entre si através de uma estrutura de hélice quádrupla com duas pontes dissulfeto (De VOS et al., 1992) e tem sido usado em tratamentos de nanismo, fraturas ósseas (casos de osteoporose), queimadura de pele, hemorragia por úlceras, doenças cardiovasculares, entre outros. Como o hormônio é uma proteína não-glicosilada, sistemas de expressão genética presentes em procariotos (tal qual E. coli) tem sido preferidos em relação à microrganismos ou sistemas celulares mais complexos para a produção de hGH recombinante.

SHIN, N. K. et al. (1998) construíram um sistema com proteínas de fusão utilizando hGH e hTNF- $\alpha$ (fator $\alpha$ do tumor de necrose humano), aumentando a eficiência de expressão e da posterior purificação. Fazendo uso de cultivos descontínuos-alimentados com alta concentração celular ( $75 \mathrm{~g} \mathrm{~L}^{-1}$ ), alcançaram-se um nível de expressão de $23 \%$ do total de proteínas celulares e uma concentração máxima de $9 \mathrm{~g} \mathrm{~L}^{-1}$, embora aproximadamente $80 \%$ do hormônio estivesse presente na forma de corpos de inclusão.

Clonando o gene de uma protease neutra do Bacillus amyloliquefaciens em E. coli W3110, UCHIDA et al. (1997) construíram um sistema de expressão e secreção para o espaço periplásmico da célula, sob controle do promotor tac, para transcrição do gene estrutural do hGH de $22 \mathrm{KDa}$. Em cultivos realizados em incubador rotativo, obtiveram concentrações de $100 \mathrm{mg} \mathrm{L}^{-1}$ deste hormônio no espaço periplásmico. Modificações 
posteriores no vetor com o gene estrutural do hGH de $20 \mathrm{KDa}$ (uma isoforma do hGH humano), fez com que a concentração aumentasse de $2,1 \mathrm{mg} \mathrm{L}^{-1}$, obtida anteriormente, para $28,2 \mathrm{mg} \mathrm{L}^{-1}$ no espaço periplásmico.

SHIN, C. S. et al. (1998) investigaram a síntese de hGH a partir da fusão de proteínas com concentrações celulares médias (15 $\left.\mathrm{g} \mathrm{L}^{-1}\right)$ em cultivo descontínuoalimentado. Com diferentes estratégias de alimentação, observaram a relação entre velocidades específicas de crescimento $\left(\mu_{\mathrm{x}}\right)$ e de produção $\left(\mu_{\mathrm{p}}\right)$. Também notaram que, com uma velocidade constante de alimentação, o nível máximo de expressão obtido em hGH foi de 26,1 \% e, com uma velocidade exponencial, atingiu 25,9 \% do total das proteínas celulares, mostrando com isso que o nível de expressão independe da forma de alimentação da fonte de carbono. Concluíram que o crescimento das células em uma velocidade próxima da velocidade máxima de crescimento e, posteriormente, alimentar com o meio de cultivo as células sob indução (em uma velocidade ótima dentro de uma faixa onde os subprodutos não são acumulados), é a melhor configuração para se atingir um teor máximo de hGH.

Embora utilizando um outro microrganismo (a levedura Pichia pastoris), ECAMILLA-TREVIÑO et al. (2000) obtiveram a síntese de hGH a partir de um sistema de expressão induzido por metanol sob controle do promotor álcool oxidase $1(A O X 1)$ e um polipeptídeo sinalizador de Saccharomyces cerevisiae para guiar a secreção do hGH para o caldo de fermentação. Cultivando o microrganismo sob indução por limitação de oxigênio, obtiveram como resultado $49 \mathrm{mg} \mathrm{L}^{-1}$ de hGH recombinante (representando $40 \%$ do total de proteínas no meio de cultivo) após 48 horas de indução, com uma concentração celular de $73 \mathrm{~g} \mathrm{~L}^{-1}$. 


\subsection{Considerações sobre o meio de cultivo}

Em se tratando da síntese de produtos heterólogos, algumas variáveis importantes das condições de fermentação devem ser otimizadas, tais como: condições de crescimento (temperatura, pH e oxigênio dissolvido), métodos de indução, inibição mínima por metabólitos, além da obtenção de sistemas genéticos bem adequados (conjunto de genes que formam um operon e sofrem repressão ou indução dependendo do tipo da molécula presente e do produto do gene regulador da síntese da molécula alvo (BAILEY; OLLIS, 1986)). Uma atenção também especial deve ser dada à composição do meio de cultivo.

Altas concentrações celulares são geralmente atingidas quando adiciona-se componentes complexos aos meios, como por exemplo, extrato de levedura, bactotriptona e, em alguns casos, casaminoácidos (OLSSON; HAHN-HAGERDAL, 1995). Recentemente, esforços consideráveis têm sido feitos para atingir-se uma alta concentração celular em meio de cultivo definido (WEUSTER-BOTZ et al., 1995). Contudo, são preferidos meios de cultivo mínimos quando se pretende estudar cinéticas de crescimento e de produção, metabolismo celular e regulação de sistemas genéticos, pois permitem a quantificação de compostos de carbono, bem como calcular velocidades específicas (ROTHEN et al., 1998).

Modificações na composição do meio de cultivo também podem atuar de forma positiva na capacidade de produção de células, como é o caso da suplementação com aminoácidos durante a fase de crescimento (no caso de cepas auxotróficas) ou na fase de síntese de produtos heterólogos, desfavorecendo assim o estabelecimento de condições de estresse da célula, fenômeno este conhecido como "metabolic burden" . 
Contudo, em cultivos de E. coli, ocorre a formação de ácidos orgânicos (sob forma de seus íons) - principalmente acetato - que age como inibidor no crescimento celular e na síntese de produtos heterólogos (AXE; BAILEY, 1995; ARISTIDOU et al., 1994). Alguns autores citam que esta formação dá-se em maior quantidade em meio de cultivo complexo do que em meio definido.

Em meio de cultivo complexo, a quantidade de nutrientes (disponível sob a forma de aminoácidos e vitaminas presentes no extrato de levedura ou bacto-triptona) faz com que o microrganismo consuma estes compostos para biossíntese e a fonte de carbono (glicose) para obtenção de energia, utilizando as vias fermentativas como forma de regulação do fluxo de nutrientes presentes. Uma maior concentração de extrato de levedura pode acarretar uma maior concentração de subprodutos no meio de cultivo, como por exemplo o ácido acético (SUAREZ et al., 1998).

Correlações entre velocidade específica de crescimento e de formação de ácido acético indicam que em presença de valores baixos de crescimento a síntese praticamente não existe. Porém isto é dependente do tipo da cepa e das condições do processo (KILIKIAN et al., 2000).

\subsubsection{Suplementação do meio de cultivo durante o crescimento de cepas auxotróficas}

LEE et al. (1997) estudaram os efeitos da composição do meio na expressão de uma proteína de fusão denominada TGF- $\alpha$-PE40, um possível agente anti-tumoral em certos tipos de câncer, sob controle do promotor tac. Utilizando a cepa E. coli RR1, empregaramse um meio de cultivo complexo suplementado com tiamina e glicose como fonte de 
carbono. Todavia, os autores notaram efeitos de inibição ocasionados pela formação de ácido acético na fase de indução, tendo sido levados a optar por glicerol como fonte de carbono e energia. Chama a atenção o fato de que a prolina e a leucina (componentes dos quais esta cepa é auxotrófica) foram pouco consumidas, sendo a prolina esgotada horas depois de ter sido adicionada na forma de pulso.

ROTHEN et al. (1998), com a intenção de otimizar o meio de cultivo, estudou o crescimento da cepa HB 101 (auxotrófica em relação a prolina, a leucina e a tiamina) em meios de cultivo definidos. Verificou que a prolina era mais rapidamente exaurida pelas células do que a leucina, necessitando uma quantidade maior do primeiro aminoácido em relação à estequiométrica. $\mathrm{O}$ autor verificou um efeito inibitório no crescimento do microrganismo para os aminoácidos sintetizados a partir do piruvato, fato também observado por GSCHAEDLER; BOUDRANT (1994) e YEE; BLANCH (1993).

Uma forma de atenuar esta inibição no crescimento celular seria efetuar um cultivo descontínuo-alimentado, permitindo uma melhor assimilação do nutriente pelo microrganismo - principalmente o aminoácido - a fim de obter uma alta concentração celular.

LI et al. (1998) investigaram a adição de precursores de aminoácidos (glutamato, cisteína e glicina), extrato de levedura e ATP na expressão do gene que codifica a glutationa pela célula E. coli WSH-KE1 recombinante. Notaram que, valendo-se de uma estratégia exponencial de alimentação, atingiu-se $80 \mathrm{~g} \mathrm{~L}^{-1}$ de concentração celular e 880 $\mathrm{mg} \mathrm{L}^{-1}$ de GSH recombinante, aumentando em $40 \%$ o rendimento do produto. 


\subsubsection{Suplementação do meio de cultivo com aminoácidos precursores da proteína-alvo}

A composição em aminoácidos da molécula-alvo pode ser drasticamente diferente do teor médio existente dentro da célula bacteriana, podendo causar uma demanda adicional sobre a síntese de aminoácidos quando do aumento da expressão do produto-alvo, isto é, um determinado aminoácido pode ser requerido em maior quantidade do que aquela disponível no meio intracelular.

Comparando cultivos em meio mínimo de E. coli RR1 [pBR329] e E. coli JM105, HARCUM, et al. (1992) relizaram um estudo de alimentação da fonte de carbono e aminoácidos em um processo descontínuo-alimentado, a fim de aumentar o rendimento de uma proteína heteróloga (cloranfenicol-acetil-transferase, CAT), variando a concentração inicial de fenilalanina na solução de alimentação. Os resultados obtidos mostraram que o teor de CAT é dependente da concentração de fenilalanina adicionada (atingindo um máximo com baixas concentração deste aminoácido) e da ação de proteases de choque térmico, como a protease La $(94 \mathrm{KDa})$. Concluíram que uma alta velocidade de síntese do produto-alvo causa uma alta taxa de degradação protêica, provavelmente devido à ação de proteases.

Usando as mesmas cepas descritas acima, RAMIREZ; BENTLEY (1993) estudaram estratégias de alimentação que poderiam minimizar o estresse causado pela superexpressão de uma molécula heteróloga. Com base no teor de aminoácidos constituintes da moléculamodelo CAT e no teor médio destes presente nas proteínas da E. coli, utilizaram a fenilalanina como precursor-chave da síntese de CAT, tendo sido o estudo dividido em dois 
conjuntos de ensaios: um sob a forma não-induzida e outro sob a forma induzida com IPTG.

No primeiro conjunto,e fazendo uso dos microrganismos E. coli RR1 (pBR329, vetor constitutivo) e E. coli JM105 (pSH101, vetor induzível), foi observada uma semelhança entre os picos de CAT para os dois sistemas cepas/vetores. Sugeriu-se, então, que a velocidade de tradução da proteína, e não a velocidade de transcrição do DNA, é influenciada pela adição de aminoácidos.

Os resultados mostrados neste trabalho sugerem que uma simples adição de um precursor apropriado pode aumentar o rendimento de um produto recombinante de 2 a 6 vezes. Contudo, concentrações deste precursor próximas daquelas existentes na célula e/ou na proteína-alvo não contribuirá para uma melhoria no rendimento específico da proteína e é possível que uma adição de uma alta concentração deste precursor possa causar uma desordem na regulação biossíntética de todo o metabolismo necessário à síntese da proteína.

No segundo conjunto de experimentos, o sistema E. coli JM105/pSH101 foi induzido com IPTG e obteve-se, com um teor de $15 \%$ de fenilalanina acima do estequiométrico, um pico de concentração de CAT constante e por um período maior.

O estudo do efeito das estratégias de alimentação com nutrientes na fase pósindução tem recebido pouca atenção. Depois da indução, a atividade metabólica dos hospedeiros é influenciada pela expressão de produtos heterólogos, fazendo com que o método de alimentação de nutrientes durante a fase de indução seja tão importante para a eficiente produção da molécula-alvo quanto na fase pré-indução. 
WONG et al. (1998) estudaram seis diferentes estratégias de alimentação para maximizar a produção de um bioadesivo em E. coli AS002 (BL21[DE3]plysS) contendo o vetor pAG9. Como resultado, constataram que o maior valor de biomassa seca (BMS) foi alcançado usando uma velocidade constante de alimentação, embora o maior teor do produto (em \% das proteínas totais) tenha sido atingido com o uso de uma alimentação cuja velocidade variava linearmente com o tempo. Os menores intervalos de tempo de cultivo para alcançar concentrações máximas de BMS e de fração de bioadesivo foram conseguidos utilizando velocidade exponencial.

Um trabalho que merece destaque é o de BYLUND et al. (2000) no qual estudou-se a influência do aumento de escala para a produção de hGH. Além dos parâmetros rendimento do produto e qualidade, foram enfocados e comparados outros, como rendimento celular, concentração de glicose e respiração celular, formação de subprodutos e lise celular em E. coli W3110, bem como a degradação desta proteína em cultivos aeróbios do tipo descontínuos-alimentados (com glicose como fonte de carbono) em reatores contínuos de diferentes dimensões.

Os autores verificaram que as variáveis mais importantes foram o oxigênio dissolvido (OD) e a concentração de glicose no meio de crescimento. Um baixo valor de OD interfere na produção de hGH recombinante e no metabolismo celular, seja pelo redirecionamento do fluxo de carbono para manutenção, seja pela formação de subprodutos, como os de fermentação ácido-mista. Sendo assim, concluíram que a forma de condução do processo no que diz respeito à vazão de aeração e à velocidade de alimentação de nutrientes são fatores que devem ser levados em consideração quando o processo sofre um aumento de escala. 


\section{Materiais e Métodos}

\subsection{Meios de cultivo}

Os meios de cultivo foram preparados usando-se água destilada, sendo adicionado a solução de antibiótico (item 3.2.4) após a autoclavação do biorreator (item 3.6), nos casos onde desejava-se exercer pressão seletiva para o microrganismo Escherichia coli RR1.

\subsubsection{Meio TYE (sólido)}

Por litro: $10 \mathrm{~g}$ Bactotriptona, $5 \mathrm{~g}$ Extrato de levedura , $8 \mathrm{~g} \mathrm{NaCl}, 15 \mathrm{~g}$ Ágar bacteriológico, $\mathrm{pH} 7,5$.

\subsubsection{Meio $2 \times T Y$}

Por litro: 16g Bactotriptona, $10 \mathrm{~g}$ Extrato de levedura, $5 \mathrm{~g} \mathrm{NaCl}, \mathrm{pH}$ 7,0 .

Dados preliminares obtidos em incubador rotativo e em biorreator por AFFONSO (2000)* no Laboratório do Departamento de Aplicação de Técnicas Nucleares em Ciências Biológicas (IPEN) com a cepa $E$. coli RR1 mostraram que a cinética de crescimento celular melhorou com o aumento das concentrações de reagentes complexos em relação às já existentes no meio de cultivo da cepa BL21(DE3)plysS.

Baseado em trabalhos desenvolvidos no LEB, como p. ex., KILIKIAN (1998), SUAREZ (1997), GOMBERT (1996) e LIRIA (1995), onde o meio de cultivo da cepa $E$. coli BL21(DE3)plysS já contém uma dada concentração de solução de micronutrientes, AFFONSO (2000) fez uso desta, na mesma concentração, também verificando um aumento 
no fator de conversão glicose a células. Portanto, usou-se as mesmas concentrações do meio de cultivo da cepa BL21(DE3)plysS,- a menos das concentrações de extrato de levedura e bactotriptona - cujos valores finais são descritos nos itens 3.1.3 e 3.1.4. Esta é a composição do meio de cultivo adotada nos ensaios descontínuos e nos descontínuos alimentados, tendo recebido a denominação de meio basal.

\subsubsection{Meio basal para inóculo (FASS et al. (1991), modificado por COSTA} (1993), modificado por AFFONSO (2000))

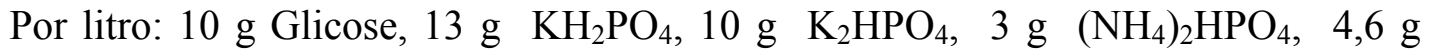
$\mathrm{NaH}_{2} \mathrm{PO}_{4} \cdot \mathrm{H}_{2} \mathrm{O}, 0,46 \mathrm{~g} \mathrm{MgSO}_{4} .7 \mathrm{H}_{2} \mathrm{O}, 2 \mathrm{~g}$ Extrato de Levedura, $1 \mathrm{~g}$ Bactotriptona, $3 \mathrm{~mL}$ Solução de Micronutrientes 1 e 2, pH 7,0,

\subsubsection{Meio basal para biorreator (FASS et al. (1991), modificado por COSTA (1993), modificado por AFFONSO (2000))}

Por litro: $10 \mathrm{~g}$ Glicose, $13 \mathrm{~g} \mathrm{KH}_{2} \mathrm{PO}_{4}, 10 \mathrm{~g} \mathrm{~K} \mathrm{KPO}_{4}, 3 \mathrm{~g}\left(\mathrm{NH}_{4}\right)_{2} \mathrm{HPO}_{4}, 4,6 \mathrm{~g}$ $\mathrm{NaH}_{2} \mathrm{PO}_{4} \cdot \mathrm{H}_{2} \mathrm{O}, 2$ g $\mathrm{MgSO}_{4} \cdot 7 \mathrm{H}_{2} \mathrm{O}, 2$ g Extrato de Levedura, 1 g Bactotriptona, 3mL Solução de Micronutrientes 1 e 2, pH 7,0

\subsection{Soluções}

\subsubsection{Solução de micronutrientes 1 (BAUER; SCHILOACH, 1974)}

Por litro: $27 \mathrm{~g} \mathrm{FeCl}_{3} \cdot \mathrm{H}_{2} \mathrm{O}, 1,3 \mathrm{~g} \mathrm{ZnCl}_{2}, 2 \mathrm{~g} \mathrm{CoCl} 2 \cdot 6 \mathrm{H}_{2} \mathrm{O}, 2 \mathrm{~g} \mathrm{Na}_{2} \mathrm{MoO}_{4} \cdot 2 \mathrm{H}_{2} \mathrm{O}, 1 \mathrm{~g}$ $\mathrm{CaCl}_{2} \cdot \mathrm{H}_{2} \mathrm{O}, 1 \mathrm{~g} \mathrm{CuCl}_{2}, 0,5 \mathrm{~g} \mathrm{H}_{3} \mathrm{BO}_{3}, 100 \mathrm{~mL} \mathrm{HCl}$ concentrado. 


\subsubsection{Solução de micronutrientes 2 (BAUER; SCHILOACH, 1974)}

Por litro: 1,6 g Al $2\left(\mathrm{SO}_{4}\right)_{3} \cdot 16 \mathrm{H}_{2} \mathrm{O}, 6,8 \mathrm{~g} \mathrm{MnSO}_{4} \cdot \mathrm{H}_{2} \mathrm{O}, 23,6 \mathrm{~g} \mathrm{CaCl}_{2} .2 \mathrm{H}_{2} \mathrm{O}, 100 \mathrm{~mL}$ $\mathrm{HCl}$ concentrado.

\subsubsection{Soluções de aminoácidos}

Por mililitro: $200 \mathrm{mg}$ 1-prolina; $200 \mathrm{mg}$ 1-leucina; $100 \mathrm{mg}$ tiamina (vitamina B1).

\subsubsection{Solução de antibiótico}

$100 \mathrm{mg} \mathrm{mL}^{-1}$ Ampicilina (Sigma). (Concentração de trabalho: $100 \mu \mathrm{g} \mathrm{mL} \mathrm{m}^{-1}$ no meio líquido).

\subsubsection{Soluções para alimentação dos ensaios descontínuos-alimentados}

\begin{tabular}{|c|c|}
\hline \multirow{2}{*}{ Ensaios } & Componentes da solução de alimentação \\
\hline & Proporção entre os componentes $^{(1),(2)}$ \\
\hline \multirow{2}{*}{ da-1 } & Glicose/extrato de levedura/bactotriptona/ $\left(\mathrm{NH}_{4}\right)_{2} \mathrm{HPO}_{4} / 1$-prolina \\
\hline & $1,0: 0,4: 0,1: 0,3: 0,035$ \\
\hline \multirow{2}{*}{ da- 2} & Glicose/1-prolina \\
\hline & $1,0: 0,035$ \\
\hline \multirow{2}{*}{ da-3 } & Glicose/extrato de levedura/bactotriptona/l-prolina \\
\hline & $1,0: 0,2: 0,1: 0,0012$ \\
\hline
\end{tabular}

Legenda: ${ }^{(1)}$ :base de cálculo para $10 \mathrm{~g} \mathrm{~L}^{-1}$ de glicose

${ }^{(2)}$ : proporção em $\% \mathrm{w} / \mathrm{v}$. 


\subsection{Microrganismo}

O microrganismo utilizado ao longo deste trabalho foi Escherichia coli RR1 (FsupE44 lacY1 ara 14 galK2 xyl5 mtl $^{-1}$ leuB6 proA2 $\Delta(\mathrm{mcrC}-\mathrm{mrr})$ rec $A^{+}$rpsL20 thi-1 lambda ${ }^{-}$; ATCC, 2001), um rec $\mathrm{A}^{+}$derivado da cepa HB101, tendo empregado o vetor phGH (que contém o gene que codifica a síntese do hormônio de crescimento humano, hGH) para transformar as células antes dos ensaios.

Este microrganismo é metabolicamente deficiente em 1-prolina, 1-leucina e tiamina, sendo portanto auxotrófica para estas substâncias. O gene $r e c \mathrm{~A}^{+}$refere-se a uma protease que é ativada quando o microrganismo encontra-se em estado de estresse (regulon SOS), dando lugar a que ocorram recombinações homólogas no DNA, ao qual está ligado.

\subsection{Preparo do pré-inóculo e do inóculo}

A etapa de transformação (inserção do vetor phGH no interior celular da cepa RR1) e incubação a $30{ }^{\circ} \mathrm{C}$ "overnight" (16 horas) em placa era realizada no Laboratório de Bioengenharia (IPEN/CNEN). No Laboratório de Engenharia Bioquímica do Departamento de Engenharia Química (EPUSP), com o auxílio de uma alça microbiológica, transferia-se uma colônia da placa para $50 \mathrm{~mL}$ de meio $2 \mathrm{xTY}$ contendo antibiótico (item 3.2.4) em frasco erlenmeyer de $250 \mathrm{~mL}$. Este frasco era levado ao incubador rotativo $\left(30{ }^{\circ} \mathrm{C}, 200\right.$ $\min ^{-1}$ ) por 14 horas, constituindo o pré-inóculo.

Após a incubação acima indicada, transferiam-se alíquotas de $0,5 \mathrm{~mL}$ da suspensão de células para frascos erlenmeyer de $500 \mathrm{~mL}$ (contendo $50 \mathrm{~mL}$ de meio para inóculo (conforme item 3.1.3 ) e antibiótico (item 3.2.4)). Estes frascos foram levados ao incubador

rotativo $\left(30^{\circ} \mathrm{C}, 200 \mathrm{~min}^{-1}\right)$ por 7 horas, constituindo o inóculo para o cultivo em biorreator. 


\subsection{Cultivos em biorreator}

O reator utilizado neste trabalho foi o BioFlo III (New Brunswick Scientific), que encontra-se acoplado a um microcomputador IBM-PC 386 equipado com o programa AFS

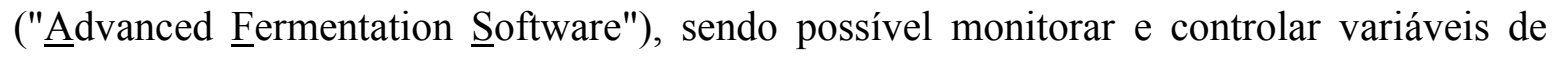
cultivo como pH, agitação e temperatura, bem como monitorar o oxigênio dissolvido.

Em todos os cultivos a temperatura foi mantida em $30^{\circ} \mathrm{C}$ e o $\mathrm{pH}$ foi monitorado por um eletrodo Mettler modelo K8S/225 e controlado em 7,0 \pm 0,2 através da adição de solução de $\mathrm{NH}_{4} \mathrm{OH} 25 \%$ ou de $\mathrm{NaOH} 2 \mathrm{~N}$. O volume útil inicial foi de $4 \mathrm{~L}$, sendo que a fração de inóculo correspondeu a $10 \%$ deste volume. A agitação foi mantida em $700 \mathrm{~min}^{-1}$ e a aeração em 1vvm, sendo a concentração de oxigênio dissolvido (OD) monitorada por eletrodo polarográfico (New Bruswick Scientific) e controlada entre $30 \%$ e $100 \%$, sendo necessário promover a mistura de oxigênio puro no gás de entrada do reator nos ensaios onde a concentração de oxigênio dissolvido atingia valores menores que $30 \%$ usando-se fluxômetros de massa (MFC) modelo 5850E (Brooks Instruments).

\subsection{Esterilizações}

A solução de $\mathrm{NH}_{4} \mathrm{OH} 25 \%$ foi esterilizada por filtração em membrana $0,22 \mu \mathrm{m}$, bem como as soluções de 1-prolina e tiamina. A solução de antibióticos foi preparada assepticamente com água deionizada. Os demais reagentes e meios de cultivo foram esterilizados em autoclave a $121{ }^{\circ} \mathrm{C}$ por 20 minutos. Soluções de glicose foram autoclavadas em separado em $\mathrm{pH}$ entre 4,0 e 4,5 para evitar a caramelização deste nutriente. O biorreator foi esterilizado (contendo o meio de cultivo) em autoclave por 30 minutos à $121^{\circ} \mathrm{C}$. 


\subsection{Procedimentos analíticos}

As rotinas de tratamento analítico de amostras são apresentadas a seguir:

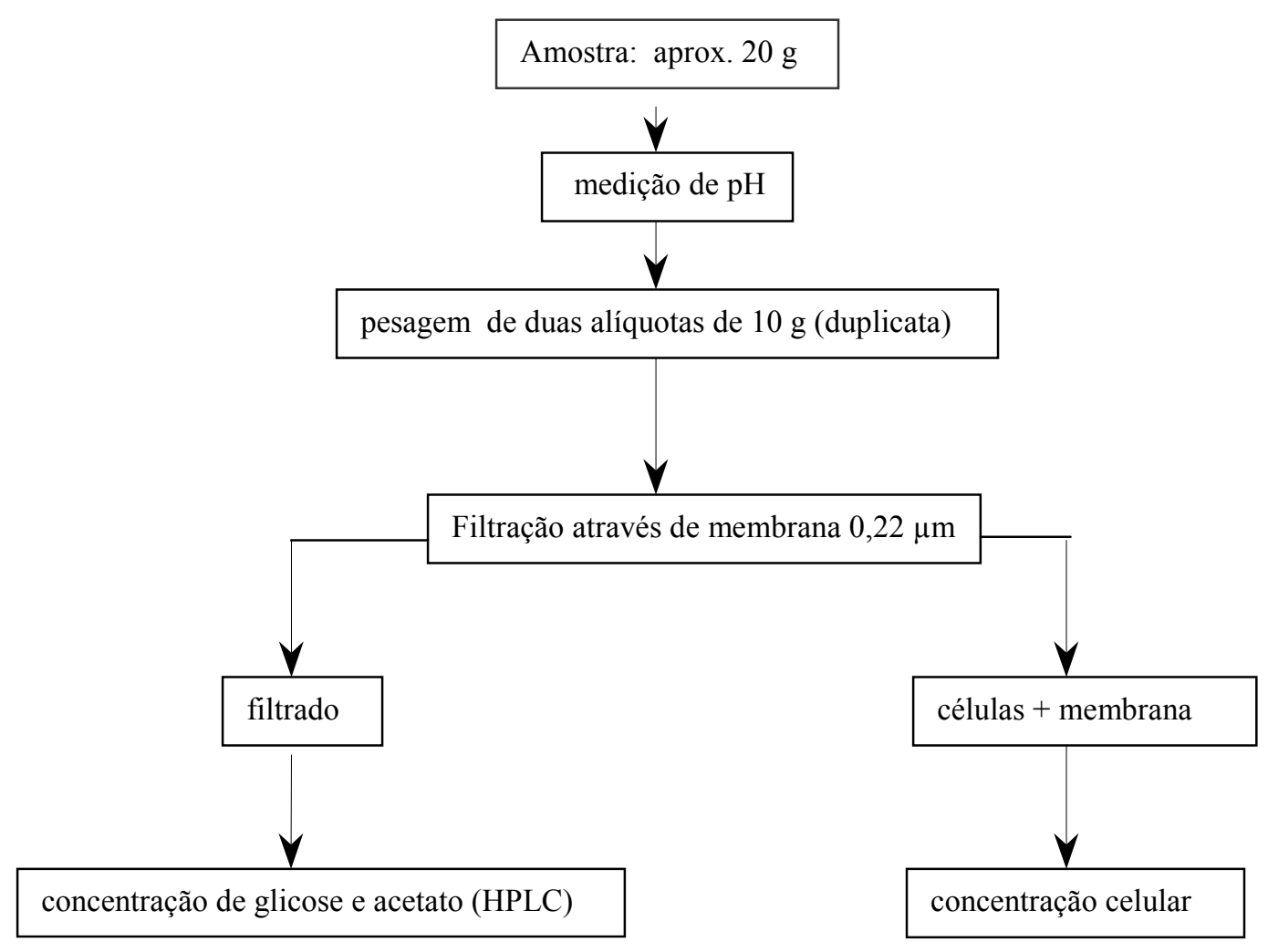

\subsubsection{Determinação da concentração celular $(X)$}

A concentração celular (massa seca) foi determinada por filtração de uma massa conhecida de amostra em membrana $0,22 \mu \mathrm{m}$ e determinação da massa de células retida na membrana após secagem em microondas (15 min., Potência $180 \mathrm{~W})$. O filtrado era recolhido para análise posterior.

Ao longo dos ensaios, com uma maior concentração celular presente, a amostra coletada apresentava dificuldades na filtração. A secagem era então realizada em estufa a $85{ }^{\circ} \mathrm{C}$ por 6 horas (sendo os tubos de centrifuga previamente tarados e identificados) partindo-se de uma massa conhecida de amostra. Estes tubos eram centrifugados por 10 
minutos à $7.300 \mathrm{~g}$ em centrífuga Jouan (modelo MR1812). O sobrenadante era recolhido para análise posterior e o precipitado de células, ressuspendido em $\mathrm{NaCl} 0,9 \%$, centrifugado novamente, o sobrenadante descartado, e os tubos contendo o precipitado, colocados na estufa.

\subsubsection{Determinação de acetato}

O acetato foi determinado utilizando-se cromatografia líquida de alta pressão (HPLC) em um equipamento WATERS modelo 600E pela passagem da amostra por um refratômetro WATERS modelo 410. As condições de trabalho foram: coluna Shodex KC811, fase móvel $\mathrm{H}_{3} \mathrm{PO}_{4} \quad 0,1 \%$ e vazão de $1 \mathrm{~mL} \mathrm{~min}^{-1}$, temperatura da coluna $40{ }^{\circ} \mathrm{C}$, pressão de 350 psi e temperatura do refratômetro de $30^{\circ} \mathrm{C}$.

\subsubsection{Determinação da concentração de hGH}

Esta análise era feita em um dos laboratórios do Departamento de Aplicação de Técnicas Nucleares em Ciências Biológicas (IPEN-CNEN). A produção do hormônio sintetizado pelo microrganismo era avaliada usando-se cromatografia de fase reversa (RPHPLC) em um equipamento SHIMADZU (modelo CLASS-VP) pela passagem de $50 \mu \mathrm{L}$ de amostra por uma pré-coluna 214GD54 Protein C4 da (Vydac) e coluna 214TP54 Protein C4 (Vydac), comparando-se o pico obtido com o do padrão de hGH recombinante (tempo de retenção 32,9 minutos) da empresa $\mathrm{WHO}$, cuja área corresponde à massa de $10 \mu \mathrm{g}$ de hGH. A área integrada com o auxílio do software Class VP corresponde à concentração (em $\mu \mathrm{g} \mathrm{mL}^{-1}$ ) de hGH na amostra.

Condições de trabalho: fase móvel composta por $71,5 \%$ de Tris e $28,5 \%$ de npropanol, temperatura da coluna de $45^{\circ} \mathrm{C}$ e $50 \mu \mathrm{L}$ de amostra. 


\subsubsection{Determinação das vazões de entrada de ar no birreator}

A vazão de ar na entrada do reator foi determinada e controlada pela passagem da corrente por um fluxômetro de massa (modelo 5850E) da Brooks Instruments, o qual foi calibrado em relação a um rotâmetro de precisão (FISCHER \& PORTER modelo FP. 2F 14 20-5/25) carregando um "floating" CD.

\subsubsection{Determinação das frações molares de $\mathrm{O}_{2}$ e $\mathrm{CO}_{2}$ no gás de exaustão do biorreator}

As determinações das frações molares de $\mathrm{O}_{2}$ e $\mathrm{CO}_{2}$ foram feitas pela passagem do gás de exaustão do reator em analisador paramagnético (BECKMAN modelo 755) e em analisador espectrofotométrico de infravermelho (Automated Custom System modelo 3300), respectivamente.

\subsection{Determinação da velocidade específica de respiração $\left(Q_{02}\right)$}

A velocidade específica de respiração, Q02, foi determinada usando-se o Método do Balanço Gasoso. A expressão de cálculo desta velocidade relaciona os valores da vazão de Ar na entrada do biorreator e as frações molares de $\mathrm{O}_{2}$ e $\mathrm{CO}_{2}$ no gás de exaustão da seguinte forma:

$$
\mathrm{Q}_{\mathrm{O}_{2}}=\frac{\phi_{\mathrm{e}} \mathrm{Y}_{\mathrm{O}_{\mathrm{e}}}-\phi_{\mathrm{s}} \mathrm{Y}_{\mathrm{O}_{\mathrm{s}}}}{\mathrm{XV}} \quad\left[\mathrm{mmol} \mathrm{g}^{-1} \mathrm{~h}^{-1}\right]
$$

Eq. (1)

onde as variáveis são definidas como:

$$
\begin{aligned}
& \phi_{\mathrm{e}}=\text { vazão molar do gás que entra no biorreator }\left(\mathrm{mmol} \mathrm{h}^{-1}\right) \text {; } \\
& \phi_{\mathrm{s}}=\text { vazão molar do gás que sai no biorreator }\left(\mathrm{mmol} \mathrm{h}^{-1}\right)
\end{aligned}
$$


$\mathrm{Y}_{\mathrm{Oe}}=$ fração molar de oxigênio presente no gás de entrada do biorreator;

$\mathrm{Y}_{\mathrm{Os}}=$ fração molar de oxigênio no gás de saída do biorreator;

$\mathrm{V}=$ volume de meio do biorreator $(\mathrm{L})$;

$\mathrm{X}=$ concentração celular determinada como massa de matéria seca (item 3.7.1).

Como o gás de entrada no biorreator em quase todos os ensaios (com exceção do ensaio da-1, que teve a suplementação de $\left.\mathrm{O}_{2}\right)$, a fração molar de $\mathrm{O}_{2}$ foi de $0,21\left(\mathrm{Y}_{\mathrm{Oe}}=0,21\right)$ e a vazão medida através do fluxômetro de massa descrito no item 3.7.4 .

A fração molar de $\mathrm{O}_{2}$ existente no gás que sai do biorreator, $\mathrm{Y}_{\mathrm{Os}}$, é determinada pela leitura no medidor paramagnético conforme descrito no item 3.7.5 e a vazão molar de saída do biorreator, $\phi_{\mathrm{s}}$, determinada por cálculo através da equação (2). Esta é um balanço de massa para o Nitrogênio, que por ser inerte, a mesma massa de $\mathrm{N}_{2}$ que entra em um determinado intervalo de tempo é a mesma que sai no gás de exaustão. Portanto,

$$
\phi_{\mathrm{s}}=\frac{0,79 * \phi_{\mathrm{e}}}{1-\mathrm{Y}_{\mathrm{CO}_{2}}-\mathrm{Y}_{\mathrm{O}_{2}}} \quad\left[\mathrm{mmol} \mathrm{h}^{-1}\right] \quad \text { Eq. (2) }
$$

\subsection{Tratamento dos dados experimentais}

As curvas das variáveis em função do tempo foram alisadas através do Logiciel du Lissage, gentilmente cedido pelo Dr. Diogo A. Simões, da UFPE. Este programa está baseado em uma variação do Método Spline, que emprega o ajuste de um polinômio de grau $\mathrm{n}$ a um intervalo de dois pontos, incorporando um número de pontos à frente previamente definido. 


\subsubsection{Cálculo de velocidades específicas}

Para este cálculo, os polinômios gerados pelo Logiciel du Lissage foram deduzidos analiticamente a cada 1 hora, obtendo-se assim as derivadas necessárias para substituição nas equações a seguir:

- Velocidade específica de crescimento $(\mu)$ :

$\mu=\frac{1}{\mathrm{X}} \frac{\mathrm{dX}}{\mathrm{dt}} \quad\left[\mathrm{h}^{-1}\right]$

onde: $\mathrm{X}=$ concentração celular $\quad\left[\mathrm{g} \mathrm{L}^{-1}\right]$;

$\mathrm{t}=$ tempo $\quad[\mathrm{h}]$

- Velocidade específica de consumo de glicose $\left(\mu_{\mathrm{s}}\right)$ :

$\mu_{\mathrm{s}}=\frac{1}{\mathrm{X}} \frac{\mathrm{dG}}{\mathrm{dt}} \quad\left[\mathrm{g} \mathrm{g}^{-1} \mathrm{~h}^{-1}\right]$

onde: $\mathrm{X}=$ concentração celular $\quad\left[\mathrm{g} \mathrm{L}^{-1}\right]$.

$$
\mathrm{G}=\text { concentração de glicose presente } \quad\left[\mathrm{g} \mathrm{L}^{-1}\right] \text {. }
$$

- Velocidade específica de formação de acetato:

$$
\mu_{\mathrm{Ac}}=\frac{1}{\mathrm{X}} \frac{\mathrm{dAc}}{\mathrm{dt}} \quad\left[\mathrm{mg} \mathrm{g}^{-1} \mathrm{~h}^{-1}\right]
$$

onde: $\mathrm{X}=$ concentração celular $\quad\left[\mathrm{g} \mathrm{L}^{-1}\right]$

$$
\text { Ac }=\text { concentração de acetato formado } \quad\left[\mathrm{mg} \mathrm{L}^{-1}\right] .
$$

No item 3.10 encontra-se um exemplo de cálculo demonstrando como foram obtidas as concentrações de acetato e de ácido acético. 


\subsubsection{Fator de conversão substrato a células $\left(Y_{X / G}\right)$}

$$
Y_{X / G}=\frac{\left(X-X_{0}\right)}{G_{0}-G} \quad\left[\mathrm{~g} \mathrm{~g}^{-1}\right]
$$

onde: $\mathrm{X}=$ concentração celular $\quad\left[\mathrm{g} \mathrm{L}^{-1}\right]$

$$
\begin{aligned}
& \mathrm{X}_{0}=\text { concentração celular no instante inicial de cultivo } \quad\left[\mathrm{g} \mathrm{L}^{-1}\right] \\
& \mathrm{G}=\text { concentração de glicose final } \quad\left[\mathrm{g} \mathrm{L}^{-1}\right] \\
& \mathrm{G}_{0}=\text { concentração de glicose no instante inicial de cultivo } \quad\left[\mathrm{g} \mathrm{L}^{-1}\right] .
\end{aligned}
$$

\subsubsection{Produtividade em células}

$$
\mathrm{P}_{\mathrm{X}}=\frac{\mathrm{X}_{\mathrm{f}}-\mathrm{X}_{0}}{\mathrm{t}_{\mathrm{f}}} \quad\left[\mathrm{g} \mathrm{L}^{-1} \mathrm{~h}^{-1}\right]
$$

onde: $\mathrm{X}_{\mathrm{f}}=$ concentração celular no instante de término da fonte de carbono $\left[\mathrm{g} \mathrm{L}^{-1}\right]$

$$
\begin{aligned}
& \mathrm{X}_{0}=\text { concentração celular no instante inicial do cultivo }\left[\mathrm{g} \mathrm{L}^{-1}\right] \\
& \mathrm{t}_{\mathrm{f}}=\text { instante de término da fonte de carbono (glicose) }
\end{aligned}
$$

\subsection{Exemplo de cálculo para obtenção das concentrações de acetato}

Para a análise de acetato foi utilizada a coluna Shodex Ionpak (modelo KC811) por ser uma forte trocadora de cátions. O pico obtido pela passagem de uma amostra é representativo do acetato*, que encontra-se sob a forma de ácido acético em pH 2,0 (pH da fase móvel).

Para um exemplo de cálculo, usamos a equação de Henderson-Hasselbach, que fornece o valor de $\mathrm{pH}$ para ácidos fracos: 


$$
\mathrm{pH}=\mathrm{pk}_{\mathrm{a}}-\log \frac{[\mathrm{HAc}]}{\left[\mathrm{Ac}^{-}\right]}
$$

1) Usando-se esta equação, determina-se a concentração de acetato a $\mathrm{pH} 2,0$ presente na amostra.

2) Em seguida, determina-se a concentração total molar, denominada $C_{T}$, que corresponde às concentrações de ácido acético dissociado e acetato:

$$
\mathrm{C}_{\mathrm{T}}=[\mathrm{HAc}]_{\text {dissoc. }}+\left[\mathrm{Ac}^{-}\right]
$$

Esta determinação é feita em pH 2,0 e em qualquer outro valor de pH. A concentração de acetato, em pH 2,0, é muito pequena. Inserindo a equação (4) na equação (3) e isolando o termo referente à concentração de ácido acético, tem-se:

$$
\mathrm{pH}=\mathrm{pK}_{\mathrm{a}}-\log \frac{[\mathrm{HAc}]}{\left[\mathrm{C}_{\mathrm{T}}-[\mathrm{HAc}]\right]}
$$

que resulta, após algumas passagens matemáticas, em:

$$
[\mathrm{HAc}]=\frac{\mathrm{C}_{\mathrm{T}} * 10^{\mathrm{pK}_{\mathrm{a}}-\mathrm{pH}}}{1+10^{\mathrm{pK}_{\mathrm{a}}-\mathrm{pH}}}
$$

Com a curva de calibração $\mathrm{C}_{\mathrm{T}}=3,0 \times 10^{-8} *$ área $+0,0012\left(\mathrm{r}^{2}=0,9932\right)$ e o valor de área 164166 da amostra no instante de tempo 10h do ensaio d9, a concentração de acetato total resulta em:

$$
\mathrm{C}_{\mathrm{T}}=0,006125 \quad\left[\mathrm{~mol} \mathrm{~L}^{-1}\right]
$$


Substituindo os valores de $\mathrm{pH}$ do cultivo $(\mathrm{pH} 7,0)$ e de $\mathrm{pK}_{\mathrm{a}}\left(\mathrm{pK}_{\mathrm{a}}=4,757\right)$ do ácido acético na equação (6), tem-se que:
$[\mathrm{HAc}]=\mathrm{C}_{\mathrm{T}} * 0,005682$
$\left[\mathrm{mol} \mathrm{L}^{-1}\right]$
Eq. (6)
$\left[\mathrm{Ac}^{-}\right]=\mathrm{C}_{\mathrm{T}} * 0,99432$
$\left[\mathrm{mol} \mathrm{L}^{-1}\right]$
Eq. (7)

Multiplicando pela massa molecular do íon acetato $\left(\mathrm{MM}_{\mathrm{Ac}}=59 \mathrm{~g} \mathrm{~mol}^{-1}\right)$ e a massa molar do ácido acético $\left(\mathrm{MM}_{\mathrm{HAc}}=60 \mathrm{~g} \mathrm{~mol}^{-1}\right)$, obtém-se a concentração de acetato:
$\mathrm{HAc}=[\mathrm{HAc}] * 60 * 1000$
$\left[\mathrm{mg} \mathrm{L}^{-1}\right]$
Eq. (8)
$\mathrm{Ac}=\left[\mathrm{Ac}^{-}\right] * 59 * 1000$
$\left[\mathrm{mg} \mathrm{L}^{-1}\right]$
Eq. (9)

que é a concentração, em $\mathrm{mg} \mathrm{L}^{-1}$, de acetato e ácido acético presente na amostra, que neste exemplo resulta em :

$$
\begin{aligned}
& \mathrm{HAc}=2,1 \mathrm{mg} \mathrm{L}^{-1} \\
& \mathrm{Ac}=359,3 \mathrm{mg} \mathrm{L}^{-1}
\end{aligned}
$$

\subsection{Processo descontínuo alimentado}

\subsubsection{Processo descontínuo alimentado por pulsos:}

Este tipo de processo consiste na forma de alimentação ao biorreator mais simples que existe e foi realizada do seguinte modo: 
Em um determinado instante do cultivo (geralmente quando a glicose presente no biorreator foi completamente esgotada), introduz-se uma solução de alimentação com um determinado volume a fim de que a concentração final de glicose no caldo de fermentação seja a desejada. Tal concentração na alimentação é calculada por balanços de massa e de volume de cada componente presente nela.

\subsubsection{Processo descontínuo alimentado por vazão exponencial:}

No processo utilizado aqui, como não houve nem entrada e nem saída de células, o acúmulo de células foi devido ao seu crescimento. Portanto, obtêm-se:

$$
\begin{aligned}
& \text { acúmulo de células }=\text { crescimento celular } \\
& \frac{\mathrm{d}(\mathrm{VX})}{\mathrm{dt}}=\mathrm{V}\left(\frac{\mathrm{dX}}{\mathrm{dt}}\right)_{c}
\end{aligned}
$$

Com a relação acima e com um balanço mássico onde a variação da concentração de substrato é nula, deduz-se a equação abaixo (um desenvolvimento mais detalhado encontra-se em SUÁREZ, 1997):

$$
\varphi=\frac{\mathrm{V}_{0} \mathrm{X}_{0} \mu_{0}}{\mathrm{~S}_{0} \mathrm{Y}_{\mathrm{X} / \mathrm{S}}} \exp (\mu \mathrm{t})
$$

onde:

$\phi=$ vazão do meio de alimentação $\left(\mathrm{mL} \mathrm{h}^{-1}\right)$;

$\mathrm{V}_{0}=$ volume útil do biorreator no início da alimentação (L);

$\mathrm{X}_{0}=$ concentração celular no início da alimentação $\left(\mathrm{g} \mathrm{L}^{-1}\right)$;

$\mu_{0}=$ velocidade específica de crescimento adotada $\left(\mathrm{h}^{-1}\right)$; 


$$
\begin{aligned}
& \mathrm{S}_{0}=\text { concentração de glicose no meio de alimentação }\left(\mathrm{g} \mathrm{mL}^{-1}\right) ; \\
& \mathrm{Y}_{\mathrm{X} / \mathrm{S}}=\text { fator de conversão substrato a células }\left(\mathrm{g} \mathrm{g}^{-1}\right) ; \\
& \mathrm{t}=\text { valor atual do tempo de alimentação }(\mathrm{h}) .
\end{aligned}
$$

No caso do ensaio da-3, as variáveis acima receberam os seguintes valores:

Tabela 3.11.2.1: Variáveis utilizadas no cálculo da alimentação exponencial e seus respectivos valores.

\begin{tabular}{|c|c|}
\hline Variáveis & Valores \\
\hline $\mathrm{Y}_{\mathrm{x} / \mathrm{s}}\left(\mathrm{gg}^{-1}\right)$ & 0,40 \\
\hline $\mathrm{S}_{0}\left(\mathrm{~g} \mathrm{~mL}^{-1}\right)$ & 0,30 \\
\hline $\mathrm{V}_{0}(\mathrm{~L})$ & 3,80 \\
\hline $\mathrm{X}_{0}\left(\mathrm{~g} \mathrm{~L}^{-1}\right)$ & 3,50 \\
\hline$\mu_{0}\left(\mathrm{~h}^{-1}\right)$ & 0,08 \\
\hline
\end{tabular}

Inserindo estes valores na equação (11), o resultado é mostrado na equação baixo:
Equação final $\Rightarrow \quad \phi=8,87 * \exp \left(0,08^{*} \mathrm{t}\right)$
Eq. (12) 


\section{Resultados e Discussões}

\subsection{Ensaios em incubador rotativo}

Baseados em resultados obtidos anteriormente pelo IPEN e, com o objetivo de alcançar uma alta concentração celular, tornou-se importante o estudo do crescimento do microrganismo E. coli RR1. Para tanto, elaborou-se ensaios para conhecimento da cinética de crescimento deste microrganismo. A Tabela 4.1.1 apresenta uma descrição dos ensaios e a Tabela 4.1.2 apresenta um resumo dos resultados alcançados.

Tabela 4.1.1: Resumo das características dos ensaios realizados em incubador rotativo.

\begin{tabular}{|c|c|}
\hline Ensaios & Descrição \\
\hline S1 & Meio basal, temperatura de $30^{\circ} \mathrm{C}, 2,2 \mathrm{~g} \mathrm{~L}^{-1}$ de glicose. \\
\hline S2 & Meio basal, $37^{\circ} \mathrm{C}, 2,3 \mathrm{~g} \mathrm{~L}^{-1}$ de glicose, avaliação de expressão basal do hGH. \\
\hline S3 & Meio basal, $30^{\circ} \mathrm{C}$. \\
\hline S4 & Meio basal, tiamina $\left(4 \mu \mathrm{g} \mathrm{mL}^{-1}\right), 30^{\circ} \mathrm{C}$. \\
\hline S5 & Meio basal, 1-leucina $\left(350 \mathrm{mg} \mathrm{L}^{-1}\right), 30^{\circ} \mathrm{C}$. \\
\hline S6 & Meio basal, 1-prolina $\left(350 \mathrm{mg} \mathrm{L}^{-1}\right), 30^{\circ} \mathrm{C}$. \\
\hline S7 & $\begin{array}{l}\text { Meio basal, adição de 1-prolina, l-leucina e tiamina nas concentrações acima } \\
\text { descritas, } 30^{\circ} \mathrm{C} \text {. }\end{array}$ \\
\hline S8 & Idêntico ao ensaio S6, mas com 20 horas de duração. \\
\hline S9 & Semelhante ao ensaio S6, adição de 1-prolina $\left(500 \mathrm{mg} \mathrm{L}^{-1}\right)$. \\
\hline S10 & Repetição do ensaio S8. \\
\hline
\end{tabular}


Tabela 4.1.2: Resumo dos parâmetros dos ensaios realizados em incubador rotativo.

\begin{tabular}{|c|c|c|c|c|c|c|c|c|c|}
\hline $\begin{array}{c}\text { Variáveis } \\
\text { Ensaios }\end{array}$ & $\begin{array}{c}\mathrm{X}_{0} \\
\left(\mathrm{gL}^{-1}\right)\end{array}$ & $\begin{array}{c}\mathrm{X}_{\mathrm{f}} \\
\left(\mathrm{gL}^{-1}\right)\end{array}$ & $\begin{array}{c}\mathrm{G}_{0} \\
\left(\mathrm{~g} \mathrm{~L}^{-1}\right)\end{array}$ & $\begin{array}{c}\mathrm{G}_{\mathrm{F}} \\
\left(\mathrm{g} \mathrm{L}^{-1}\right)\end{array}$ & $\begin{array}{c}\mathrm{t}_{\mathrm{F}} \\
(\mathrm{h})\end{array}$ & $\begin{array}{c}\mathrm{T}_{\mathrm{t}} \\
(\mathrm{h})\end{array}$ & $\begin{array}{c}\mu_{\text {máx }} \\
\left(\mathrm{h}^{-1}\right)\end{array}$ & $\mathrm{Y}_{\mathrm{x} / \mathrm{s}}$ & $\mathrm{P}_{\mathrm{x}}$ \\
\hline $\mathrm{S} 1$ & 0,35 & 1,45 & 2,2 & 0 & 10 & 14 & 0,27 & 0,50 & 0,14 \\
\hline $\mathrm{S} 2$ & 0,24 & 1,52 & 2,3 & 0 & 6 & 12 & 0,32 & 0,55 & 0,25 \\
\hline $\mathrm{S} 3$ & 0,13 & 2,04 & 12,3 & 4,9 & $\mathrm{n} / \mathrm{z}$ & 14 & 0,48 & 0,26 & $0,15^{(2)}$ \\
\hline $\mathrm{S} 4$ & $1,07^{(1)}$ & 2,1 & 10,5 & 5,1 & $\mathrm{n} / \mathrm{z}$ & 14 & 0,42 & 0,19 & $0,15^{(2)}$ \\
\hline $\mathrm{S} 5$ & $0,74^{(1)}$ & 1,65 & 11,18 & 7,7 & $\mathrm{n} / \mathrm{z}$ & 14 & 0,28 & 0,26 & $0,12^{(2)}$ \\
\hline $\mathrm{S} 6$ & $0,71^{(1)}$ & 2,85 & 11 & 2,2 & $\mathrm{n} / \mathrm{z}$ & 14 & 0,44 & 0,24 & $0,24^{(2)}$ \\
\hline $\mathrm{S} 58$ & 0,02 & 2,82 & 10,66 & 0 & 14 & 20 & 0,67 & 0,26 & 0,20 \\
\hline & $0,78^{(1)}$ & 2,78 & 11 & 2,4 & $\mathrm{n} / \mathrm{z}$ & 14 & 0,35 & 0,23 & $0,23^{(2)}$ \\
\hline & 0,05 & 2,42 & 10,13 & 0 & 13 & 19 & 0,67 & 0,23 & 0,18 \\
\hline & 2,68 & 10,12 & 0 & 14 & 20 & 0,52 & 0,26 & 0,19 \\
\hline
\end{tabular}

Legenda: (1) : amostras feitas no tempo 4 horas de cultivo.

(2) : produtividade calculada no instante da última amostra.

$\mathrm{X}_{0}, \mathrm{X}_{\mathrm{f}}$ : concentrações celulares inicial e final.

$\mathrm{G}_{0}, \mathrm{G}_{\mathrm{f}}$ : concentrações de glicose inicial e final.

$\mu_{\text {máx }}$ : velocidade específica máxima de crescimento.

$\mathrm{Y}_{\mathrm{x} / \mathrm{s}}$ : fator de conversão substrato a células.

$\mathrm{P}_{\mathrm{x}}$ : produtividade em células.

$t_{\mathrm{f}}$ : tempo decorrido para exaustão da glicose.

$\mathrm{T}_{\mathrm{t}}$ : tempo total de ensaio.

n/z: glicose não foi exaurida do meio de cultivo. 
Inicialmente foram realizados ensaios em incubador rotativo para conhecimento da cinética de crescimento da cepa $E$. coli RR1 (contendo o vetor com o gene estrutural do hGH) nas temperaturas de 30 e $37^{\circ} \mathrm{C}$. Como este microrganismo possui um sistema de expressão que é desencadeado por indução térmica, os objetivos do ensaio a $37^{\circ} \mathrm{C}$ foram: estabelecer um aumento da velocidade específica de crescimento (diminuindo o tempo total de cultivo em biorreator) e verificar a possibilidade de expressão basal de hGH, bom como sua conseqüência na cinética de crescimento celular.

Na temperatura de $30{ }^{\circ} \mathrm{C}$ (ensaio S1), E. coli RR1 apresentou uma velocidade específica máxima de crescimento $\left(\mu_{\text {máx }}\right)$ de $0,27 \mathrm{~h}^{-1}$ e uma produtividade $\left(\mathrm{P}_{\mathrm{x}}\right)$ de $0,14 \mathrm{~g}$ $\mathrm{L}^{-1} \mathrm{~h}^{-1}$ em 10 horas de cultivo. A fonte de carbono (glicose) foi totalmente esgotada em 10 horas de ensaio, resultando em um fator de conversão substrato a células $\left(\mathrm{Y}_{\mathrm{x} / \mathrm{s}}\right)$ de $0,50 \mathrm{~g} \mathrm{~g}^{-1}$

$\mathrm{Na}$ temperatura de $37{ }^{\circ} \mathrm{C}$ (ensaio S2), o microrganismo cresceu com velocidade específica máxima de crescimento $\left(\mu_{\text {máx }}\right)$ de $0,32 \mathrm{~h}^{-1}$, a qual é inferior ao valor de $0,66 \mathrm{~h}^{-1}$ apresentado pela cepa $E$. coli BL21 (DE3) plysS, tendo gerado uma baixa produtividade em células para a cepa $\operatorname{RR} 1\left(0,106 \mathrm{~g} \mathrm{~L}^{-1} \mathrm{~h}^{-1}\right)$ em relação a cepa BL21 (DE3) plysS $\left(0,255 \mathrm{gL}^{-1}\right.$ $\left.\mathrm{h}^{-1}\right)$. Constatou-se a presença de $\mathrm{hGH}$ em concentrações muito pequenas, o que poderia explicar o decréscimo da produtividade e do valor de $\mu_{\text {máx }}$ no ensaio S2, pois parte dos precursores biossintéticos provavelmente foi desviada para a construção da molécula-alvo.

Devido ao fato da expressão basal de hGH ser desfavorável ao crescimento celular, foi descartado o uso da temperatura de $37{ }^{\circ} \mathrm{C}$ para os cultivos subsequentes e adotada a temperatura de $30^{\circ} \mathrm{C}$.

Os perfis de concentração celular e consumo de glicose em relação ao tempo de cultivo dos ensaios S1 e S2 são mostrados nas Figuras 4.1.1 e 4.1.2. 


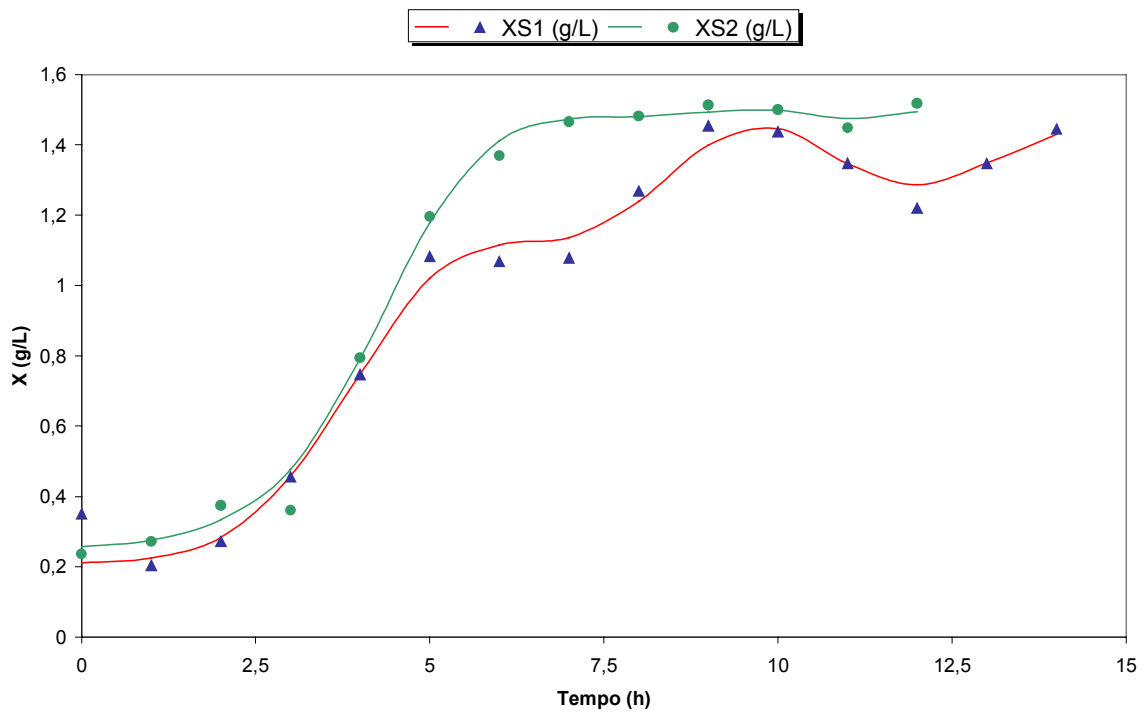

Figura 4.1.1: Concentrações celulares dos ensaios $\mathrm{S} 1\left(30^{\circ} \mathrm{C}\right)$ e $\mathrm{S} 2\left(37^{\circ} \mathrm{C}\right)$.

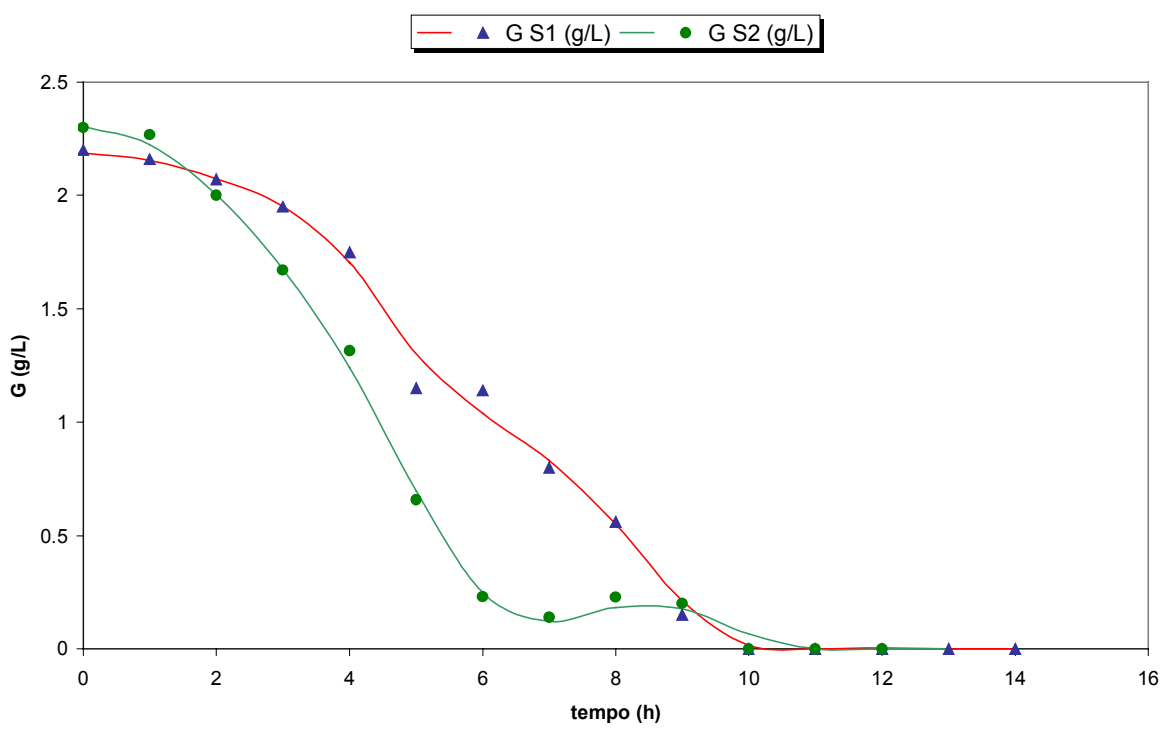

Figura 4.1.2: Concentrações de glicose dos ensaios $\mathrm{S} 1\left(30^{\circ} \mathrm{C}\right)$ e $\mathrm{S} 2\left(37^{\circ} \mathrm{C}\right)$. 
Os ensaios S1 e S2 não apresentaram a concentração inicial correta de glicose (10 g $\mathrm{L}^{-1}$ ), como mostra a Figura 4.1.2, tendo sido necessária a realização de mais um ensaio (denominado S3), adotado como referência (Figura 4.1.3 a).

Conhecendo-se a auxotrofia do microrganismo e a cinética de crescimento em meio basal, foi planejado um segundo conjunto de ensaios em incubador rotativo para a determinação da influência que cada um dos aminoácidos (1-leucina e 1-prolina) e da vitamina (tiamina) poderiam exercer sobre o crescimento celular da cepa E. coli RR1. Com esses objetivos, seguiram-se, portanto, os ensaios S4 a S7. As concentrações de trabalho de cada componente foram calculadas segundo uma média entre os valores encontrados na literatura (CHANG et al. (1999), ROTHEN et al. (1998), BROWLIE et al.. (1990)).

No ensaio S4 - Figura 4.1.3b - houve a adição de uma solução de tiamina na concentração de $4 \mu \mathrm{g} \mathrm{mL}^{-1}$, resultando uma concentração celular final de $2,1 \mathrm{~g} \mathrm{~L}^{-1}$ com 14 horas de cultivo. Novamente verificou-se um fenômeno de limitação do crescimento entre os instantes 8 e 10 horas de cultivo, fato também encontrado no ensaio S3 (entre os instantes 8 e 11 horas). Entretanto, a fonte de carbono não foi completamente consumida neste ensaio S4 e a concentração celular permaneceu a mesma, bem como a velocidade máxima de crescimento e o fator de conversão. Portanto, a adição de vitamina ao meio de crescimento não afetou o aumento de concentração celular. YEE; BLANCH (1993) também mostraram que vitaminas suplementadas ao meio não afetam o crescimento celular.

O ensaio S5 - Figura 4.1.4a - teve a finalidade de mostrar o efeito da adição de 1leucina no crescimento celular. Os resultados são apresentados na Tabela 4.1.2. Com a adição de 1-leucina em uma concentração final de $350 \mathrm{mg} \mathrm{L}^{-1}$, o crescimento celular 

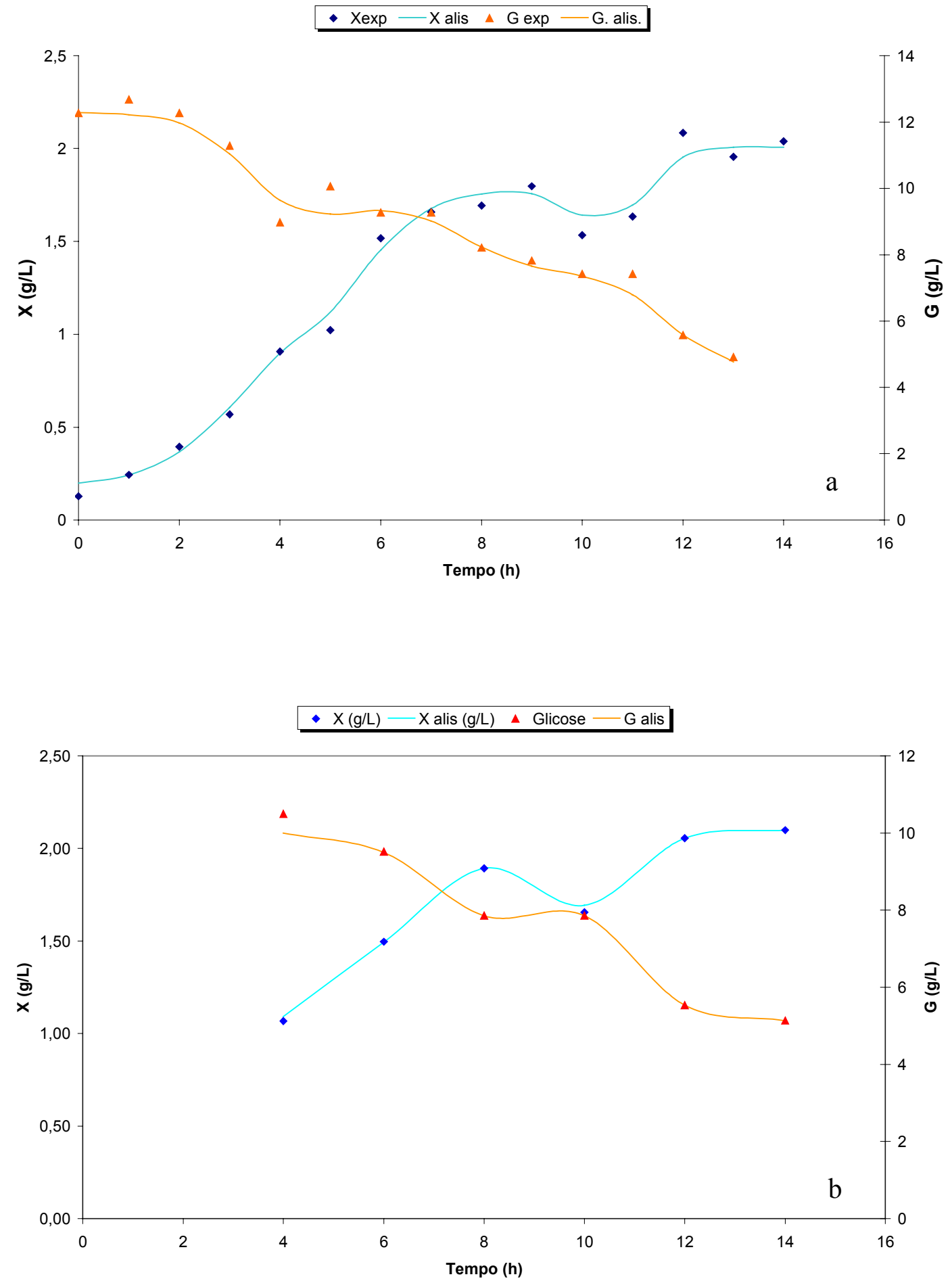

Figura 4.1.3 - Concentrações celulares e de glicose para os ensaios: (a) S3 e (b) S4. 
observado foi 19,12 \% menor que no ensaio S3, sugerindo uma possível inibição por 1leucina. Este fato também é apresentado por ROTHEN et al. (1998) e YEE; BLANCH (1993). Segundo INGRAHAM (1983), a síntese de l-leucina é regulada por um operon e a atividade da enzima $\alpha$-isopropilmalato sintase (leuA) (a primeira enzima na sua via de biossíntese) é inibida por concentrações consideráveis de 1-leucina.

O ensaio S6 - Figura 4.1.4b - teve a finalidade de estudar a adição de 1-prolina em concentração de $350 \mathrm{mg} \mathrm{L}^{-1}$, com os resultados apresentados na Tabela 4.1.2. Houve um aumento de massa celular da ordem de 39,7 \% em relação ao ensaio S3 e não foi constatada a presença de uma possível limitação no intervalo de tempo de 8 a 12 horas (fato presente nos ensaios S1, S3 e S4), conforme observado nas Figuras 4.1.1 e 4.1.3.

No ensaio S7 - Figura 4.1.4c - adicionou-se os aminoácidos anteriormente citados e a tiamina nas mesmas concentrações já descritas, sendo a finalidade conhecer a influência dessas adições em conjunto no crescimento celular. Como visto nesta figura, os valores da curva de crescimento celular são muito próximos dos valores do ensaio S6, o que sugere que o aminoácido 1-prolina tem uma importância maior para a obtenção de um aumento da concentração celular que a 1-leucina e tiamina.

Entretanto, analisando o conjunto de ensaios S3 a S7, percebe-se que a glicose não foi totalmente consumida pelo microrganismo devido ao tempo de cultivo insuficiente. Com base nesta informação, foi realizado o ensaio S10 (uma repetição do ensaio S6) com um tempo maior de cultivo, mostrado pela Figura 4.1.5b. A concentração celular alcançada foi $14,3 \%$ menor que a obtida no ensaio S6 com esgotamento da glicose em 12 horas. Os parâmetros encontram-se descritos na Tabela 4.1.2. 
$\mathrm{X}(\mathrm{g} / \mathrm{L})-\mathrm{X}$ alis $(\mathrm{g} / \mathrm{L}) \quad \Delta \mathrm{G}(\mathrm{g} / \mathrm{L})-$ Glicose
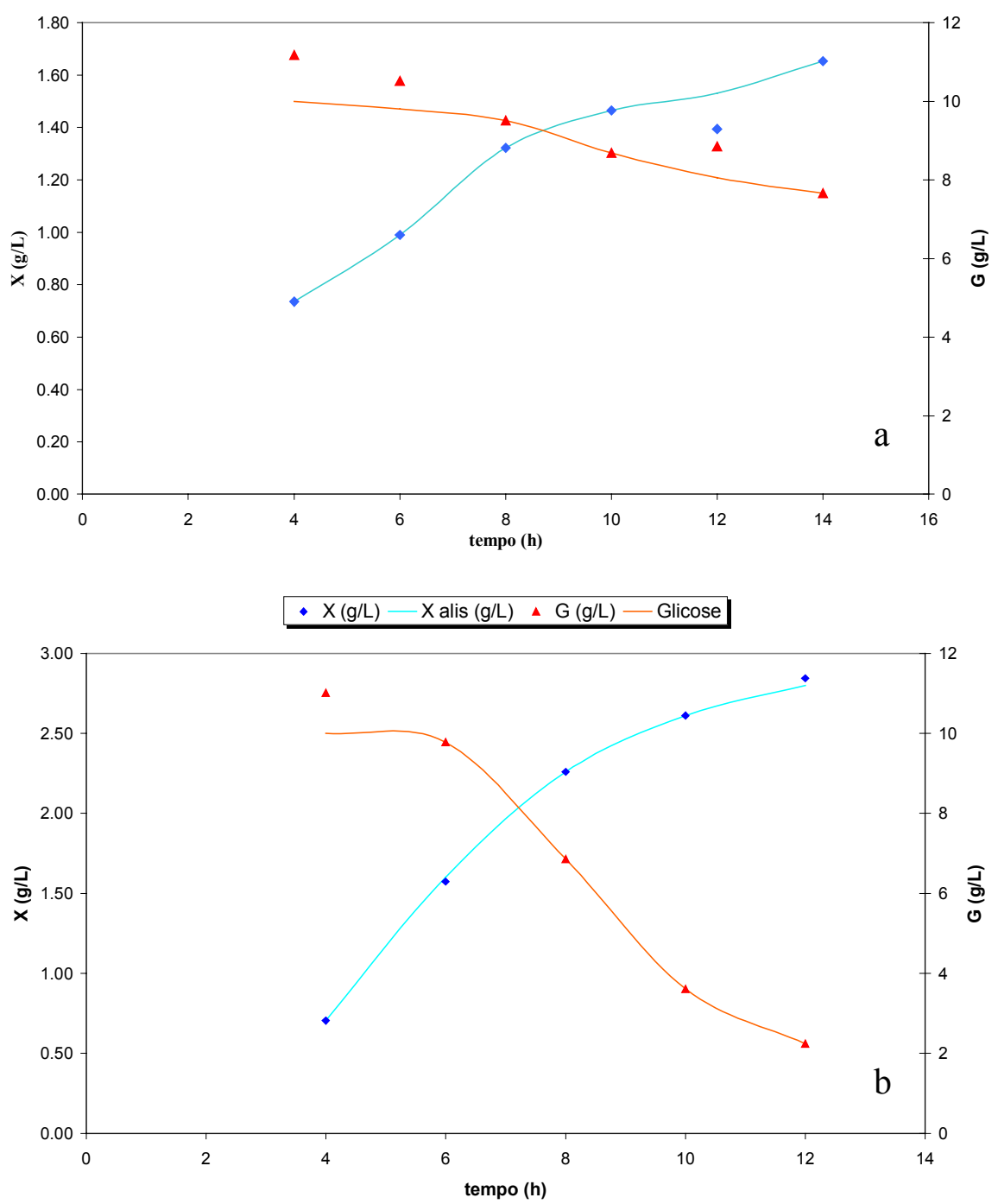

- $\mathrm{X}(\mathrm{g} / \mathrm{L})-\mathrm{X}$ alis $(\mathrm{g} / \mathrm{L}) \Delta \mathrm{G}(\mathrm{g} / \mathrm{L})-$ Glicose

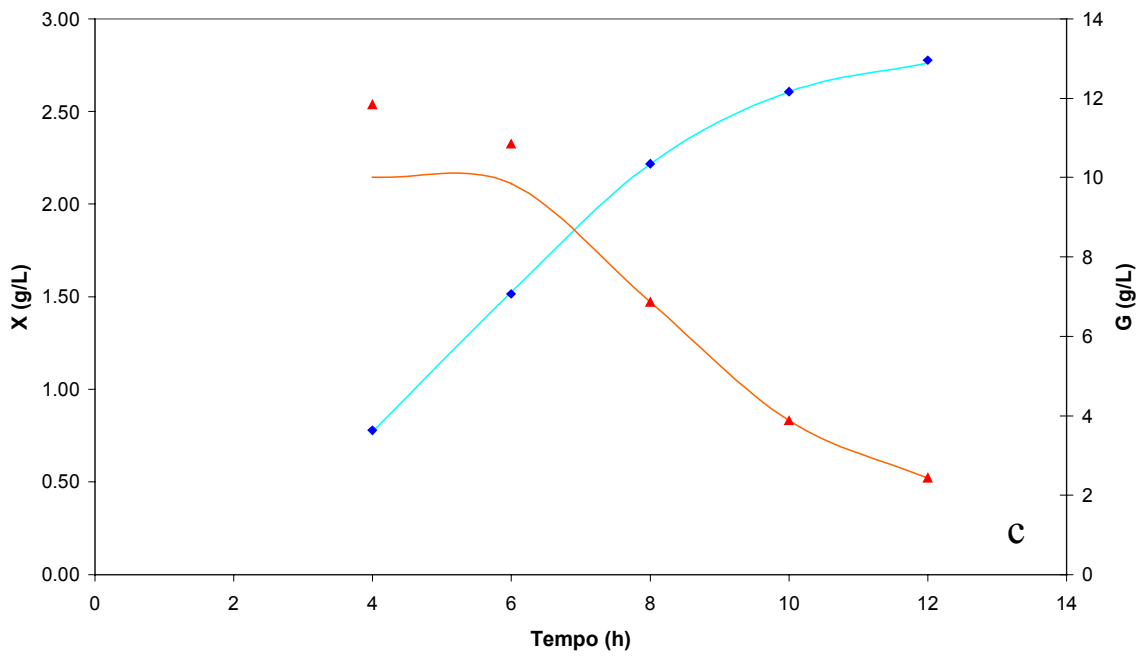

Figura 4.1.4 - Concentrações celulares e de glicose para os ensaios:(a) S5, (b) S6 e (c) S7 . 
Com o conhecimento dos resultados dos ensaios S6 e S10 e com a intenção de se alcançar uma maior massa celular, foi realizado o ensaio S9 - Figura 4.1.5a - com adição de uma solução de 1-prolina ao meio de crescimento na concentração final de $500 \mathrm{mg} \mathrm{L}^{-1}$. Neste ensaio, apesar de que o microrganismo tenha atingido $\mu_{\text {máx }}$ no mesmo instante do ensaio S10 - Figura 4.1.5c - o crescimento foi mais lento em relação ao ensaio S10. Isto sugere uma possível inibição pela 1-prolina. Após as 8 horas iniciais, as velocidades praticamente se igualam, o que pode indicar uma necessidade nutricional ainda não suprida, mesmo com uma concentração alta de 1-prolina.

No ensaio S9, a velocidade específica máxima de crescimento foi praticamente a mesma que a obtida no ensaio S3 (dados os erros experimentais), mas 32,5\% menor em relação ao ensaio S8. Porém, a concentração celular final foi praticamente a mesma dos ensaios S6 ao S8, indicando que um aumento na concentração celular não está ligado diretamente ao aumento na concentração de 1-prolina.

Com este resultado, adotou-se para os experimentos em biorreator a concentração de 1-prolina em $350 \mathrm{mg} \mathrm{L}^{-1}$, não sendo utilizada soluções de 1-leucina e de tiamina. 


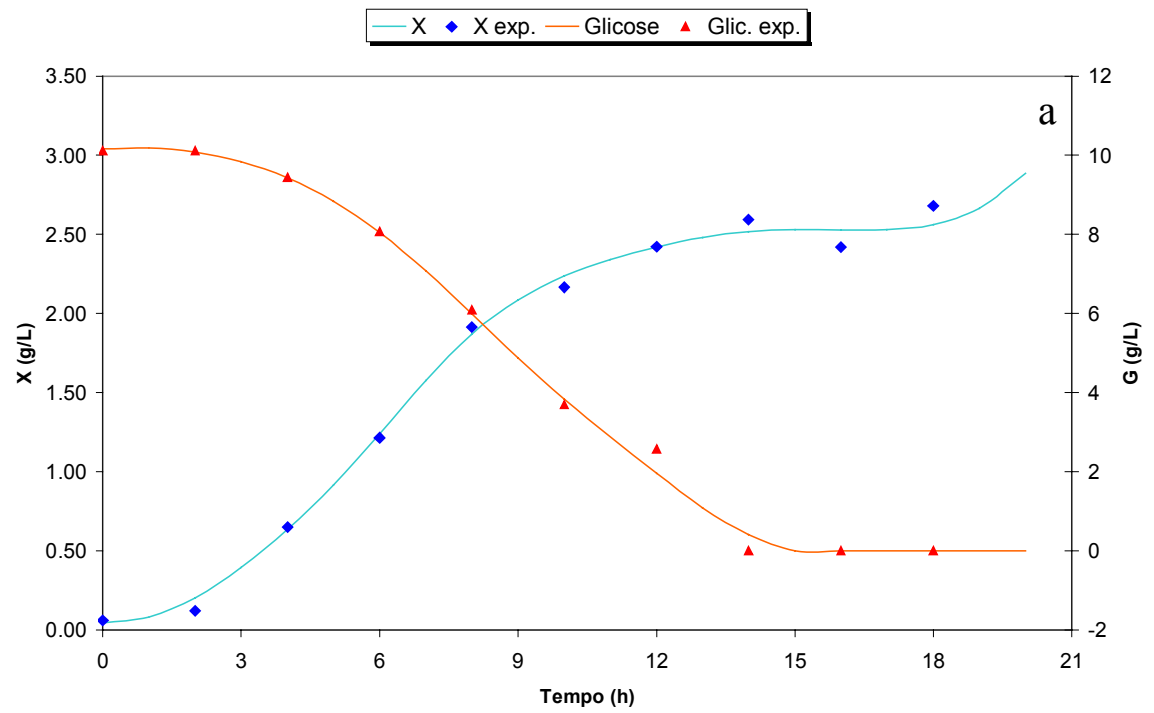

- X $\bullet$ X exp. - Glicose $\wedge$ Glic. exp.

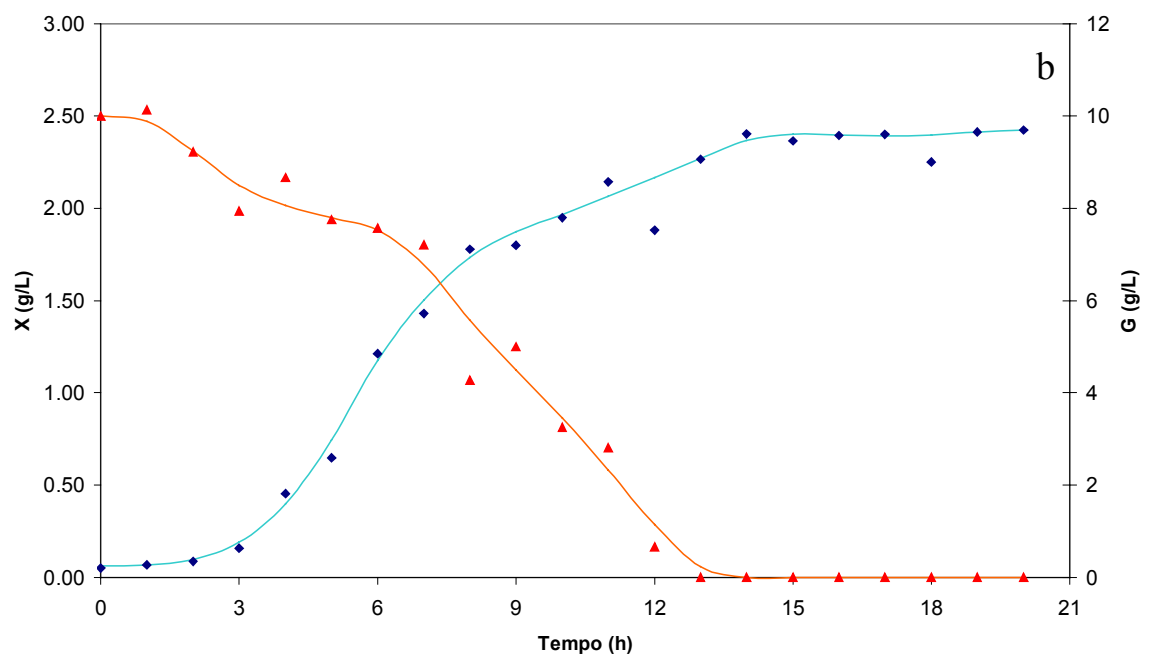

$-\mu \mathrm{x}(\mathrm{S} 9)-\mu \times(\mathrm{S} 10)$

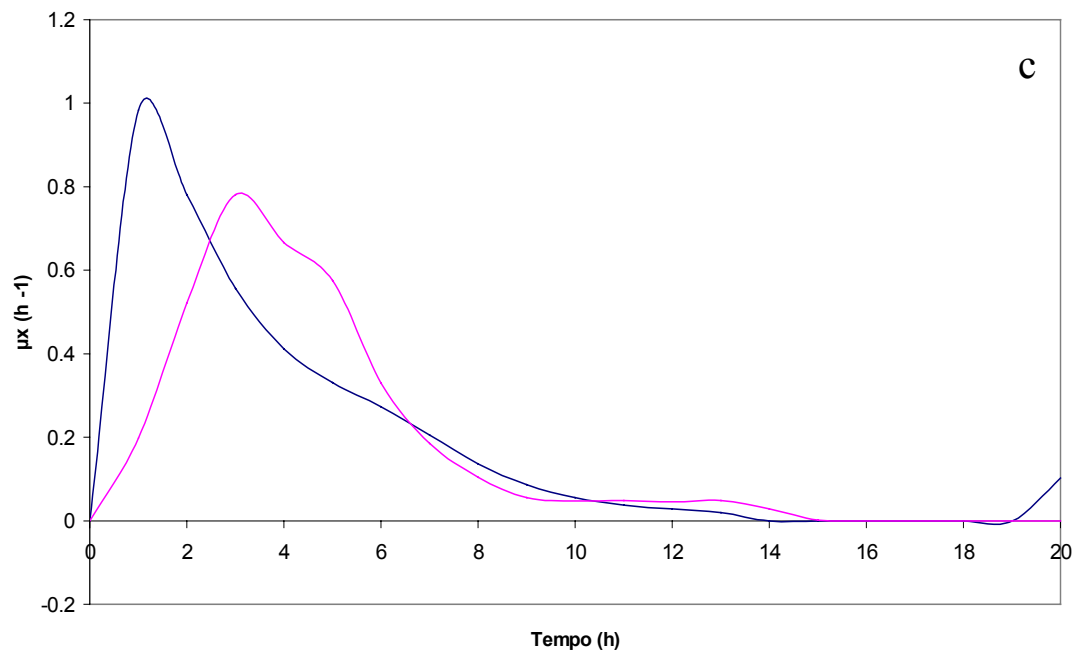

Figura 4.1.5 - Concentrações celular e de glicose para os ensaios (a) S9 e (b) S10. (c ) Comparação entre as duas velocidades de crescimento para os dois ensaios. 


\subsection{Ensaios em biorreator}

Iniciou-se o estudo da cinética de crescimento do microrganismo E. coli RR1 em biorreator repetindo um experimento realizado anteriormente no IPEN, usando o meio basal descrito no item 3.1.4 do capítulo de Materiais e Métodos, em temperatura de $30^{\circ} \mathrm{C}$, sem a adição de 1-prolina e sem a avaliação da expressão basal de hGH (ensaio d5).

Este ensaio d5 é importante porque o resultado alcançado com o crescimento celular sem a adição de aminoácidos foi o melhor obtido. Os demais ensaios deste primeiro conjunto renderam concentrações celulares menores, mesmo que esses fossem suplementados com 1-prolina, possivelmente devido a troca dos lotes de célula.

Na tentativa de estabelecer a importância de cada componente complexo do meio de cultivo, optou-se por um conjunto de ensaios tomando-se por base o meio de crescimento utilizado nos cultivos da cepa BL21 (DE3) pLysS, que consiste em:

$\begin{array}{lll}\text { Por litro: } & 13 \mathrm{~g} & \mathrm{KH}_{2} \mathrm{PO}_{4} \\ 10 \mathrm{~g} & \mathrm{~K}_{2} \mathrm{HPO}_{4} \\ 3 \mathrm{~g} & \left(\mathrm{NH}_{4}\right)_{2} \mathrm{HPO}_{4} \\ 4.6 \mathrm{~g} & \mathrm{NaH}_{2} \mathrm{PO}_{4} \cdot \mathrm{H}_{2} \mathrm{O} \\ 2 \mathrm{~g} & \mathrm{MgSO}_{4} \cdot 7 \mathrm{H}_{2} \mathrm{O} \\ 1 \mathrm{~g} & \text { Extrato de levedura } \\ 3 \mathrm{ml} & \text { Solução de micronutrientes } \\ & \text { Solução de antibiótico }\end{array}$

Em cada cultivo, o meio descrito acima foi complementado ora com extrato de levedura, ora com bactotriptona e ora com 1-prolina, conforme o ensaio destinado (Tabela 4.2.1). Na Tabela 4.2.2 encontram-se resumidos os parâmetros de cada ensaio. 
As condições que permaneceram constantes em todos os ensaios são listadas abaixo:

- biorreator de 2L;

- cultivo descontínuo;

- temperatura de $30^{\circ} \mathrm{C}$;

- meio de crescimento utilizado: o mesmo meio de crescimento da cepa E. coli BL21 (DE3) pLysS, conforme KILIKIAN (1998), suplementado com outros nutrientes dependendo do ensaio.

Tabela 4.2.1: Descrição dos ensaios realizados no primeiro conjunto.

\begin{tabular}{|c|c|}
\hline Ensaios $^{(1)}$ & Descrição \\
\hline $\mathrm{d} 1$ & $\begin{array}{l}\text { Meio de cultivo da cepa Escherichia coli BL21 (DE3) pLysS, sem adição de } \\
\text { bactotriptona e de pulso de 1-prolina. }\end{array}$ \\
\hline $\mathrm{d} 2$ & $\begin{array}{l}\text { Mesmo meio acima, mas com adição de 1-prolina (concentração de } 350 \\
\mathrm{mg} \mathrm{L}^{-1} \text { ) }\end{array}$ \\
\hline $\mathrm{d} 3$ & $\begin{array}{l}\text { Aumento da concentração de extrato de levedura de } 1 \mathrm{~g} \mathrm{~L}^{-1} \text { para } 2 \mathrm{~g} \mathrm{~L}^{-1} \text {, sem } \\
\text { bactotriptona e adição de l-prolina }\left(350 \mathrm{mg} \mathrm{L}^{-1}\right) \text {. Pulso de glicose }\left(2 \mathrm{~g} \mathrm{~L}^{-1}\right) \\
\text { nos instantes finais do cultivo para teste de expressão do hGH. }\end{array}$ \\
\hline $\mathrm{d} 4$ & $\begin{array}{l}\text { Adição de } 1 \mathrm{gL}^{-1} \text { de bactotriptona, permanecendo em } 1 \mathrm{~g} \mathrm{~L}^{-1} \text { a concentração } \\
\text { de extrato de levedura e adição de 1-prolina }\left(350 \mathrm{mg} \mathrm{L}^{-1}\right) \text {. Pulso de glicose } \\
\left(2 \mathrm{~g} \mathrm{~L}^{-1}\right) \text { nos instantes finais do cultivo para teste de expressão do } \mathrm{hGH} \text {. }\end{array}$ \\
\hline $\mathrm{d} 5^{(2)}$ & $\begin{array}{l}\text { Meio basal, biorreator de } 4 \mathrm{~L} \text {, cultivo descontínuo (repetição de ensaio } \\
\text { realizado pelo IPEN). }\end{array}$ \\
\hline $\mathrm{d} 6$ & $\begin{array}{l}\text { Duplicata do ensaio d5 com adição de 1-prolina em concentração de } 350 \\
\mathrm{mg} \mathrm{L}^{-1} \text {. }\end{array}$ \\
\hline
\end{tabular}

Legenda: segue a mesma da Tabela 4.1.2

(1) : A apresentação destes ensaios não seguem a ordem cronológica na qual foram feitos;

(2) : Este ensaio utilizou o primeiro lote de células da cepa $E$. coli RR1. Os demais ensaios contidos nesta Tabela foram realizados com o segundo lote. 
Tabela 4.2.2 : Parâmetros dos ensaios em biorreator realizados no primeiro conjunto.

\begin{tabular}{|c|c|c|c|c|c|c|c|c|c|}
\hline Ensaios & $\begin{array}{c}\mathrm{X}_{0} \\
(\mathrm{~g} / \mathrm{L})\end{array}$ & $\begin{array}{c}\mathrm{X}_{\mathrm{f}} \\
(\mathrm{g} / \mathrm{L})\end{array}$ & $\begin{array}{c}\mathrm{G}_{0} \\
(\mathrm{~g} / \mathrm{L})\end{array}$ & $\begin{array}{c}\mathrm{G}_{\mathrm{f}} \\
(\mathrm{g} / \mathrm{L})\end{array}$ & $\begin{array}{c}\mathrm{t}_{\mathrm{f}} \\
(\mathrm{h})\end{array}$ & $\begin{array}{c}\mathrm{T}_{\mathrm{t}} \\
(\mathrm{h})\end{array}$ & $\begin{array}{c}\mu_{\text {máx }} \\
\left(\mathrm{h}^{-1}\right)\end{array}$ & $\begin{array}{c}\mathrm{Y}_{\mathrm{x} / \mathrm{s}} \\
(\mathrm{g} / \mathrm{g})\end{array}$ & $\begin{array}{c}\mathrm{P}_{\mathrm{x}} \\
(\mathrm{g} / \mathrm{Lh})\end{array}$ \\
\hline $\mathrm{d} 1$ & 0,04 & 0,61 & 10,7 & 9,9 & $\mathrm{n} / \mathrm{z}$ & 14 & 0,30 & 0,67 & 0,051 \\
\hline $\mathrm{d} 2$ & 0,35 & 1,74 & 10,12 & 6,3 & $\mathrm{n} / \mathrm{z}$ & 32 & 0,22 & 0,36 & 0,073 \\
\hline $\mathrm{d} 3$ & 0,02 & 2,52 & 10,2 & 0 & 28 & 38 & 0,73 & 0,24 & 0,090 \\
\hline $\mathrm{d} 4$ & 0,13 & 2,39 & 10,06 & 1,2 & $\mathrm{n} / \mathrm{z}$ & 38 & 0,48 & 0,25 & 0,185 \\
\hline $\mathrm{d} 5$ & 0,02 & 5,10 & 10,50 & 0 & 17 & 23 & 0,53 & 0,48 & 0,300 \\
\hline $\mathrm{d} 6$ & 0,17 & 2,95 & 9,60 & 0 & 28 & 32 & 0,26 & 0,29 & 0,126 \\
\hline
\end{tabular}

Legenda: segue a mesma da Tabela 4.2.1 .

Para o primeiro experimento (denominado d1), o meio para crescimento da cepa $E$. coli RR1 foi o meio de crescimento destinado aos cultivos da cepa E. coli BL21 (DE3) pLysS. Constatou-se que não houve crescimento celular, nem um consumo de glicose significativo. Isto se deve provavelmente às auxotrofias que o microrganismo possui, não obtendo nutrientes suficientes para biossíntese.

No segundo experimento (denominado d2) realizado em paralelo ao descrito acima, utilizou-se o mesmo meio de crescimento, mas neste caso suplementado com $350 \mathrm{mg} \mathrm{L}^{-1}$ de 1-prolina. O microrganismo obteve um crescimento ainda muito baixo, porém com uma concentração celular final cerca de $65 \%$ maior do que o ensaio d1, conforme mostra a Figura 4.4.1.

Sendo o crescimento pequeno (ensaio d2) - Figura 4.2.1-, com uma concentração celular final de $1,74 \mathrm{~g} \mathrm{~L}^{-1}$ depois de 32 horas e com um fator de conversão substrato a 

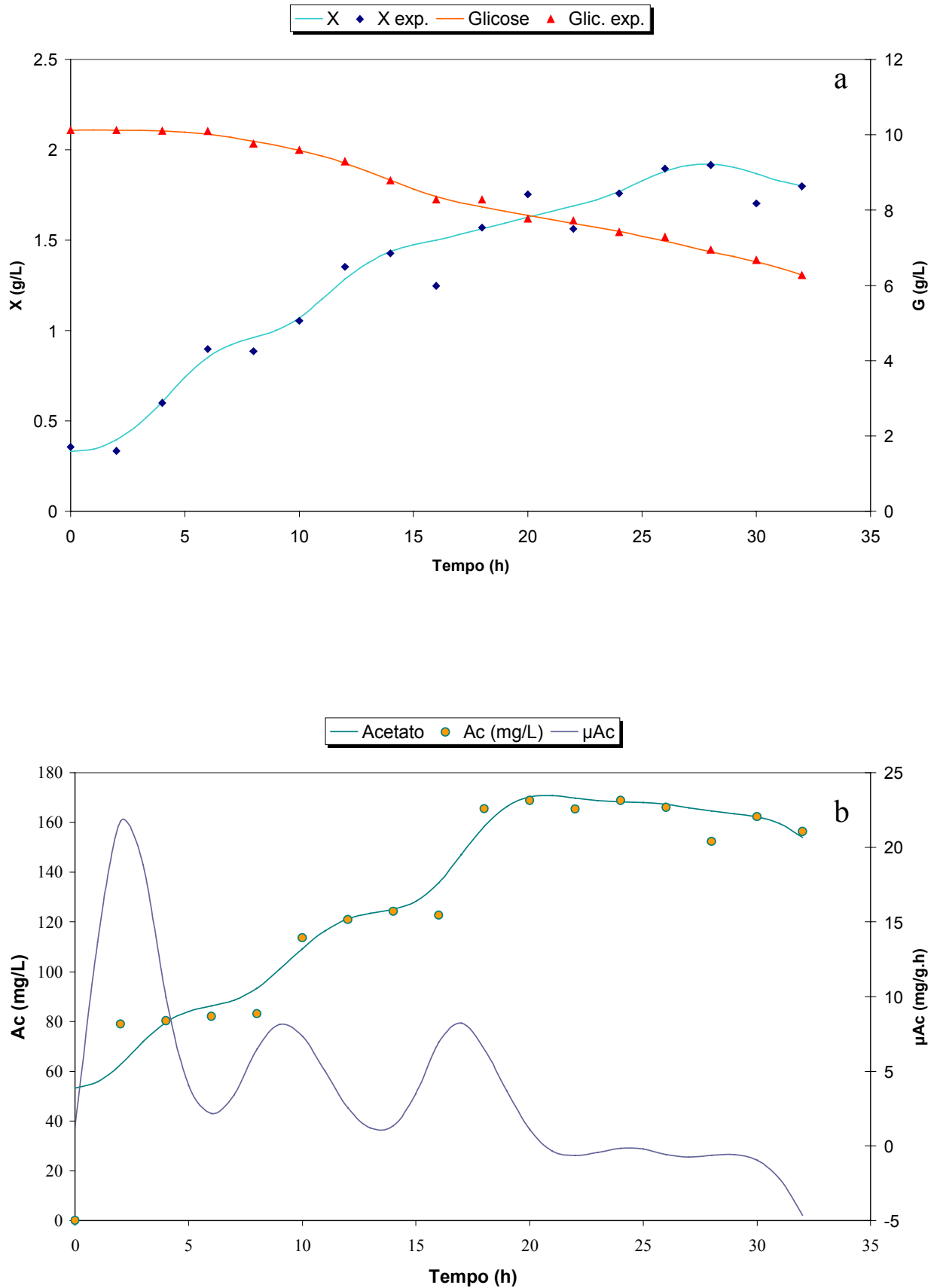

Figura 4.2.1 - Ensaio d2 : (a) Concentrações celular e de glicose; (b) concentração e perfil da velocidade específica de formação de acetato. 
células de $0,36 \mathrm{~g} \mathrm{~g}^{-1}$, o consumo de base para manter o $\mathrm{pH}$ constante foi pequeno, fazendo com que a bomba de base fosse acionada pouco depois de 8 horas de ensaio e a massa total de $\mathrm{NH}_{4} \mathrm{OH} 25 \%$ adicionada ao biorreator de 1,6 g durante todo o cultivo. A concentração de oxigênio dissolvido atingiu seu menor valor em $93 \%$ e a composição dos gás de exaustão foi avaliada, onde os valores de fração de $\mathrm{O}_{2}$ mostraram uma velocidade específica máxima de consumo de oxigênio ( $\left.\mathrm{Q}_{\mathrm{O} 2}\right)$ da ordem de $24,5 \mathrm{mmol} \mathrm{g}^{-1} \mathrm{~h}^{-1}$.

Como o consumo de glicose foi baixo no ensaio d2 (com uma concentração final de $6,3 \mathrm{~g} \mathrm{~L}^{-1}$ em 32 horas de ensaio e $\mu_{\mathrm{s} \text { máx }}$ de $0,16 \mathrm{~g} \mathrm{~g}^{-1} \mathrm{~h}^{-1}$ ), a concentração de acetato foi baixa, com seu valor máximo de 168,8 $\mathrm{mg} \mathrm{L}^{-1}$ - Figura 4.2.1b - (6,63 \% menor que o ensaio d5), em 20 horas de cultivo e decrescendo logo em seguida. Para comparação, no ensaio d5 a máxima concentração celular foi de $5,1 \mathrm{~g} \mathrm{~L}^{-1}$ em 17 horas de cultivo (a mesma concentração celular foi obtida em ensaio anteriormente realizado no IPEN). Analisando a curva de concentração celular em função do tempo (Figura 4.2.5a), encontramos dois comportamentos diferentes no crescimento celular. Nos primeiros instantes, $\mu$ atinge o valor máximo de $0,53 \mathrm{~h}^{-1}$ (Figura 4.2.5b) decorrente de um início de fase exponencial. Nos instantes seguintes, $\mu$ atinge um valor menor $\left(0,10 \mathrm{~h}^{-1}\right)$ e a cinética descreve um crescimento linear, típico de limitação por nutrientes, mesmo com a fonte de carbono (glicose) ainda presente no caldo.

A velocidade específica de consumo de substrato $\left(\mu_{\mathrm{s}}\right)$ aumenta praticamente de forma linear de $0,02 \mathrm{~g} \mathrm{~g}^{-1} \mathrm{~h}^{-1}$ chegando a $0,8 \mathrm{~g} \mathrm{~g}^{-1} \mathrm{~h}^{-1}$ ( $\left.\mu_{\text {smáx }}\right)$. A formação de acetato (principal subproduto) deu-se quase que linearmente no intervalo de tempo onde $\mu_{\mathrm{s}}$ é baixo - Figura 4.2.5c -. Em condições de limitação no consumo de glicose e em baixa velocidade específica de crescimento, este microrganismo pode consumir acetato, o que é explicado 
pela fosforilação parcial da enzima isocitrato desidrogenase do ciclo TCA, redirecionando parte do fluxo de carbono para o desvio do glioxilato.

Estes resultados dos ensaios d1 e d2 comprovam a necessidade de suplementar o meio de cultivo da cepa $E$. coli RR1 com 1-prolina, por ser uma deficiência conhecida do microrganismo. Contudo, como o microrganismo não atingiu uma concentração esperada tal como no ensaio d5 (5,1 $\left.\mathrm{g} \mathrm{L}^{-1}\right)$, acredita-se que deva existir alguma diferença entre os dois lotes de células utilizados neste trabalho.

Analisando-se os resultados dos ensaios d5, d1 e d2, seguiram-se 2 ensaios em biorreator: o ensaio d3, contendo o meio de crescimento da cepa BL21 (DE3) pLysS com 2 $\mathrm{g} \mathrm{L}^{-1}$ de extrato de levedura suplementado com 1-prolina na concentração de $350 \mathrm{mg} \mathrm{L}^{-1}$; e o ensaio d4, com meio contendo $1 \mathrm{~g} \mathrm{~L}^{-1}$ de bactotriptona, também suplementado com 1prolina.

Nestes ensaios ( $\mathrm{d} 3$ e d4) também foi realizado um teste de indução por choque térmico, elevando-se a temperatura do cultivo de $30{ }^{\circ} \mathrm{C}$ para $42{ }^{\circ} \mathrm{C}$ (choque realizado em 16 minutos devido as características do equipamento).

O ensaio d3 obteve 2,52 $\mathrm{g} \mathrm{L}^{-1}$ como concentração celular final e exaustão total da glicose em 28 horas, conforme mostrado na Figura 4.2.3a e o ensaio d4 obteve 2,39 $\mathrm{g} \mathrm{L}^{-1}$, sem a glicose ser completamente esgotada (Figura 4.2.4). No instante de 33 horas, uma solução de glicose com concentração de $4 \mathrm{~g} \mathrm{~L}^{-1}$ foi alimentada para iniciar a fase de indução por choque térmico nos dois ensaios (Figuras 4.2.3 e 4.2.4). Com um total de 6 horas de indução, constatou-se que não houve expressão de hGH em nenhuma das amostras dos 2 ensaios. 

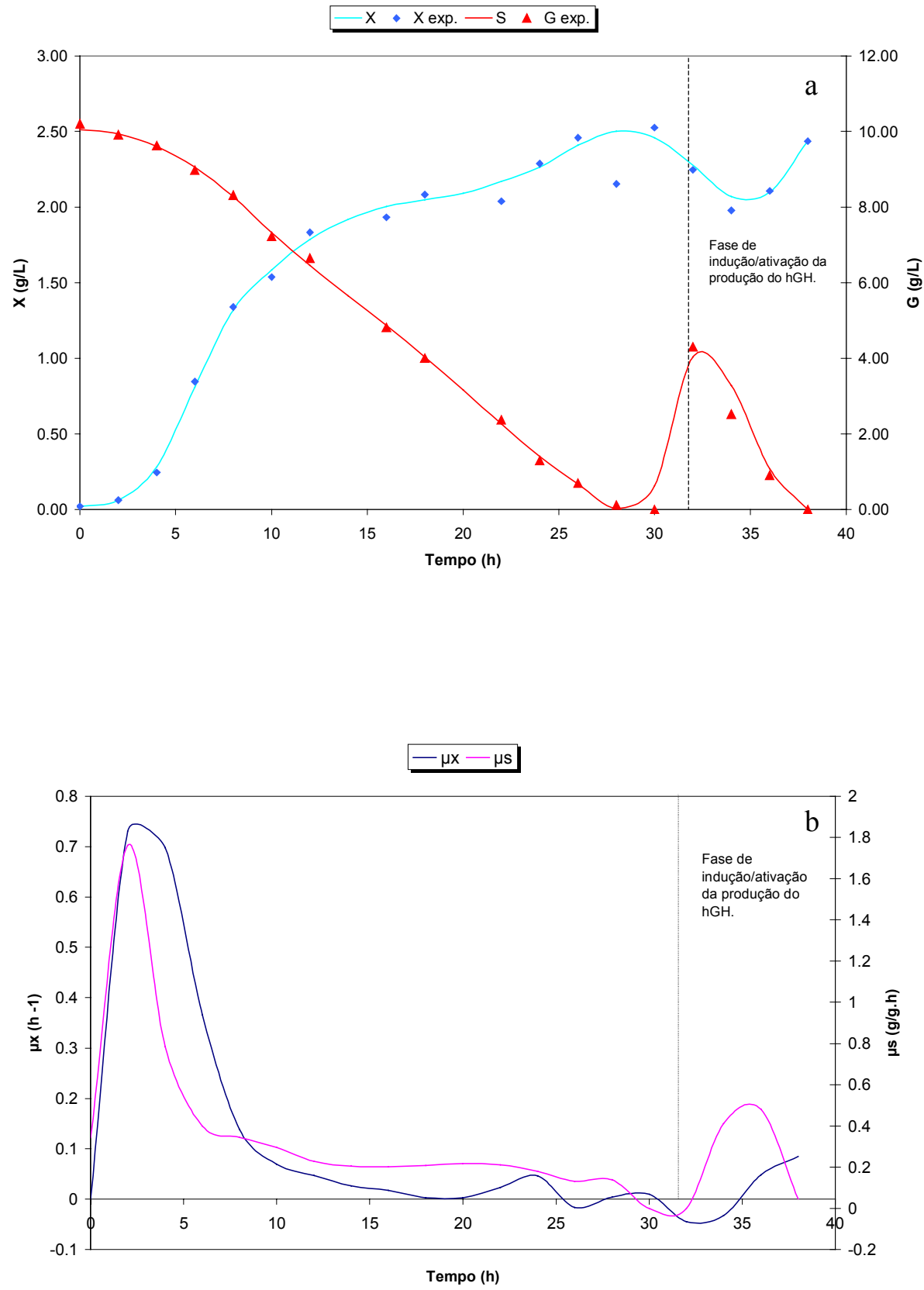

Figura 4.2.3 - Ensaio d3: (a) Perfis de concentração celular e de glicose, (b) velocidades específicas de crescimento e de consumo de glicose. 

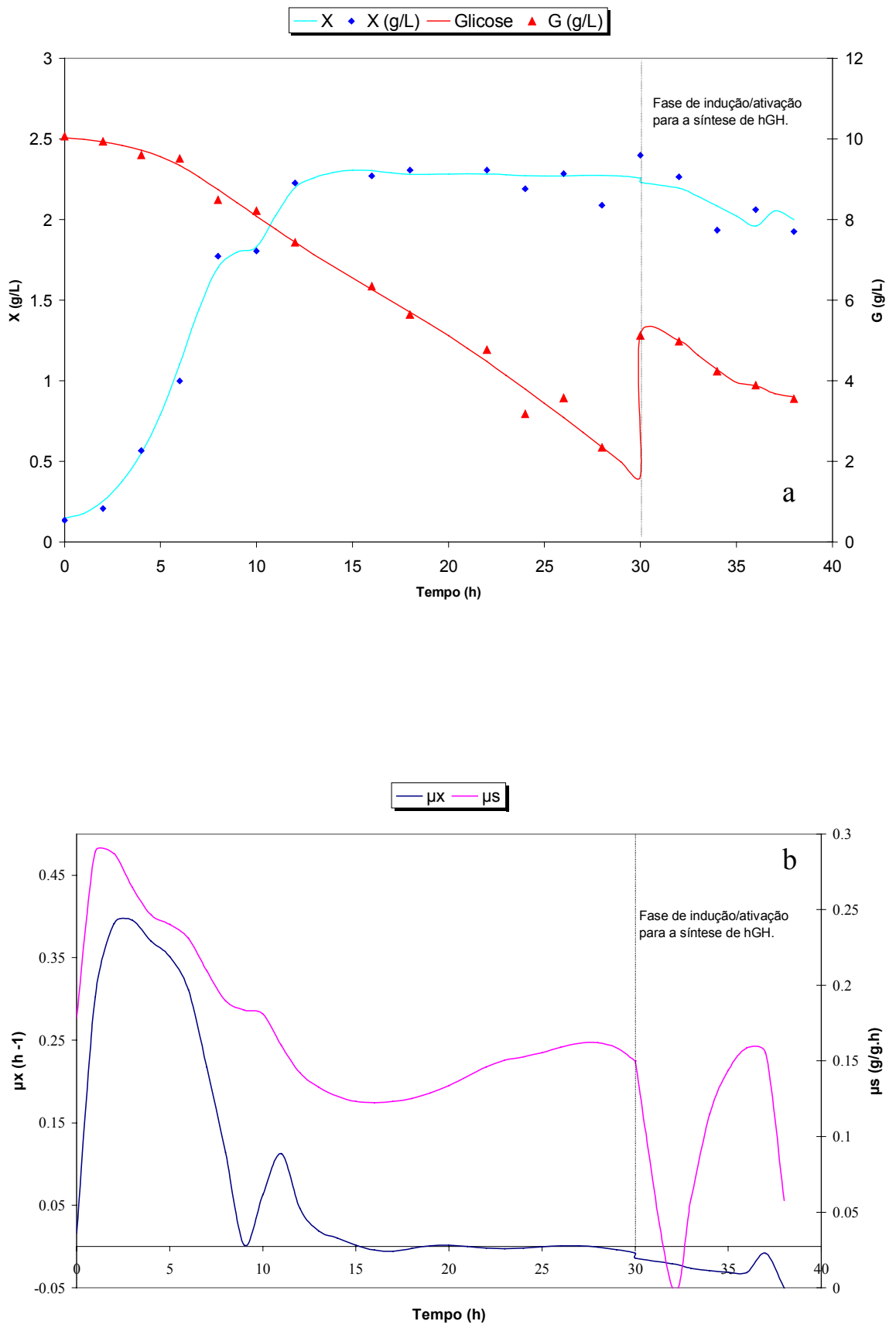

Figura 4.2.4 - Ensaio d4: (a) Perfis de concentração celular e de glicose, (b) velocidades específicas de crescimento e de consumo de glicose. 

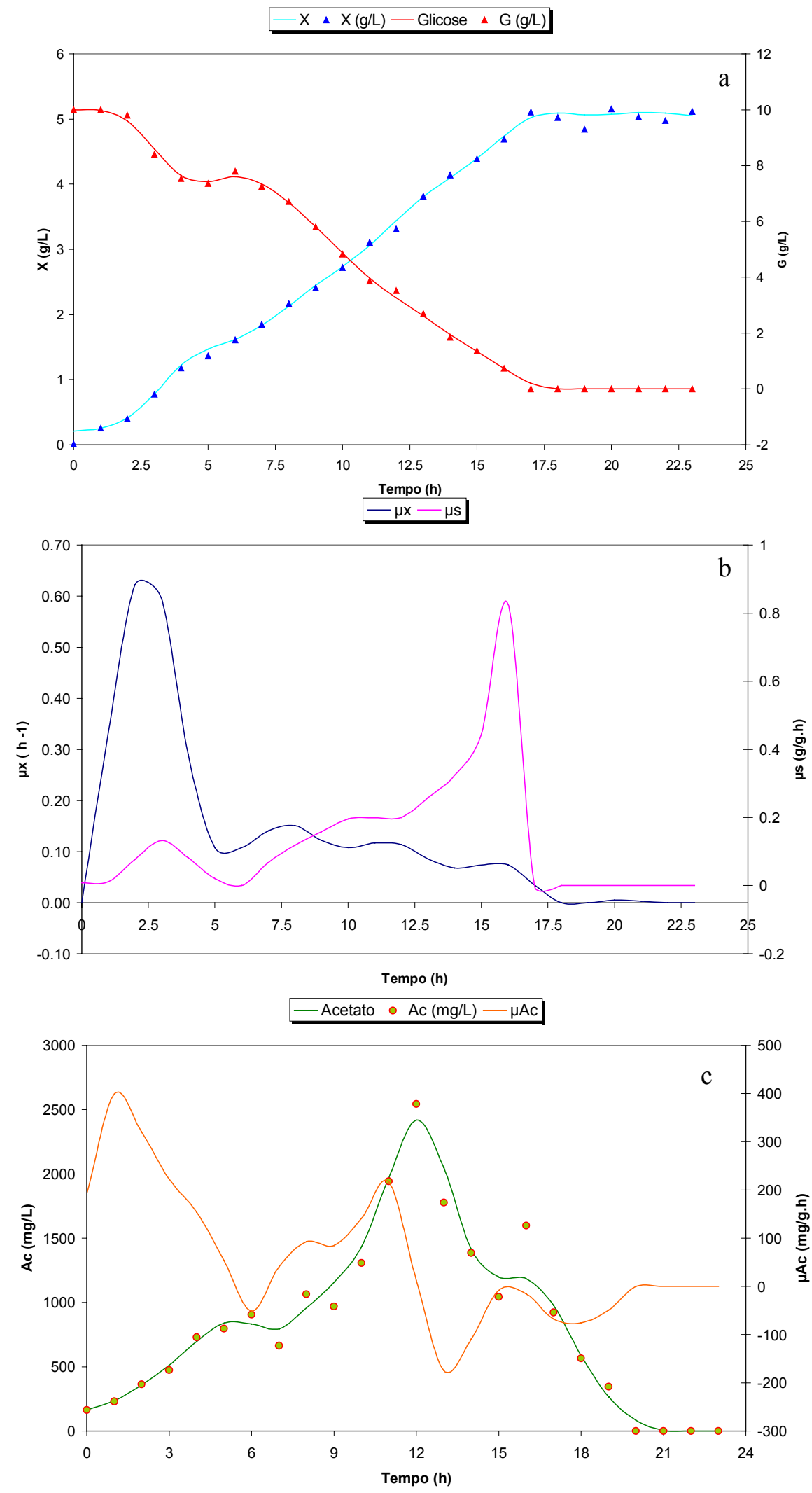

Figura 4.2.5: -Ensaio d5: (a) Concentrações celular e de glicose; (b) velocidades específicas de crescimento e de consumo de glicose; (c) Concentração e perfil da velocidade específica de formação de acetato. 
Para o ensaio d3, o microrganismo apresentou uma velocidade específica máxima de crescimento $\left(\mu_{\text {máx }}\right)$ de $0,73 \mathrm{~h}^{-1}$ e uma velocidade específica máxima de consumo de substrato $\left(\mu_{\text {smáx }}\right)$ de $1,76 \mathrm{~g} \mathrm{~g}^{-1} \mathrm{~h}^{-1}$ (Figura 4.2.3b), muito maior daquela alcançada nos ensaios anteriores ( $\mathrm{d} 1$ e d2), com um fator de conversão substrato a células de 0,24. Para o ensaio $\mathrm{d} 4$, os valores de $\mu_{\text {máx }}$ foram $0,48 \mathrm{~h}^{-1}$ e de $\mu_{\text {smáx }} 0,56 \mathrm{~g} \mathrm{~g}^{-1} \mathrm{~h}^{-1}$, com um fator de conversão de 0,25 (Figura 4.2.4b).

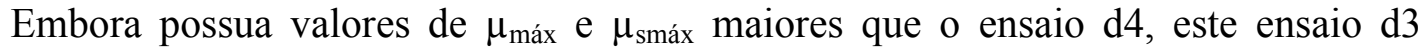
contemplou a mesma concentração final de células e exaustão completa da glicose, resultando um $\mathrm{Y}_{\mathrm{x} / \mathrm{s}}$ aproximadamente 3,9\% menor do que o d4, isto é, os ensaios d3 e d4 são praticamente iguais em relação à massa celular e fator de conversão, dados os erros experimentais. Em comparação ao ensaio d5, a exaustão completa de glicose no ensaio d3 ocorreu em 28 horas, um tempo de cultivo cerca de 1,65 vezes maior que para o ensaio d5. Portanto, parece que o microrganismo usado neste conjunto de ensaios (que são provenientes do segundo lote) possui alguma diferença importante para aquele microrganismo do início do trabalho, usado no ensaio d5.

O oxigênio dissolvido (na fase de crescimento do ensaio d3) decresceu até valores próximos de $89 \%$ da saturação alcançados no instante de 8 horas de ensaio, elevando-se logo em seguida e estabilizando em valores próximos a $95 \%$. No ensaio d4, a concentração de oxigênio dissolvido chegou a 88,9 \% da saturação nas 9 horas iniciais de cultivo, elevando-se para valores acima de $90 \%$ no restante do ensaio, conforme Figura 4.2.6. 


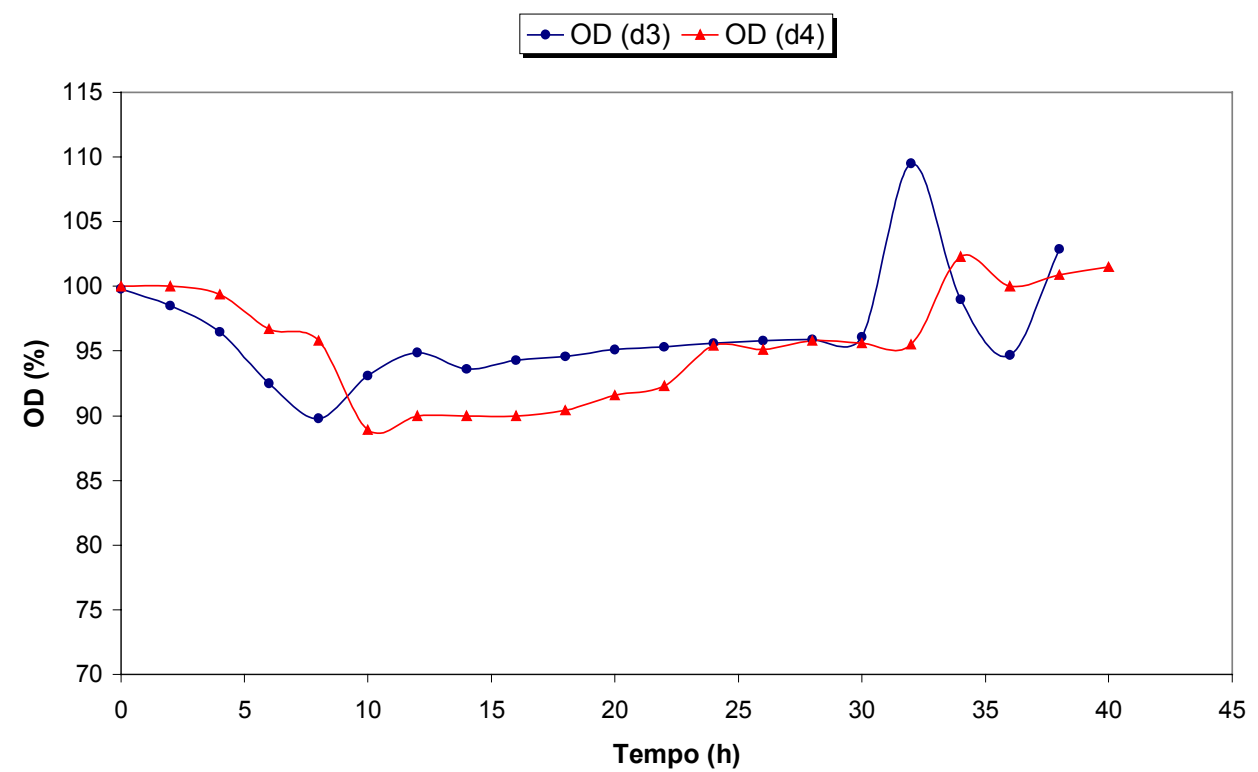

Figura 4.2.6: Variação das concentrações de oxigênio dissolvido para os ensaios d3 e d4 durante o tempo de cultivo.

Mesmo com uma suposta fase exponencial de 5 horas de duração, o crescimento celular do ensaio d4 estabilizou-se no patamar de $2,4 \mathrm{~g} \mathrm{~L}^{-1}$ de células (Figura 4.2.4), muito abaixo dos 5,1 $\mathrm{g} \mathrm{L}^{-1}$ alcançados no ensaio d5. Também foi realizada a avaliação da composição do gás de exaustão e o microrganismo apresenta uma velocidade específica máxima de respiração da ordem de $4,16 \mathrm{mmol} \mathrm{g}^{-1} \mathrm{~h}^{-1}$.

Fechando o objetivo deste conjunto de ensaios (alcançar valores maiores de concentrações celulares) realizou-se o ensaio denominado d6, que teve a mesma composição de meio basal de crescimento do ensaio d5 (item 3.1.4), mas suplementado com 1-prolina na concentração final de $350 \mathrm{mg} \mathrm{L}^{-1}$. Como resultados, alcançou-se uma concentração celular final de $2,95 \mathrm{~g} \mathrm{~L}^{-1}$ em 28 horas de cultivo, aproximadamente $42 \%$ menor que a concentração celular atingida no ensaio d5, e exaustão completa da glicose em 28 horas de cultivo (Figura 4.2.7). No ensaio d5, a glicose foi totalmente exaurida em 17 horas de cultivo. 

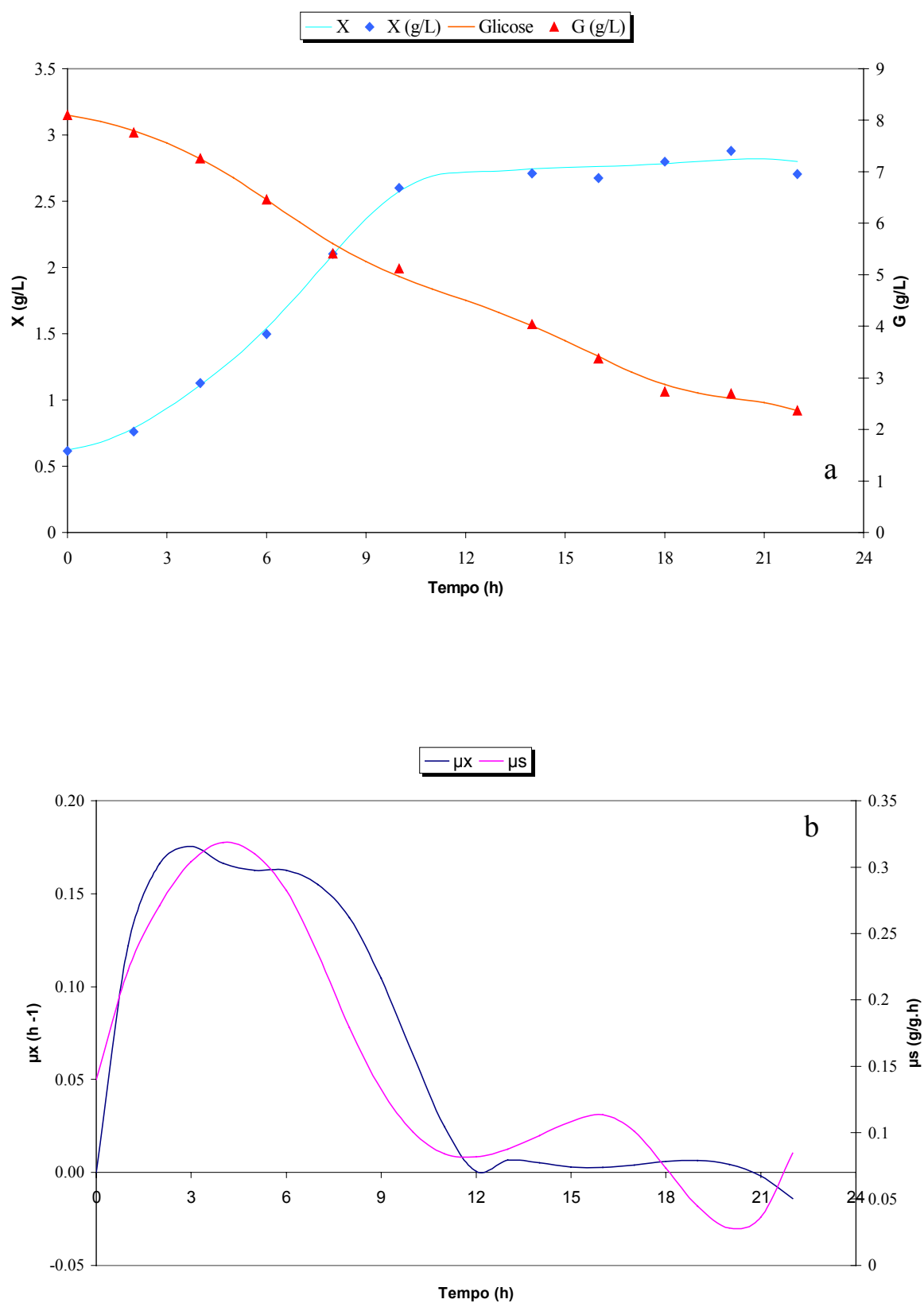

Figura 4.2.7 - Ensaio d6: (a) Concentrações celular e de glicose, (b) velocidades específicas de crescimento e de consumo de glicose. 
Entende-se, através deste conjunto de resultados, que os microrganismos utilizados no primeiro e segundo lote possuem diferenças importantes que fazem com que apresentem capacidades diferentes de crescimento (como pode ser constatado nos ensaios d5 e d6), dificultando a comparação entre os resultados obtidos com os dois lotes de células.

Um outro conjunto de ensaios foi elaborado com o mesmo objetivo de aumentar a massa celular, cujas características básicas são citadas abaixo:

- cultivos descontínuos;

- $\quad$ biorreator de 4L;

- temperatura de $30^{\circ} \mathrm{C}$;

- meio basal descrito no capítulo Materiais e Métodos, item 3.1.4.

Tabela 4.2.3: Descrição dos ensaios realizados no segundo conjunto.

\begin{tabular}{|c|c|}
\hline Ensaios & Descrição \\
\hline $\mathrm{d} 5^{(1)}$ & $\begin{array}{l}\text { Meio basal, biorreator de } 4 \mathrm{~L} \text {, cultivo descontínuo (repetição de ensaio } \\
\text { realizado pelo IPEN). }\end{array}$ \\
\hline d7 & $\begin{array}{l}\text { Ensaio semelhante ao d5, a menos da temperatura de } 37^{\circ} \mathrm{C} \text {. Avaliação de } \\
\text { expressão basal do hGH. }\end{array}$ \\
\hline $\mathrm{d} 8$ & $\begin{array}{l}\text { Aumento da concentração de extrato de levedura de } 2 \mathrm{~g} \mathrm{~L}^{-1} \text { para } 4 \mathrm{~g} \mathrm{~L}^{-1} \text { no } \\
\text { meio basal, sem a adição de 1-prolina. }\end{array}$ \\
\hline d9 & $\begin{array}{l}\text { Ensaio semelhante ao d8, suplementado com solução de 1-prolina (350 mg } \\
\left.\mathrm{L}^{-1}\right) .\end{array}$ \\
\hline $\mathrm{d} 10$ & $\begin{array}{l}\text { Ensaio semelhante ao d8, com meio de crescimento contendo }\left(\mathrm{NH}_{4}\right) \mathrm{HPO}_{4} \\
\text { em concentração } 3,5 \mathrm{~g} \mathrm{~L}^{-1} \text { (no meio basal já existem } 3,0 \mathrm{~g} \mathrm{~L}^{-1} \text { ). }\end{array}$ \\
\hline
\end{tabular}

Legenda: segue a mesma da tabela 4.1.2

${ }^{(1)}$ : é o mesmo ensaio d5 descrito anteriormente na Tabela 4.2.1. 
Tabela 4.2.4 : Parâmetros dos ensaios em biorreator realizados no segundo conjunto.

\begin{tabular}{|c|c|c|c|c|c|c|c|c|c|}
\hline Ensaios & $\begin{array}{c}\mathrm{X}_{0} \\
(\mathrm{~g} / \mathrm{L})\end{array}$ & $\begin{array}{c}\mathrm{X}_{\mathrm{f}} \\
(\mathrm{g} / \mathrm{L})\end{array}$ & $\begin{array}{c}\mathrm{G}_{0} \\
(\mathrm{~g} / \mathrm{L})\end{array}$ & $\begin{array}{c}\mathrm{G}_{\mathrm{f}} \\
(\mathrm{g} / \mathrm{L})\end{array}$ & $\begin{array}{c}\mathrm{t}_{\mathrm{f}} \\
(\mathrm{h})\end{array}$ & $\begin{array}{c}\mathrm{T}_{\mathrm{t}} \\
(\mathrm{h})\end{array}$ & $\begin{array}{c}\mu_{\text {máx }} \\
\left(\mathrm{h}^{-1}\right)\end{array}$ & $\begin{array}{c}\mathrm{Y}_{\mathrm{x} / \mathrm{s}} \\
(\mathrm{g} / \mathrm{g})\end{array}$ & $\begin{array}{c}\mathrm{P}_{\mathrm{x}} \\
(\mathrm{g} / \mathrm{Lh})\end{array}$ \\
\hline $\mathrm{d} 5$ & 0,02 & 5,10 & 10,50 & 0 & 17 & 23 & 0,53 & 0,48 & 0,300 \\
\hline $\mathrm{d} 7$ & 0,18 & 3,20 & 10,3 & 0 & 16 & 21 & 0,4 & 0,29 & 0,226 \\
\hline $\mathrm{d} 8$ & 0,52 & 5,25 & 12,7 & 0 & 19 & 20 & 0,37 & 0,37 & 0,286 \\
\hline $\mathrm{d} 9$ & 0,31 & 5,90 & 10,4 & 0 & 11 & 17 & 0,77 & 0,54 & 0,531 \\
\hline $\mathrm{d} 10$ & 0,57 & 3,40 & 9,2 & 2,2 & $\mathrm{n} / \mathrm{z}$ & 21 & 0,42 & 0,40 & 0,170 \\
\hline
\end{tabular}

Legenda: segue a mesma da Tabela 4.2.2.

No ensaio d7 (único realizado a $37^{\circ} \mathrm{C}$ ) - contendo a mesma composição de meio de crescimento do ensaio d5 - a concentração celular alcançada foi de $3,4 \mathrm{~g} \mathrm{~L}^{-1}$ com 15 horas de cultivo, menor do que a atingida no ensaio d5 (Figura 4.2.8a). Embora se apresente aqui também, nas 5 primeiras horas, uma possível fase exponencial com $\mu_{\text {máx }}$ de $0,4 \mathrm{~h}^{-1}$, a expressão basal do hGH que ocorreu neste ensaio poderia explicar uma massa celular menor alcançada em relação ao d5.

Em um ensaio realizado na mesma temperatura $\left(37^{\circ} \mathrm{C}\right)$ e $\mathrm{pH} 7$ com a cepa $E$. coli BL21 (DE3) plysS, o valor de $\mu_{\text {máx }}$ foi $0,51 \mathrm{~h}^{-1}$, maior daquele atingido pela cepa $\mathrm{RR} 1\left(\mathrm{X}_{\mathrm{f}}=\right.$ 2,5 g.L $\mathrm{L}^{-1}, \mathrm{Y}_{\mathrm{x} / \mathrm{s}}=0,35 \mathrm{~g} \cdot \mathrm{g}^{-1}$ e $\mathrm{t}_{\mathrm{f}}=7 \mathrm{~h}$; SUAREZ, 1997). A concentração de acetato atingiu valores mais baixos para a cepa RR1 (chegando a 1330,4 mg.L ${ }^{-1}$, Figura 4.2.8c) se compararmos com os valores atingidos pela cepa BL21 (DE3) pLysS (valores da ordem de 4359,6 $\mathrm{mg} \mathrm{L}^{-1}$ ). Ressalta-se aqui que estes ensaios (d5 e d7) não foram suplementados com 

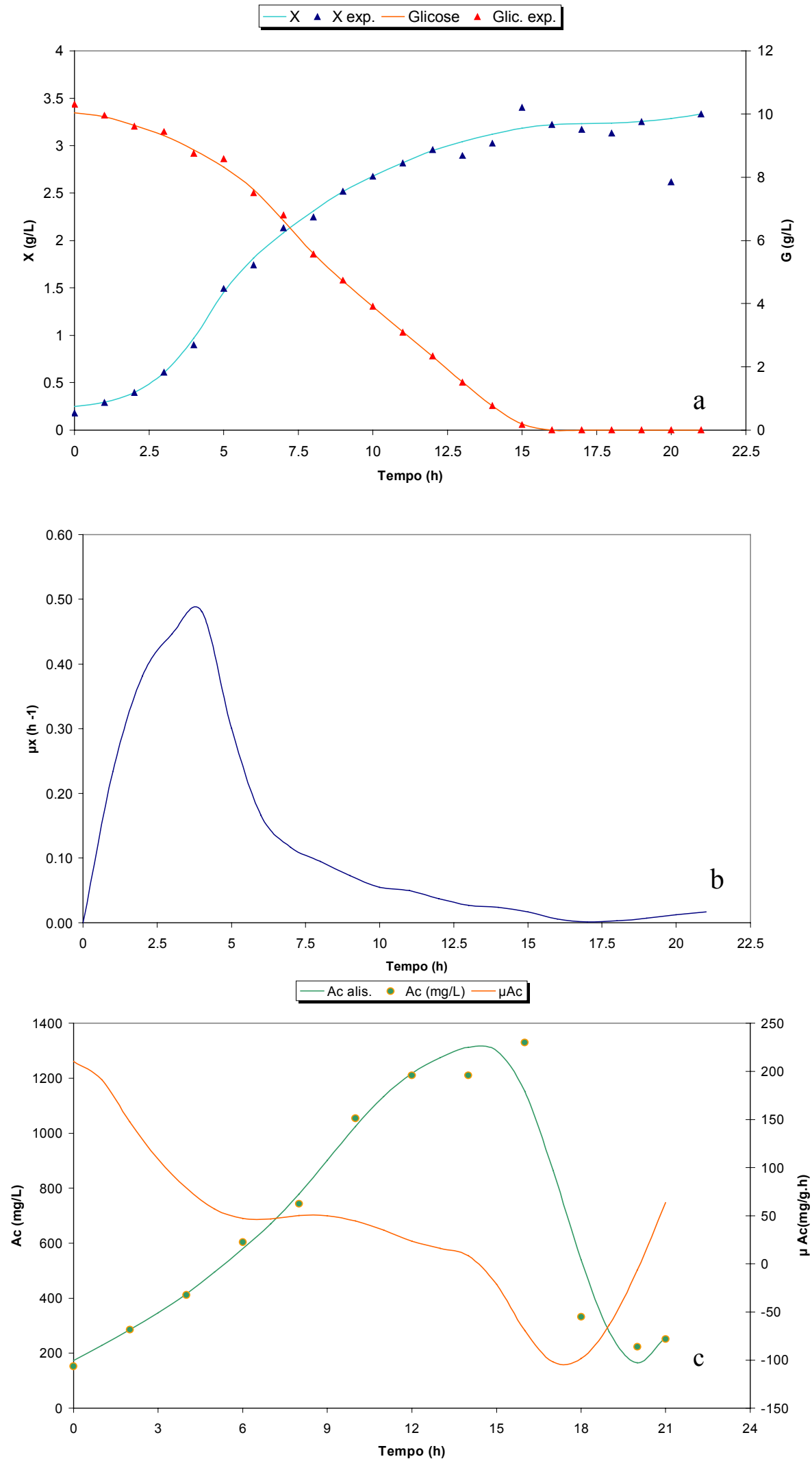

Figura 4.2.8 -Ensaio d7: (a) Concentrações celular e de glicose; (b) velocidades específicas de crescimento e de consumo de glicose; (c) Concentração e perfil de velocidade específica de formação de acetato. 
aminoácidos, porém aumentou-se a concentração de extrato de levedura de $1 \mathrm{~g} \mathrm{~L}^{-1}$ para $2 \mathrm{~g}$ $\mathrm{L}^{-1}$ no meio de crescimento da cepa RR1, em relação ao meio da BL21.

Com o objetivo de estudar o aumento da massa celular, foi realizado o ensaio d8 - semelhante ao d5, à exceção da concentração de extrato de levedura duplicada $\left(4 \mathrm{~g} \mathrm{~L}^{-1}\right)$-. Este ensaio foi elaborado como alternativa aos ensaios onde empregou-se aminoácidos como fonte suplementar de carbono devido a possível existência de outras carências que não estejam ligadas à auxotrofia do microrganismo.

Em comparação ao ensaio d5, este ensaio d8 apresentou um decréscimo no fator de conversão substrato a células de $17 \%$ - conforme mostrado na Tabela 4.2 .4 - e valores de $\mu_{\text {máx }} 15 \%$ menor, mesmo com concentrações celulares finais praticamente idênticas (Figura 4.2.9). Como resultado, no ensaio $\mathrm{d} 8$ alcançou-se uma concentração de acetato $85 \%$ menor que o d5, com uma velocidade específica máxima de formação de acetato de $83 \mathrm{mg}_{\mathrm{Ac}} \mathrm{g}^{-1} \mathrm{~h}$ 1. Como se sabe que um aumento da concentração de extrato de levedura favorece um melhor crescimento celular, nota-se que este microrganismo possui alterações metabólicas que dificultam as comparações entre os resultados obtidos.

Nos ensaios $\mathrm{d} 5$ e d8 praticamente não houve a adição de $\mathrm{NH}_{4} \mathrm{OH}$ para estabilizar o pH de cultivo e a síntese de subprodutos (ácido acético principalmente) foi baixa, sendo mantido estável o pH do meio por ação do tampão-fosfato existente.

Segundo MOAT; FOSTER (1995), o microrganismo usa o aminoácido 1-prolina como fonte alternativa de nitrogênio na ausência de $\mathrm{NH}_{4} \mathrm{OH}$ para produzir glutamato e seus derivados, e baseados nos resultados apresentados em incubador rotativo, dois outros ensaios foram realizados: d9, com adição de 1-prolina na concentração de $350 \mathrm{mg} \mathrm{L}^{-1}$ 

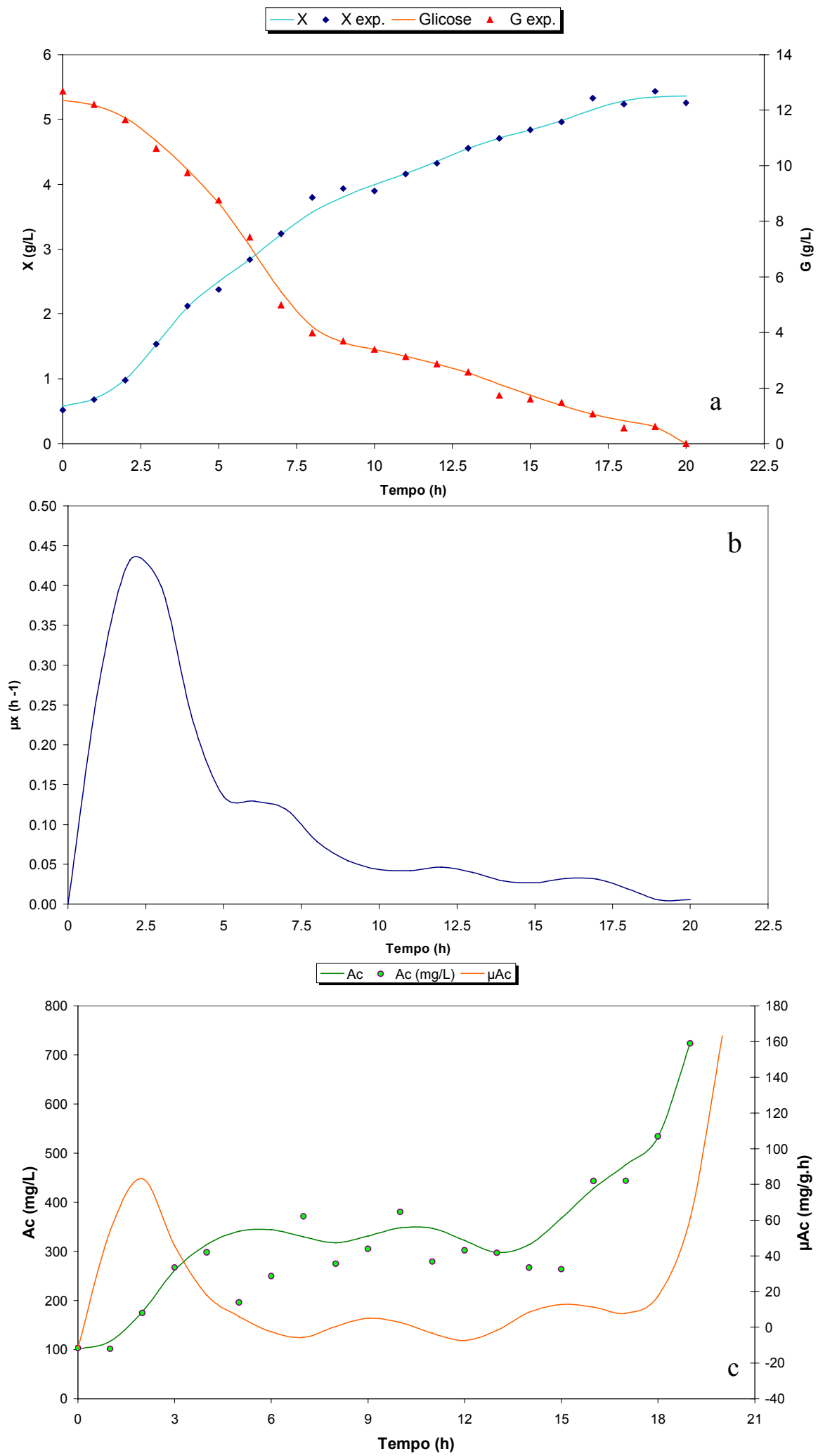

Figura 4.2.9 - Ensaio d8: (a) Concentração celular e de glicose; (b) Velocidade específica de crescimento; (c) Concentração e perfil da velocidade específica de formação de acetato. 
(Figura 4.2.10) e d10, com 3,5 $\mathrm{g} \mathrm{L}^{-1}$ de $\left(\mathrm{NH}_{4}\right) \mathrm{HPO}_{4}$ (Figura 4.2.11) no meio basal (item 3.1.4).

Comparando-se estes dois ensaios - d9 e d10 - , o ensaio d9 foi o que apresentou melhor crescimento celular. Com um $\mu_{\text {máx }}$ 54,5 \% maior que o ensaio d10, alcançou-se uma concentração celular final 57,6 \% maior, mesmo com um fator de conversão substrato a células 26,0 \% maior (Tabela 4.2.4). Contudo, o ensaio d9 apresentou uma concentração máxima de acetato de $360 \mathrm{mg} \mathrm{L}^{-1}$, enquanto que no ensaio d10 essa concentração foi de acetato foi de $323 \mathrm{mg} \mathrm{L}^{-1}$, concentrações praticamente iguais dados os erros experimentais.

A fonte de carbono foi esgotada em 12 horas de cultivo no ensaio d9, mas não foi completamente consumida no ensaio d10, mesmo com os dois exibindo as mesmas velocidades específicas de consumo de glicose. Este fato pode estar ligado à presença da 1prolina no meio, que durante o seu consumo pelo microrganismo, aumenta a atividade da enzima $\alpha$-cetoglutarato desidrogenase, tendo como conseqüência um aumento da taxa de crescimento celular.

Por uma dificuldade técnica, no ensaio d9 não foi feita a análise das concentrações de $\mathrm{O}_{2}$ e $\mathrm{CO}_{2}$ do gás de exaustão, ao contrário do ensaio d10, faltando os valores de velocidade específica de respiração do microrganismo $\left(\mathrm{Q}_{\mathrm{O} 2}\right)$. Contudo, os valores de oxigênio dissolvido (OD) - Figura 4.2.12 - mostraram que no ensaio d9 o consumo de $\mathrm{O}_{2}$ foi maior do que no ensaio d10, pois atingiu-se valores de $55 \%$ da saturação nos instantes iniciais do cultivo, verificando-se uma estabilização em $60 \%$ nos instantes subseqüentes, decaindo novamente nos instantes finais. 

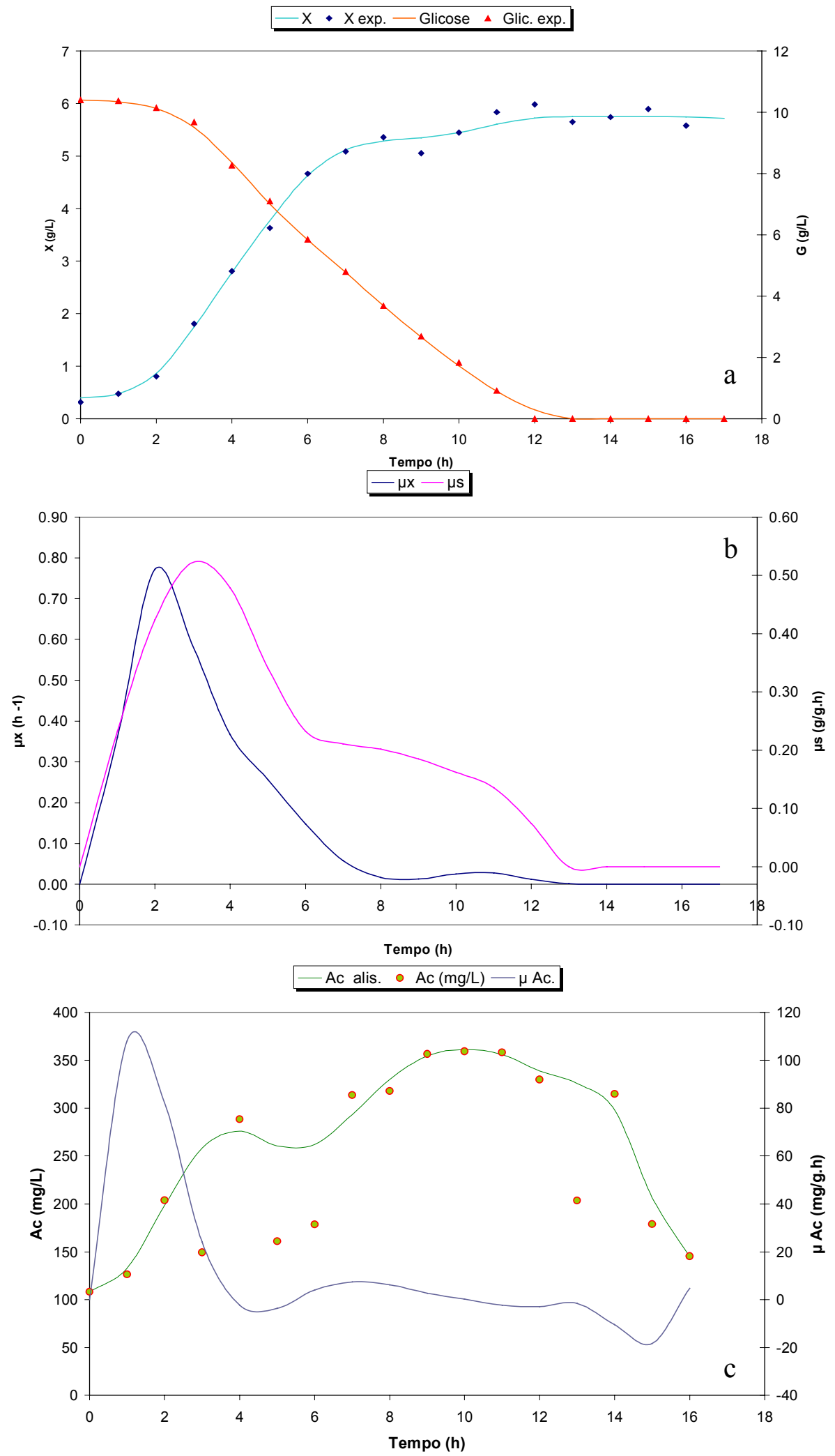

Figura 4.2.10 - Ensaio d9: (a) Concentração celular e de glicose; (b) velocidades específicas de crescimento e de consumo de substrato; (c) concentração e perfil da velocidade específica de formação de acetato. 

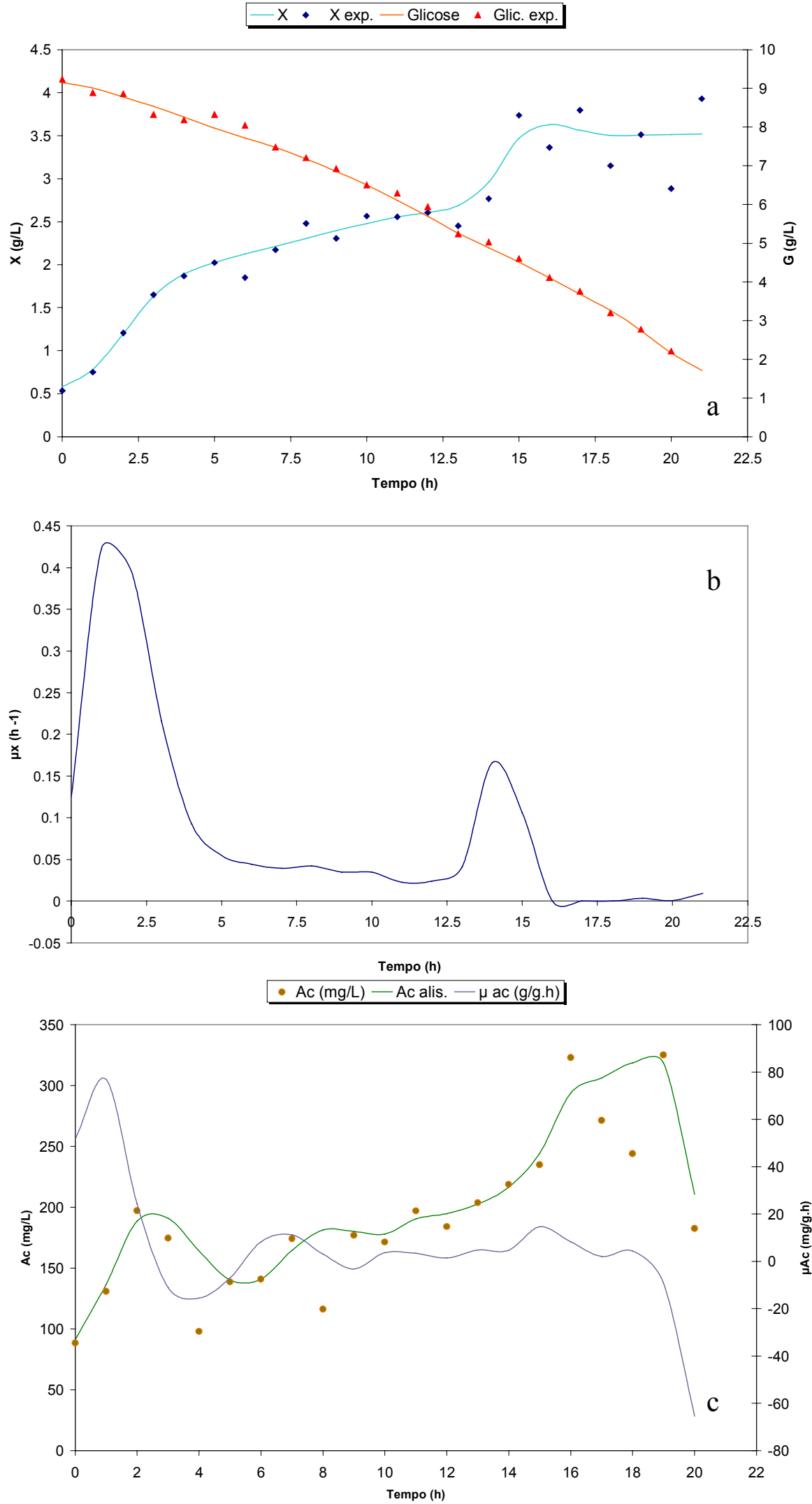

Figura 4.2.11- Ensaio d10: (a) Concentração celular e de glicose; (b) velocidade específica de crescimento; (c) concentração e perfil da velocidade específica de formação de acetato. 


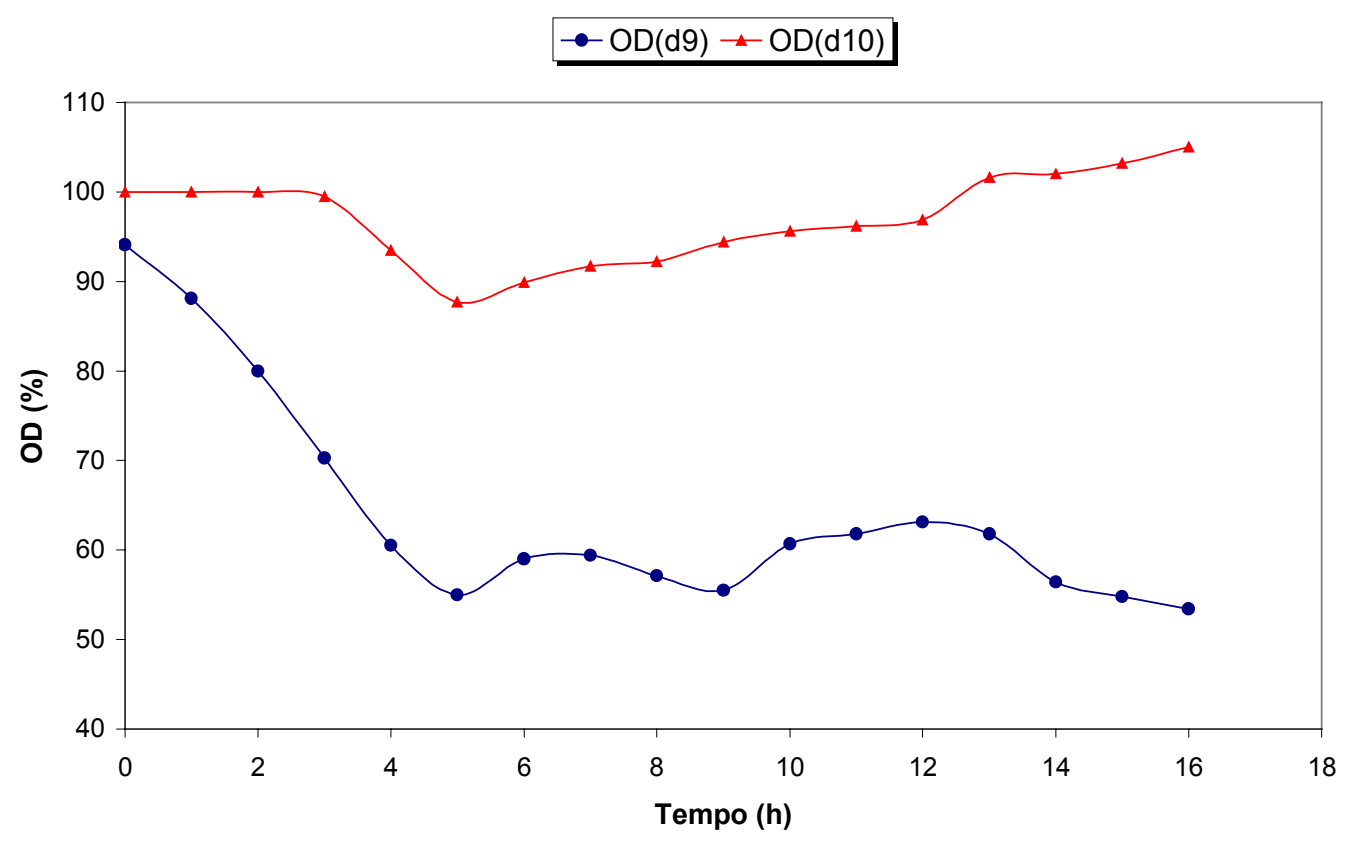

Figura 4.2.12: Variação das concentrações de oxigênio dissolvido para os ensaios d9 e d10 durante o tempo de cultivo.

\subsection{Ensaios descontínuos alimentados}

Em vista destes resultados alcançados, realizou-se o ensaio da-1 (Figuras 4.2.13 e 4.2.14), um cultivo descontínuo alimentado com pulsos de glicose e solução de bactotriptona, extrato de levedura e $\left(\mathrm{NH}_{4}\right) \mathrm{HPO}_{4}$, cuja relação entre as concentrações encontra-se no item 3.2.5 do capítulo de Materiais e Métodos. A forma escolhida para se alimentar o biorreator com nutrientes (glicose) foi a estratégia de pulsos por ser a forma mais simples de alimentação ao meio de cultivo. Com 2 pulsos, o ensaio atingiu uma concentração celular final de $8,0 \mathrm{~g} \mathrm{~L}^{-1}$ em 28 horas de cultivo (Tabelas 4.3.1 e 4.3.2). 
Tabela 4.3.1: Características dos ensaios descontínuos-alimentados

\begin{tabular}{|c|c|}
\hline Ensaios & Descrição \\
\hline da-1 & $\begin{array}{l}\text { Meio basal do ensaio d8. Cultivo descontínuo alimentado com pulsos de } \\
\text { solução de alimentação: glicose }+\mathrm{EL}+\text { bactotriptona }+\left(\mathrm{NH}_{4}\right) \mathrm{HPO}_{4} \text {. }\end{array}$ \\
\hline da-2 & $\begin{array}{l}\text { Mesmo meio do ensaio da-1, mas com alimentação de glicose e l-prolina em } \\
\text { pulsos. Elevação da temperatura de } 30^{\circ} \text { para } 42^{\circ} \mathrm{C} \text {. Ativação da síntese de } \\
\text { hGH. }\end{array}$ \\
\hline da-3 & $\begin{array}{l}\text { Mesmo meio do ensaio d5, suplementado com l-prolina. Cultivo descontínuo } \\
\text { alimentado com velocidade exponencial. Solução de alimentação: glicose }+ \\
\text { extrato de levedura + bactotriptona }+ \text { l-prolina. Elevação da temperatura de } \\
30^{\circ} \text { para } 42^{\circ} \mathrm{C} \text {. Ativação da síntese de hGH. }\end{array}$ \\
\hline
\end{tabular}

Tabela 4.3.2: Parâmetros dos ensaios realizados na forma descontínua-alimentada.

\begin{tabular}{|c|c|c|c|c|c|c|c|c|c|c|}
\hline Ensaios & $\begin{array}{c}\mathrm{X}_{0} \\
(\mathrm{~g} / \mathrm{L})\end{array}$ & $\begin{array}{c}X_{f} \\
(g / L)\end{array}$ & $\begin{array}{l}\mathrm{G}_{0}^{(2)} \\
(\mathrm{g} / \mathrm{L})\end{array}$ & $\begin{array}{c}G_{f} \\
(g / L)\end{array}$ & $\begin{array}{l}t_{f}^{(3)} \\
\text { (h) }\end{array}$ & $\begin{array}{l}T_{t} \\
\text { (h) }\end{array}$ & $\begin{array}{c}\mu_{\text {máx }} \\
\left(h^{-1}\right)\end{array}$ & $\begin{array}{c}\mu_{\text {smáx }} \\
(\mathrm{g} / \mathrm{g} \cdot \mathrm{h})\end{array}$ & $\begin{array}{c}Y_{x / s}^{(4)} \\
(g / g)\end{array}$ & $\begin{array}{c}P_{x} \\
(g / L h)\end{array}$ \\
\hline \multirow{3}{*}{ da-1 } & \multirow{3}{*}{0,03} & \multirow{3}{*}{8,0} & 10 & \multirow{3}{*}{0} & 12 & \multirow{3}{*}{29} & \multirow{3}{*}{0,75} & \multirow{3}{*}{2,54} & 0,43 & \multirow{3}{*}{0,53} \\
\hline & & & 8,0 & & 6 & & & & 0,53 & \\
\hline & & & 9,8 & & 11 & & & & 0,009 & \\
\hline \multirow{2}{*}{ da-2 } & \multirow{2}{*}{0,18} & \multirow{2}{*}{3,2} & \multirow{2}{*}{10,0} & \multirow{2}{*}{3,2} & 14 & \multirow{2}{*}{26} & \multirow{2}{*}{0,61} & \multirow{2}{*}{0,31} & 0,31 & \multirow{2}{*}{0,32} \\
\hline & & & & & 12 & & & & 0007 & \\
\hline \multirow{3}{*}{ da- $3^{(1)}$} & \multirow{3}{*}{0,78} & \multirow{3}{*}{9,2} & \multirow{3}{*}{5,0} & \multirow{3}{*}{0} & 18 & \multirow{3}{*}{36} & \multirow{3}{*}{0,36} & \multirow{3}{*}{0,11} & 0,54 & \multirow{3}{*}{0,21} \\
\hline & & & & & & & & & & \\
\hline & & & & & & & & & 0,36 & \\
\hline
\end{tabular}

Legenda: segue a mesma da tabela 4.2.2

${ }^{(1)}$ : este ensaio descontínuo alimentado foi feito usando o segundo lote de células $E$. coli RR1 (2),(3),(4): valores das variáveis nas fases descontínua e descontínua-alimentada.

A partir de 16 horas de cultivo, houve a necessidade de enriquecer o ar de entrada com $\mathrm{O}_{2}$ puro para suprir o consumo de oxigênio do microrganismo e manter o oxigênio dissolvido (OD) acima dos $30 \%$ da saturação. O OD - Figura 4.2.15 -, que alcançou valores de $28 \%$ da saturação no instante anterior às 16 horas, estabilizou-se acima de $70 \%$ 

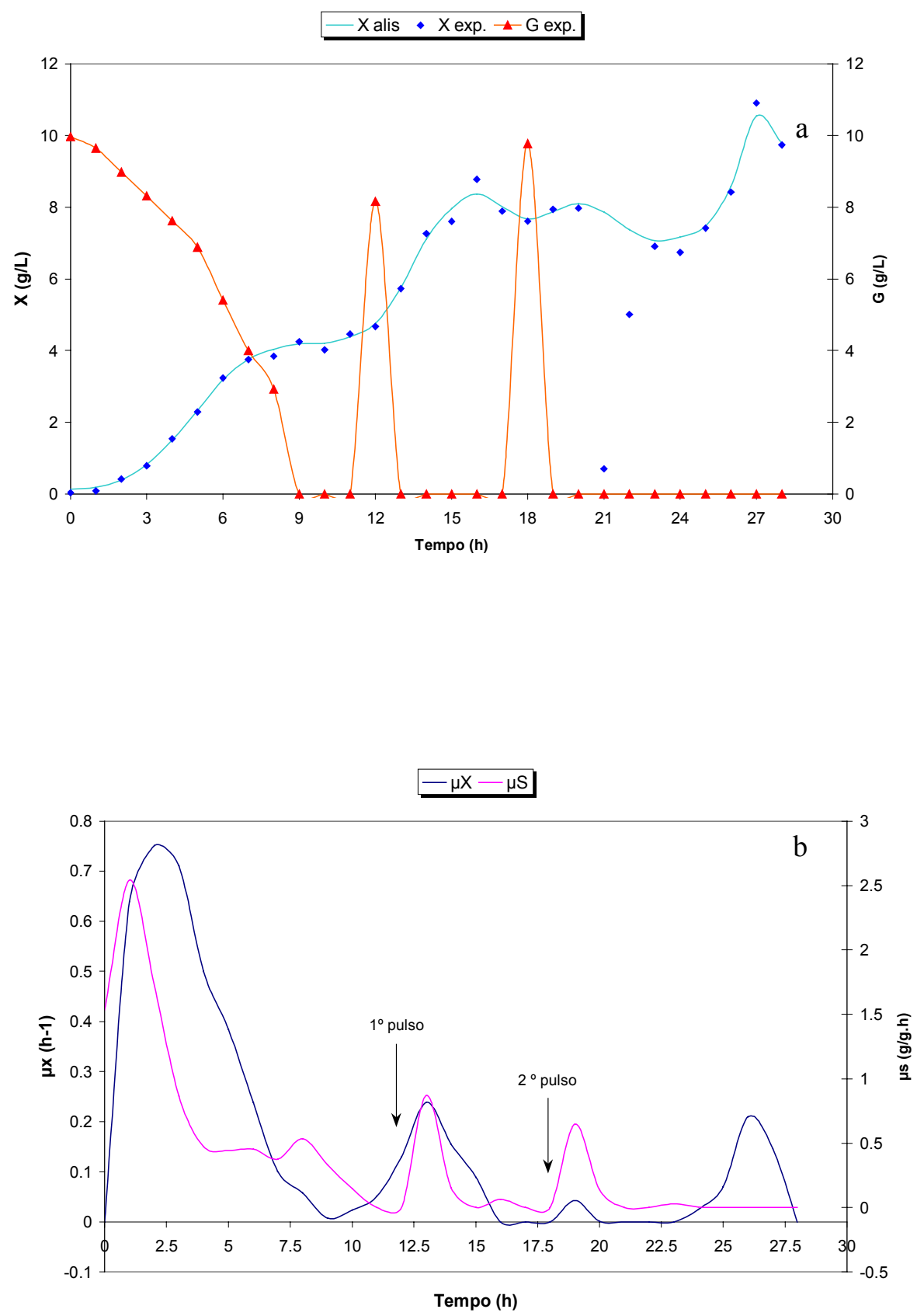

Figura 4.2.13 - Ensaio da-1 : (a) Concentração celular e de glicose mostrando o instante de cada pulso; (b) as velocidades específicas de crescimento e de consumo de glicose . 

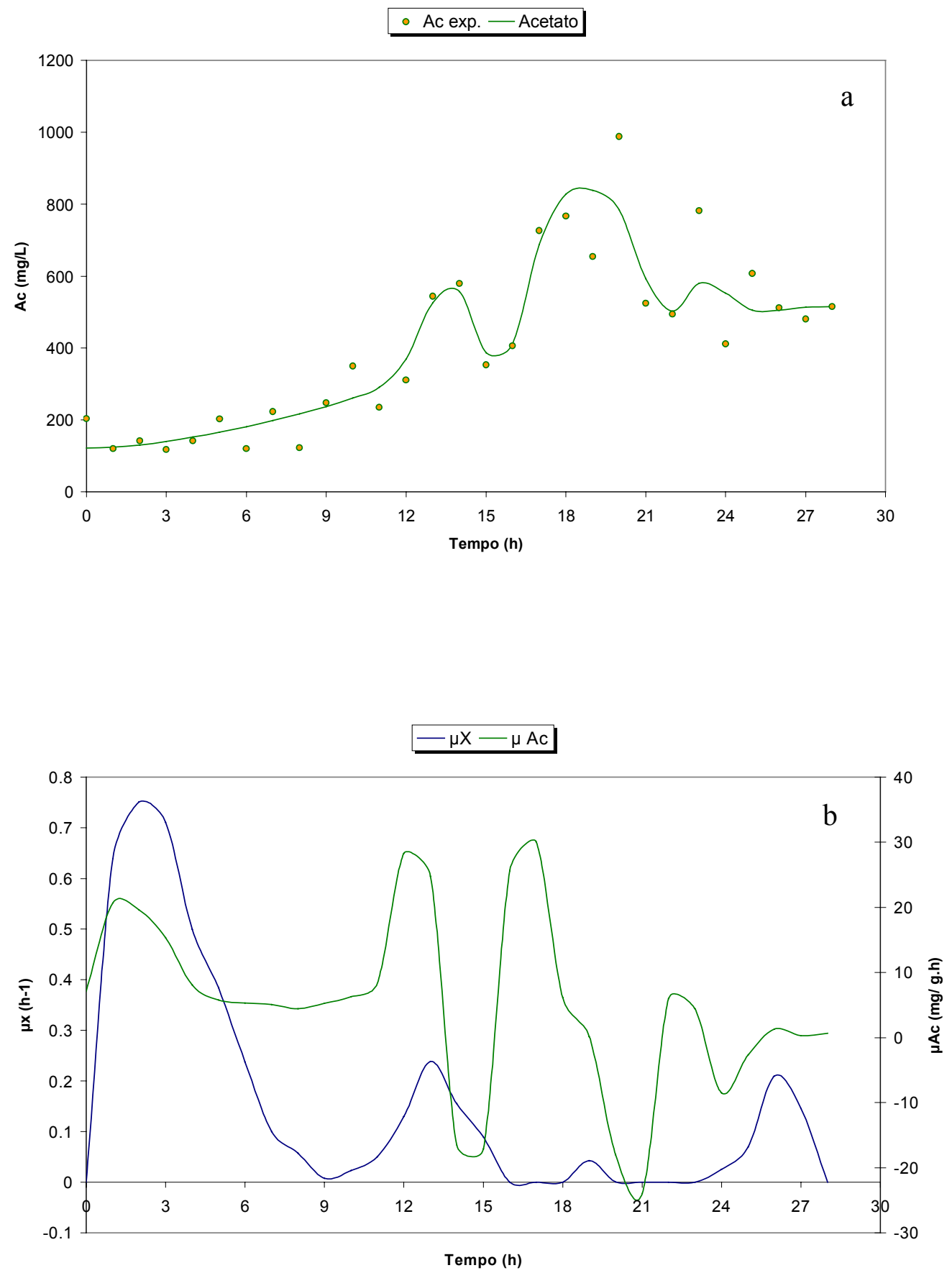

Figura 4.2.14 - Ensaio da-1 : (a) concentração de acetato produzido pelo microrganismo; (b) velocidades específicas de crescimento e síntese de acetato. 
da saturação logo após a alimentação com $\mathrm{O}_{2}$ puro, permanecendo neste valor até o final do cultivo, mostrando que não houve limitação por $\mathrm{O}_{2}$ no crescimento celular.

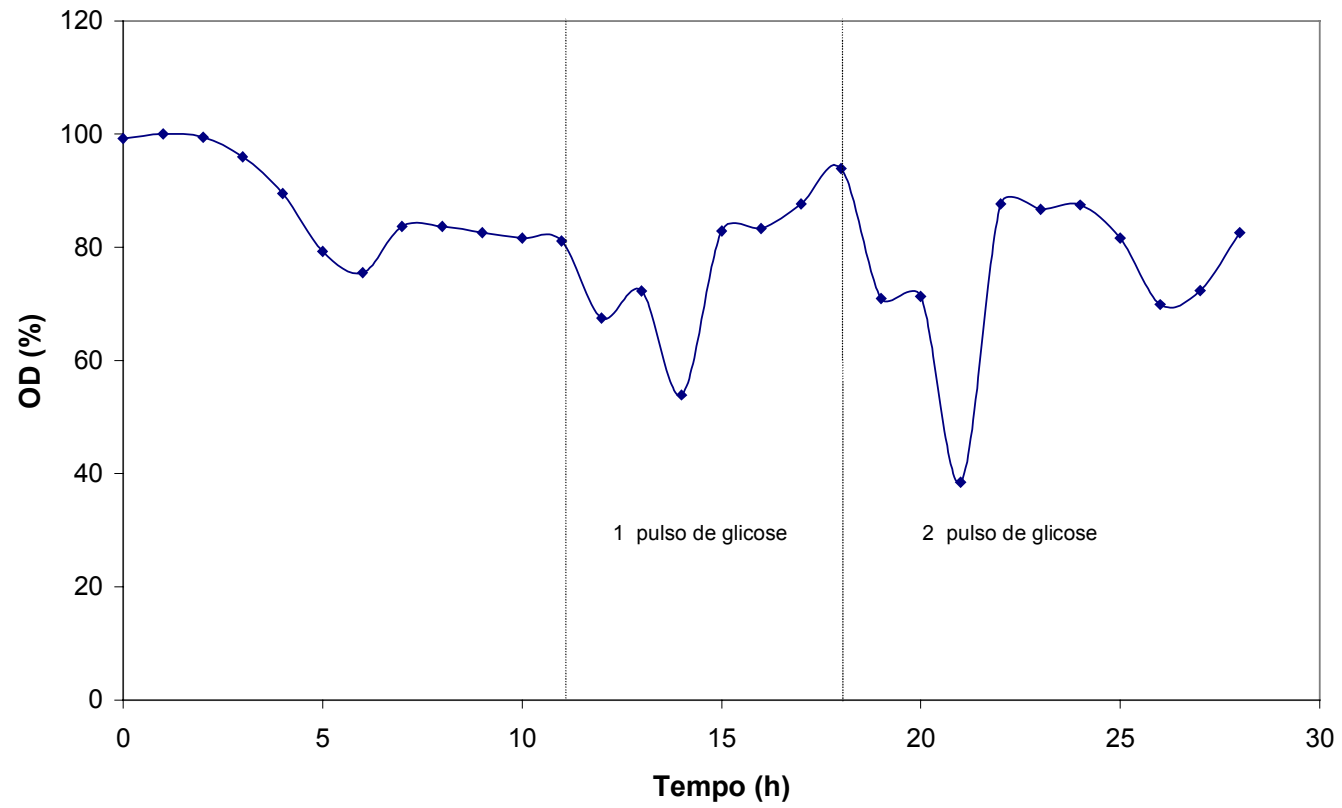

Figura 4.2.15: Perfil da variação da concentração de oxigênio dissolvido para o ensaio da-1.

Após 20 horas de cultivo, devido a dificuldade de se filtrar a suspensão de células da amostra, optou-se pelo uso de centrifugação para se medir a biomassa seca, conforme item (3.7.1). Em cada pulso, obteve-se um fator de conversão substrato a células, mostrado na Tabela 4.3.2.

O ensaio da-2 foi um cultivo descontínuo alimentado em forma de pulsos com soluções de glicose e 1-prolina (item 3.2.5), semelhante ao ensaio da-1, mas com ausência de soluções de extrato de levedura, bactotriptona e $\left(\mathrm{NH}_{4}\right)_{2} \mathrm{HPO}_{4}$, na alimentação. Ao contrário do ensaio da-1, que utilizou $\mathrm{NaOH} 2 \mathrm{~N}$ para estabilização do $\mathrm{pH}$, utilizou-se $\mathrm{NH}_{4} \mathrm{OH} 25 \%$ para a estabilização do $\mathrm{pH}$ do meio de cultivo e fonte auxiliar de $\mathrm{N}_{2}$ ao 
microrganismo. A razão de não se empregar os reagentes complexos e o sal de amônio neste ensaio foi baseada na existência de uma possível inibição do crescimento microbiano causada pelo aumento da concentração do sal de amônio no biorreator - presente no intervalo entre o segundo pulso e o final do ensaio da-1 - conforme Figura 4.2.13a.

Observando-se a Figura 4.2.16a, verifica-se que o crescimento celular praticamente não existe após o primeiro pulso de glicose e 1-prolina, talvez pelo fato de que o excesso de glicose adicionada de uma só vez possa ter reprimido algum grupo protêico ou algum grupo genético (repressão catabólica) após o pulso, ou pelo fato de que uma quantidade de amônia adicionada ao biorreator para correção do pH, atingindo uma concentração de $500 \mathrm{mg} \mathrm{L} \mathrm{L}^{-1}$ (acima da concentração crítica de $7 \mathrm{mg} \mathrm{L}^{-1}$ ), fato ocorrido também entre 16 e 17 horas devido à um problema no controle de $\mathrm{pH}$.

Analisando os resultados do ensaio da-2 e comparando-os com os do da-1 (Tabela 4.3.2), nota-se que a suplementação de extrato de levedura e bactotriptona se faz necessário para o crescimento celular, como verificou AFFONSO* (2000). Nesta fase, constatou-se uma formação acentuada de acetato (bem como de outros sub-produtos de fermentação) e uma drástica diminuição nos valores de Qo2 (Tabela 4.5.1).

$\mathrm{O}$ acetato formado na fase descontínua do ensaio da-2 possui uma velocidade específica de síntese de acetato $\left(\mu_{\mathrm{Ac}}\right)$ praticamente constante de 3 até 10 horas $(10,0 \mathrm{mgAc}$ $\mathrm{g}^{-1} \mathrm{~h}^{-1}$ ), que diminui a partir das 11 horas. Com 15 horas de cultivo, já na fase do pulso, novamente a concentração de acetato aumenta rapidamente (aumentando $\mu_{\mathrm{Ac}}$ ) e, na fase de ativação/indução, diminui até as 21 horas, elevando-se rapidamente em seguida. Juntamente com os dados de velocidade de respiração pertencentes a essa fase de ativação, que foram muito próximos de zero $\left(\mathrm{Q}_{\mathrm{O} 2}=0,02 \mathrm{mmol} \mathrm{g}^{-1} \mathrm{~h}^{-1}\right)$, conclui-se que o 

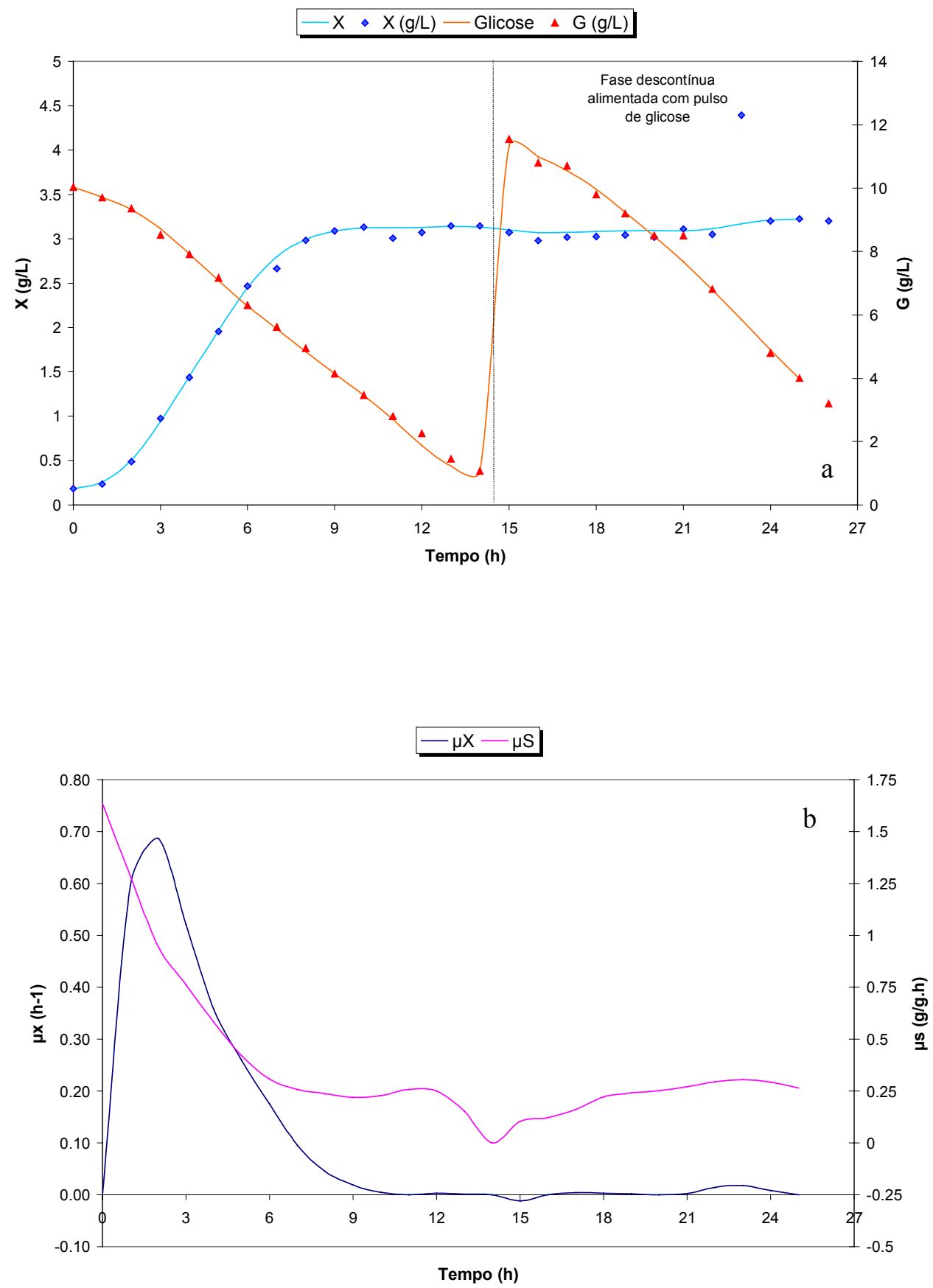

Figura 4.2.16 - Ensaio da-2: (a) concentrações celular e de glicose na fase descontínua e no pulso; (b) velocidades específicas de crescimento e de consumo de glicose. 

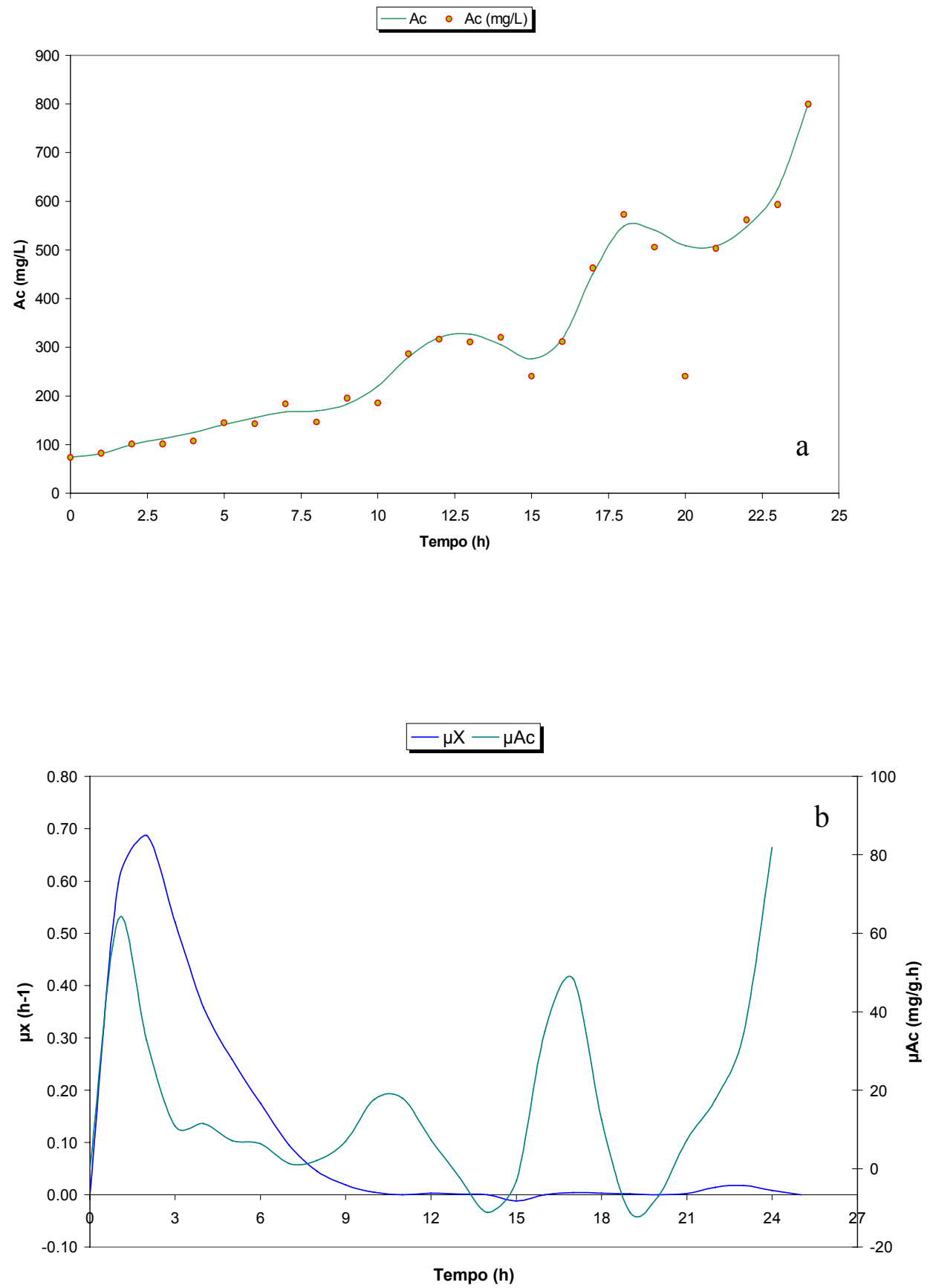

Figura 4.2.17 - Ensaio da-2 : (a) concentração de acetato produzido pelo microrganismo; (b) velocidade específica de crescimento e de formação de acetato. 
microrganismo descreve um processo basicamente fermentativo, portanto prejudicial à síntese do hormônio. A variação de OD pode ser vista na Figura 4.2.18.

Verificando-se a Figura 4.2.16, não se constata uma variação na velocidade específica de crescimento na fase de ativação. Entretanto, uma adição de soluções de extrato de levedura e micronutrientes na forma de pulsos poderia auxiliar o microrganismo no seu crescimento e na síntese do hGH por ser uma fonte alternativa de metabólitos intermediários (ou precursores de biossíntese) - conforme JENSEN; CARLSEN (1990) diminuindo a ação de um conjunto de efeitos denominado "metabolic burden". Nesta fase de estresse, acredita-se que o microrganismo E. coli RR1 consome o $\mathrm{O}_{2}$ para o "turn-over" das proteínas intracelulares, não havendo a síntese do hormônio.

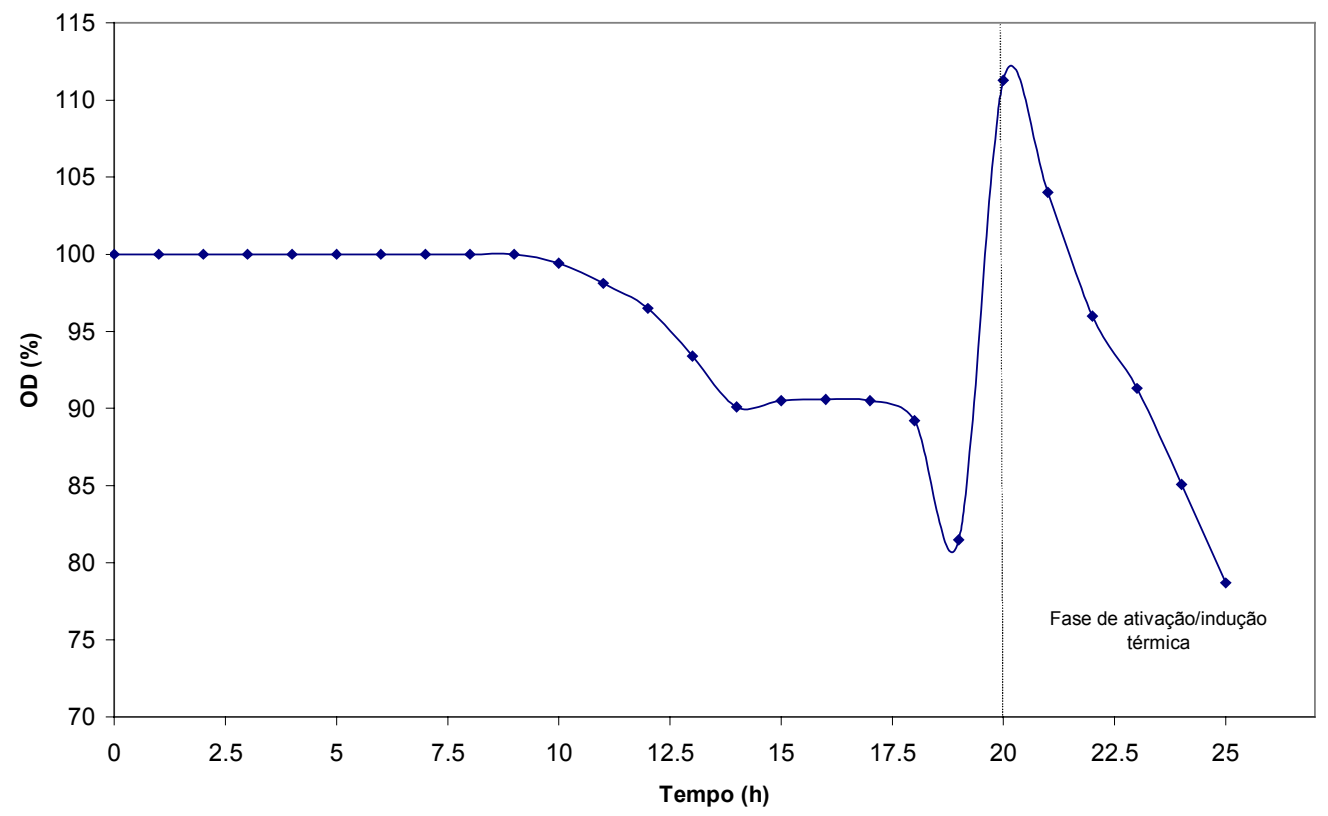

Figura 4.2.18: Perfil da variação da concentração de oxigênio dissolvido para o ensaio da-2.

O ensaio da-3 foi um cultivo descontínuo-alimentado onde se usou uma vazão exponencial de alimentação (ao contrário dos pulsos) como alternativa para obtenção de um maior crescimento celular (Figuras 4.2 .19 e 4.2 .20 ). 
Com uma fase descontínua que continha inicialmente $5 \mathrm{~g} \mathrm{~L}^{-1}$ de glicose e uma fase descontínua alimentada onde transferiu-se $60,84 \mathrm{~g}$ de glicose $\left(16 \mathrm{~g} \mathrm{~L}^{-1}\right.$, dado o volume constante), verificou-se que a concentração celular final alcançada foi ligeiramente maior do que aquela apresentada nos ensaios descontínuos-alimentados anteriores (da-1 e da-2). Este fato leva a acreditar que o microrganismo consumiu preferencialmente as fontes complexas de carbono para biossíntese e a glicose para geração de energia. Optou-se em diminuir a concentração inicial de glicose porque pensava-se em uma fase descontínua com menor duração; todavia não se procedeu, pois esta teve a duração de 18 horas.

Em seguida à fase descontínua, teve início a fase descontínua-alimentada com o fluxo de alimentação gerenciado pelo software AFS conectado ao gabinete com o biorreator utilizado no ensaio (a equação encontra-se descrita no capítulo Materiais e Métodos, item 3.11.2). Esta fase durou 13 horas, fazendo com que a concentração celular, inicialmente de 3,5 $\mathrm{g} \mathrm{L}^{-1}$, chegasse a 9,2 $\mathrm{g} \mathrm{L}^{-1}$ neste intervalo de tempo, sendo a solução de alimentação composta por glicose, extrato de levedura, bactotriptona e 1-prolina (a relação entre estes reagentes encontra-se no capítulo de Materiais e Métodos, item 3.2.5).

Este ganho de concentração celular, se comparado aos ensaios descontínuosalimentados por pulsos, pode estar relacionado com o fenômeno conhecido por repressão catabólica, causado pela glicose, presente na fase descontínua. Com uma concentração menor de glicose, esta repressão nos grupos enzimáticos é menos dramática, favorecendo o metabolismo celular voltado ao crescimento. Porém esta fase descontínua-alimentada resultou em um fator de conversão $\left(\mathrm{Y}_{\mathrm{X} / \mathrm{S}}\right)$ de $0,36 \mathrm{~g} \mathrm{~g}^{-1}, 68 \%$ menor que no ensaio da-1(nos outros pulsos praticamente não há conversão de glicose para células). Uma concentração menor de glicose pareceu ser benéfica para o microrganismo também porque praticamente não houve síntese de acetato (Figura 4.2.20) (LULI; STROHL, 1990). 

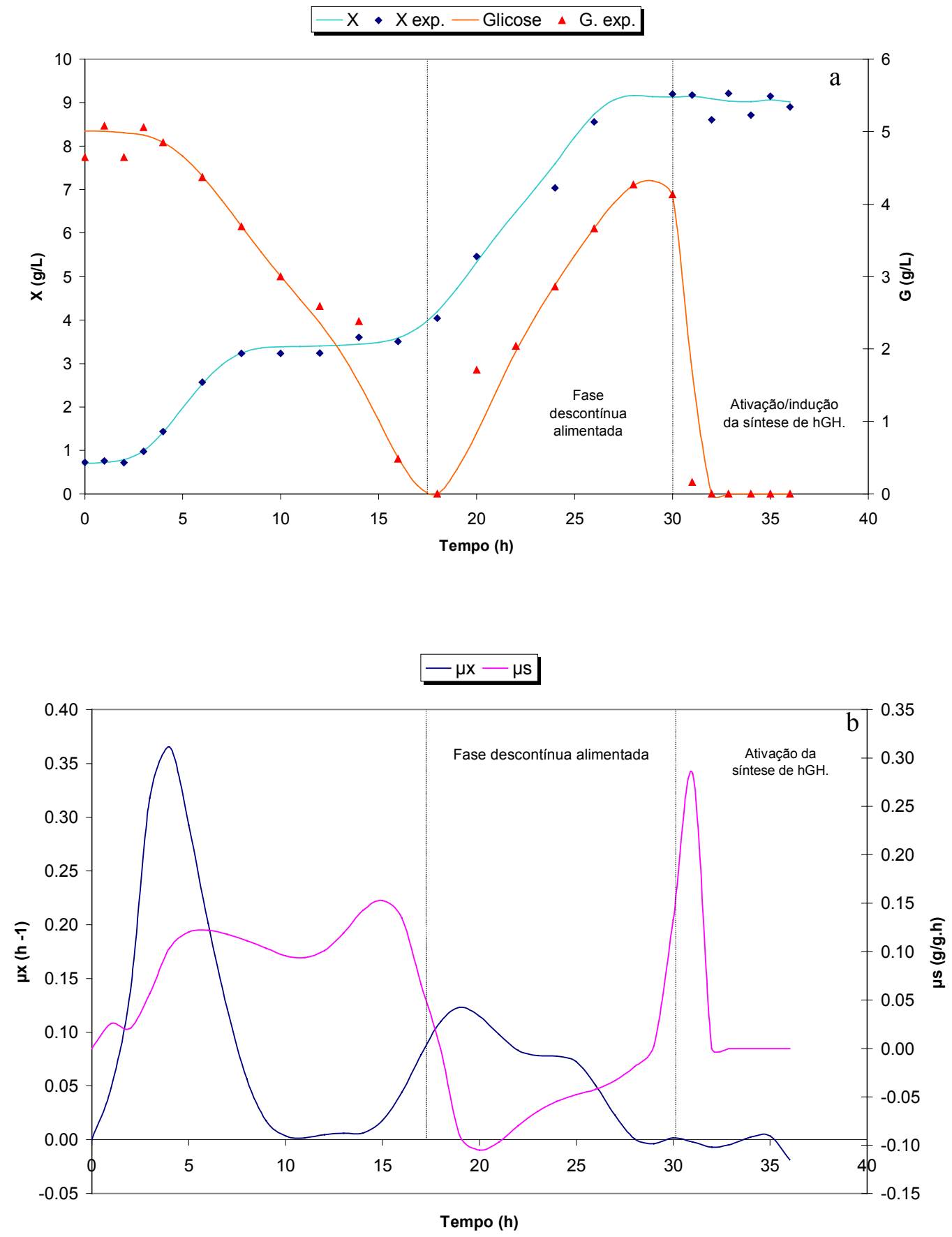

Figura 4.2.19: Ensaio da-3 : (a) Concentrações celular e de glicose ; (b) velocidades específicas de crescimento e de consumo de glicose. 

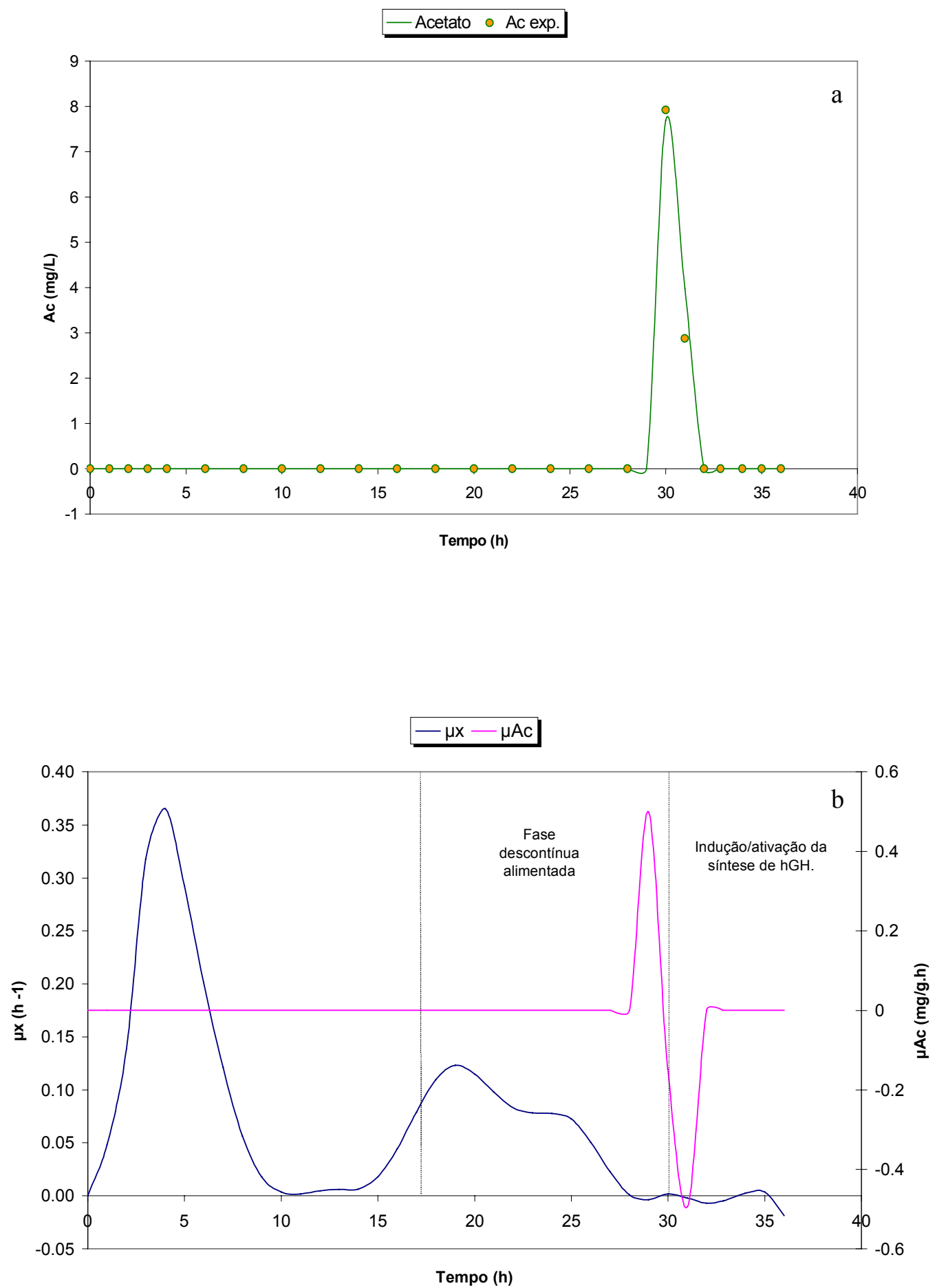

Figura 4.2.20: Ensaio da-3: (a) Concentração de acetato produzido; (b) velocidades específicas de crescimento e de formação de acetato. 
Logo após o término da fase descontínua alimentada para o crescimento, foi iniciada a indução do microrganismo. No instante zero (inicial), foi adicionada ao biorreator (em forma de pulso) uma solução com reagentes complexos (extrato de levedura e bactotriptona), segundo o trabalho de JENSEN; CARLSEN (1990), com a finalidade de suprir as necessidades do microrganismo para a síntese do hGH. Entretanto, ainda encontrava-se presente no meio de cultivo uma concentração de glicose de $4,5 \mathrm{~g} \mathrm{~L}^{-1}$, que somando-se ao efeito da elevação da temperatura, favoreceu a fermentação do meio pelo microrganismo. Somente nestes primeiros instantes é que encontrou-se concentrações de acetato nas amostras recolhidas, ao passo que nas amostras seguintes não foi verificada tal presença. A Figura 4.2.21 mostra a variação de OD durante o ensaio da-3.

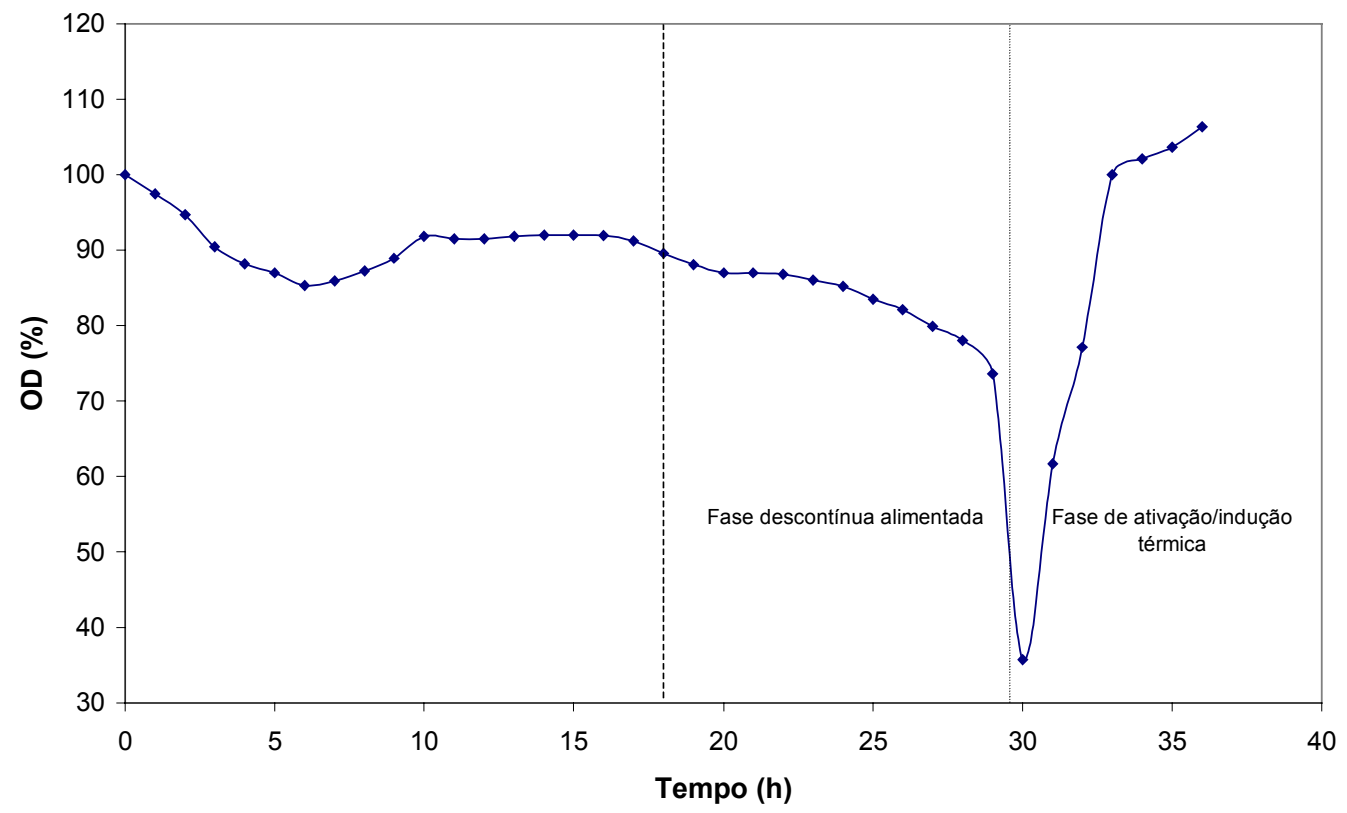

Figura 4.2.21: Perfil da variação da concentração de oxigênio dissolvido para o ensaio da-3. 


\subsection{Indução por choque térmico}

Conforme enfatizado por FRIEDS; REARDON (1993) e por YEE; BLANCH (1993), a produtividade de uma molécula heteróloga pode ser expressa como o produto entre a concentração celular, o teor de proteínas intracelulares presentes nesta concentração celular e a fração existente da molécula-alvo entre as proteínas. Estes parâmetros são influenciados por vários fatores, dentre eles: o nível de atividade biológica do hospedeiro e a eficiência de expressão da molécula de interesse.

Foi realizado o ensaio da-2, tendo por objetivo atingir uma concentração celular maior do que a alcançada nos ensaios descontínuos e, posteriormente, efetuar a ativação da síntese do hGH pela elevação da temperatura do cultivo de 30 para $42{ }^{\circ} \mathrm{C}$. Contudo, os resultados de crescimento celular verificados no ensaio da-1 não se repetiram, provavelmente devido a alguma limitação nutricional, pois as soluções de alimentação possuíam composições diferentes. Outra possibilidade foi a adição de uma quantidade de $\mathrm{NH}_{4} \mathrm{OH} 25 \%$ suficiente para a concentração de $500 \mathrm{mg} \mathrm{L}^{-1}$ no biorreator entre 16 e 17 horas. Após a adição da glicose na forma de pulso, não se constatou nenhum crescimento celular, provavelmente devido a algum efeito de repressão catabólica.

No instante de 20 horas, iniciou-se a elevação da temperatura para ativação da síntese do hGH, que ocorreu em 16 minutos e a amostra zero pós-indução retirada no instante que a temperatura atingiu $42{ }^{\circ} \mathrm{C}$. A partir deste momento, a amostragem retirada do biorreator foi a cada hora.

As amostras coletadas seguiram para posterior análise no IPEN, feitas segundo as metodologias já estabelecidas nos laboratórios da equipe do Prof. Paolo Bartolini. Para 
constatação da expressão do hGH, seguiram-se rotinas em RP-HPLC e SDS-PAGE das proteínas do espaço periplásmico extraídas sob choque osmótico e verificou-se que não houve expressão do hGH, como pode ser visto nas Figuras 4.4.1.2 e 4.4.1.3.

A Figura 4.4.1.1 é um padrão de hGH obtido pela passagem de uma determinada amostra, em RP-HPLC, segundo a metodologia mostrada no item 3.7.3. O pico com tempo de aproximadamente 33 minutos corresponde ao hGH, o qual não apareceu nas amostras do ensaio da-2 representada nas Figuras 4.4.1.2 e 4.4.1.3. Foram feitas análises nas amostras nos instantes zero e 3 horas de ativação, todavia em nenhum deles houve a expressão do hGH pelo microrganismo E. coli RR1.

Isto pode ser devido a alguns fatores: como uma concentração de acetato em níveis inibitórios para síntese do hGH; uma velocidade de respiração muito baixa, favorecendo a produção de metabólitos de fermentação; a possibilidade de perda do vetor phGH, contendo o gene estrutural do hGH, agravada pelo estresse imposto ao microrganismo pela elevada temperatura.

\subsection{Balanço Gasoso}

Com os ensaios em biorreator foram feitas análises do gás de exaustão para determinação da quantidade $\mathrm{O}_{2}$ e de $\mathrm{CO}_{2}$ produzido durante os cultivos. As frações obtidas 


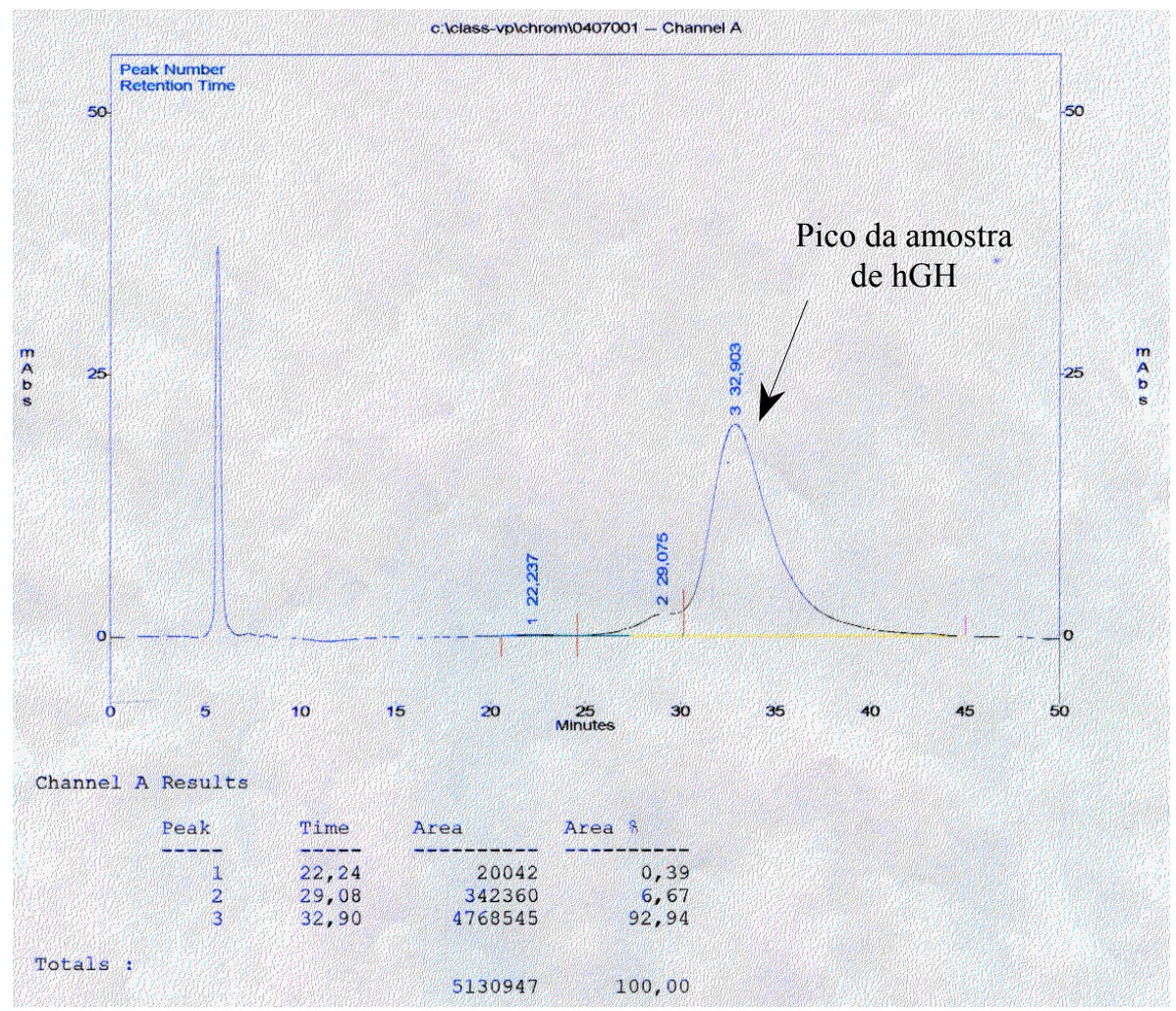

Figura 4.4.1.1 - Cromatograma de uma amostra padrão de hGH e seu tempo de retenção .

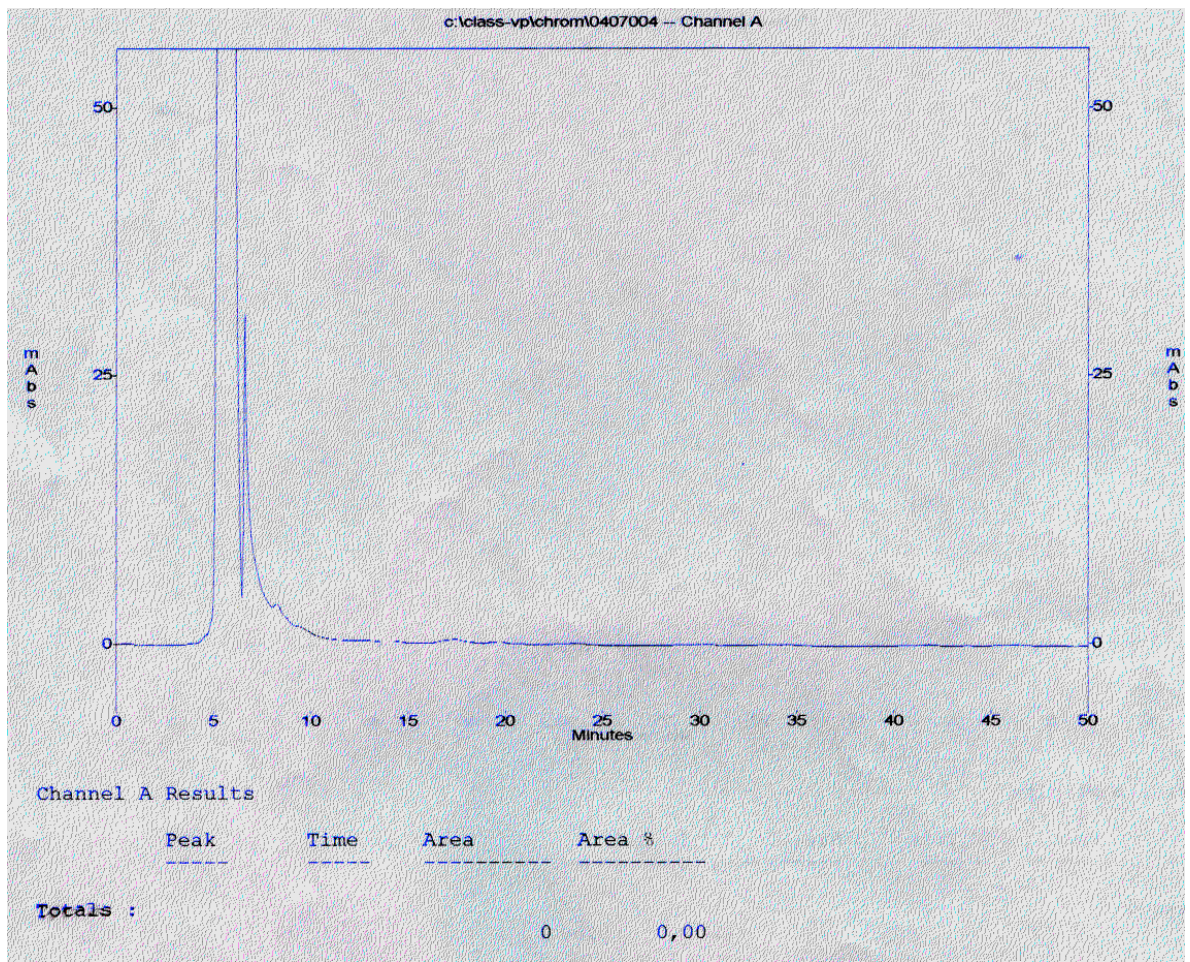

Figura 4.4.1.2 - Cromatograma da amostra 0 submetida ao choque osmóstico para avaliação da quantidade de $\mathrm{hGH}$. 


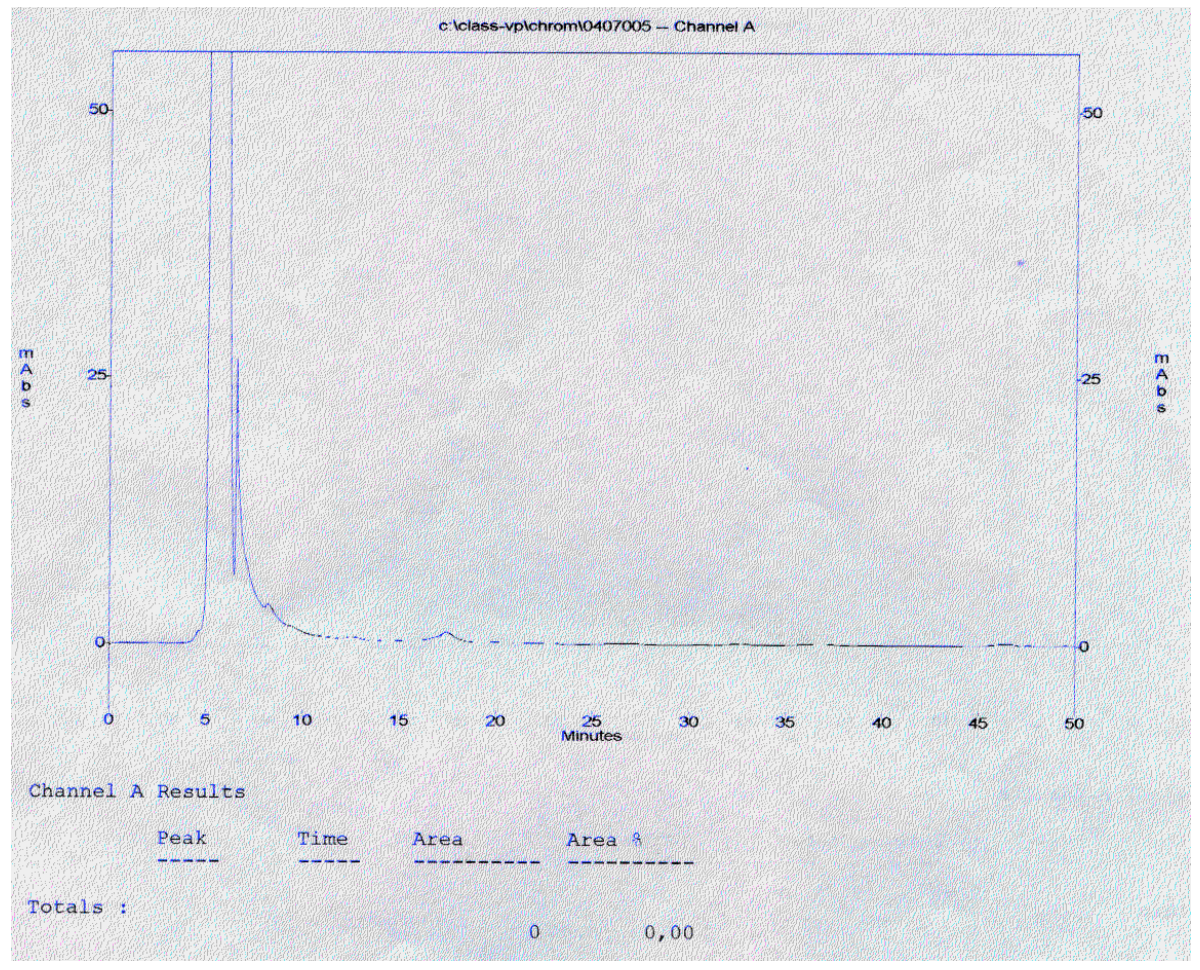

Figura 4.4.1.3 - Cromatograma da amostra 3 horas e submetida ao choque osmótico para avaliação da quantidade de hGH. 
de $\mathrm{CO}_{2}$ e $\mathrm{O}_{2}$ permitem estimar velocidades e coeficientes respiratórios segundo a técnica do Balanço Gasoso (HEINZLE; DUNN, 1991).

Para este trabalho, as variáveis medidas foram: as vazões de entrada de ar e $\mathrm{O}_{2}$ (item 3.7.4) e as frações molares de $\mathrm{O}_{2}$ e $\mathrm{CO}_{2}$ no gás de exaustão (item 3.7.5) e posteriormente calculadas as velocidades específicas de respiração $\left(\mathrm{Q}_{\mathrm{O} 2}\right.$, item 3.8) e de formação de $\mathrm{CO}_{2}$ $\left(\mathrm{Q}_{\mathrm{CO} 2}\right)$. Sabe-se que, nos instantes iniciais de cultivo, os valores obtidos de $\mathrm{Q}_{\mathrm{O} 2}$ não são muito confiáveis devido à pequena diferença entre as concentrações de oxigênio na entrada e na saída e a baixa concentração celular nestes instantes, gerando oscilações nos resultados iniciais de $\mathrm{Q}_{\mathrm{O} 2}$.

Tabela 4.5.1 - Resultados obtidos com o balanço gasoso para os ensaios descontínuos e descontínuos alimentados.

\begin{tabular}{|c|c|c|c|c|c|c|c|c|c|}
\hline Ensaios & \multicolumn{3}{|c|}{$\begin{array}{c}\text { Q02 máx } \\
(\mathrm{mmol} / \mathrm{g} . \mathrm{h})\end{array}$} & \multicolumn{3}{|c|}{$\begin{array}{c}Q_{\mathrm{CO} 2 \text { máx. }} \\
(\mathrm{mmol} / \mathrm{g} . \mathrm{h})\end{array}$} & \multicolumn{3}{|c|}{ RQ } \\
\hline $\mathrm{d} 2$ & \multicolumn{3}{|c|}{24,5} & \multicolumn{3}{|c|}{6,26} & \multicolumn{3}{|c|}{0,255} \\
\hline $\mathrm{d} 4$ & \multicolumn{3}{|c|}{4,16} & \multicolumn{3}{|c|}{5,27} & \multicolumn{3}{|c|}{1,267} \\
\hline d7 & \multicolumn{3}{|c|}{25,8} & \multicolumn{3}{|c|}{29,4} & \multicolumn{3}{|c|}{1,140} \\
\hline $\mathrm{d} 8$ & \multicolumn{3}{|c|}{5,0} & \multicolumn{3}{|c|}{46,9} & \multicolumn{3}{|c|}{9,380} \\
\hline $\mathrm{d} 10$ & \multicolumn{3}{|c|}{2,9} & \multicolumn{3}{|c|}{10,1} & \multicolumn{3}{|c|}{3,483} \\
\hline da-1 & 4,8 & 16,7 & 6,5 & 5,8 & 5,7 & 4,9 & 1,21 & 0,34 & 0,75 \\
\hline $\mathrm{da}-2$ & \multicolumn{2}{|c|}{6,2} & 1,0 & \multicolumn{2}{|c|}{-- } & 3,8 & \multicolumn{2}{|c|}{--- } & 3,800 \\
\hline da-3 & 9,3 & & 3,0 & 8,7 & & 2,7 & 0,93 & & 900 \\
\hline
\end{tabular}

Legenda: Ensaio da-1 = fase descontínua; descontínua alimentada $1^{\circ}$ pulso; descontínua alimentada $2^{\circ}$ pulso. Ensaio da-2 $=$ fase descontínua; descontínua alimentada $1^{\circ}$ pulso. Ensaio da-3 = fase descontínua; descontínua alimentada exponencialmente. 
Avaliando os resultados do ensaio descontínuo alimentado da-1, por exemplo, observa-se que para cada fase do ensaio houve um Qo2máx (Tabela 4.5.1) relacionado à mudanças no estado fisiológico do microrganismo durante o cultivo. Nota-se que o ensaio da-1 possui um Q Q2 máx no primeiro pulso da ordem de $16,7 \mathrm{mmol} \mathrm{g}^{-1} \mathrm{~h}^{-1}-$ Figura 4.5.1 - , pois nesta fase descontínua alimentada houve a adição de soluções de glicose, extrato de levedura, bactotriptona, $\left(\mathrm{NH}_{4}\right)_{2} \mathrm{HPO}_{4}$ e de 1-prolina; contudo, o ensaio da-2 possui um $\mathrm{Q}_{\mathrm{O} 2}$ máx no primeiro pulso da ordem de $1,0 \mathrm{mmol} \mathrm{g}^{-1} \mathrm{~h}^{-1}$ (um decréscimo de $94 \%$ ), porque neste pulso houve somente a adição de soluções de glicose e de 1-prolina no biorreator.

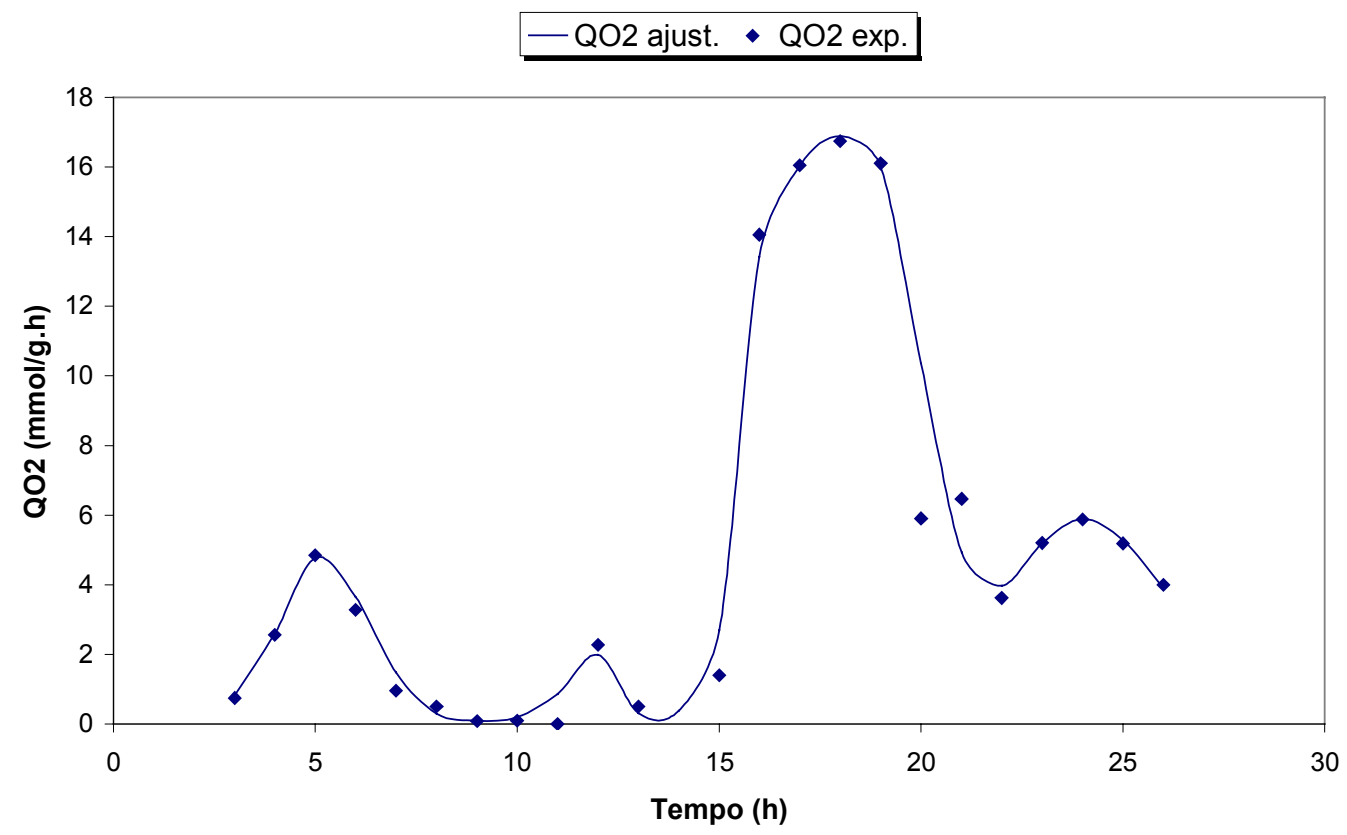

Figura 4.5.1 : Velocidade específica de consumo de oxigênio $\left(\mathrm{Q}_{\mathrm{O} 2}\right)$ em função do tempo para o ensaio da-1 .

A grande variação entre os valores de $\mathrm{Q}_{\mathrm{O} 2}$ nos dois ensaios pode ser devido à algum problema em seu metabolismo como, por exemplo: a redução de cofatores $\mathrm{NAD}^{+}$do ciclo TCA e das vias principais de catabolismo; baixa concentração de algum componente da cadeia de transporte de elétrons (CTE). Estes problemas acabam levando a um efeito de fermentação aeróbia no cultivo de crescimento do microrganismo. A concentração baixa de 
$\mathrm{NAD}^{+}$parece ser aumentada (e consequentemente a eficiência da CTE) pela introdução de 1-prolina no meio de cultivo que, por algum efeito de regulação metabólica, melhora o consumo de $\mathrm{O}_{2}$ e aumenta a velocidade de crescimento $\left(\mu_{\mathrm{x}}\right)$ que, no caso de ensaio da-2, pareceu não ser suficiente para melhorar o crescimento celular.

Os valores de $\mathrm{Q}_{\mathrm{CO} 2}$ são semelhantes para os dois ensaios descontínuos-alimentados na fase do primeiro pulso, com valores na faixa de $4,80 \mathrm{mmol} \mathrm{g}^{-1} \mathrm{~h}^{-1}$ e $6,20 \mathrm{mmol} \mathrm{g}^{-1} \mathrm{~h}^{-1}$ para o da-1 e da-2, respectivamente, embora não se possa comparar os valores dos dois cultivos antes dos pulsos devido a uma impossibilidade de leitura da fração de $\mathrm{CO}_{2}$ no ensaio da-2.

Um Q $\mathrm{CO}_{2}$ alto pode ser devido à preferência do microrganismo pelas vias metabólicas que geram descarboxilações (a via da enzima piruvato-descarboxilase e a via da $\alpha$-cetoglutarato desidrogenase, por exemplo), ou devido a disponibilidade de fontes alternativas de nutrientes (extrato de levedura e bactotriptona) que aumentam a formação de $\mathrm{CO}_{2}$ pelo microrganismo.

A diminuição nos valores de $\mathrm{Q}_{\mathrm{O} 2}$ no ensaio da-2 - Figura 4.5.2 - é um forte indicativo que o microrganismo tem seu metabolismo desbalanceado por uma limitação de algum nutriente específico ou por ação da queda do gradiente protônico resultante da desprotonação dos ácidos orgânicos sintetizados, sendo as vias metabólicas de fermentação ativadas para a geração de ATP, pois para síntese de moléculas heterólogas, valores de QO2 podem ser ou não importantes para a produção da molécula alvo, dependendo do sistema de expressão, dos metabólitos envolvidos, da localização desta mesma molécula alvo e da concentração final requerida, conforme os trabalhos de ECAMILLA-TREVINO et al. (2000), KILIKIAN (1998) e LIRIA (1995). Com isso, a concentração de sub-produtos (principalmente o acetato) resulta em valores mais altos do que em condições de $\mathrm{Q}_{\mathrm{O} 2}$ alto. 
- QO2 ajust. • QO2 exp.

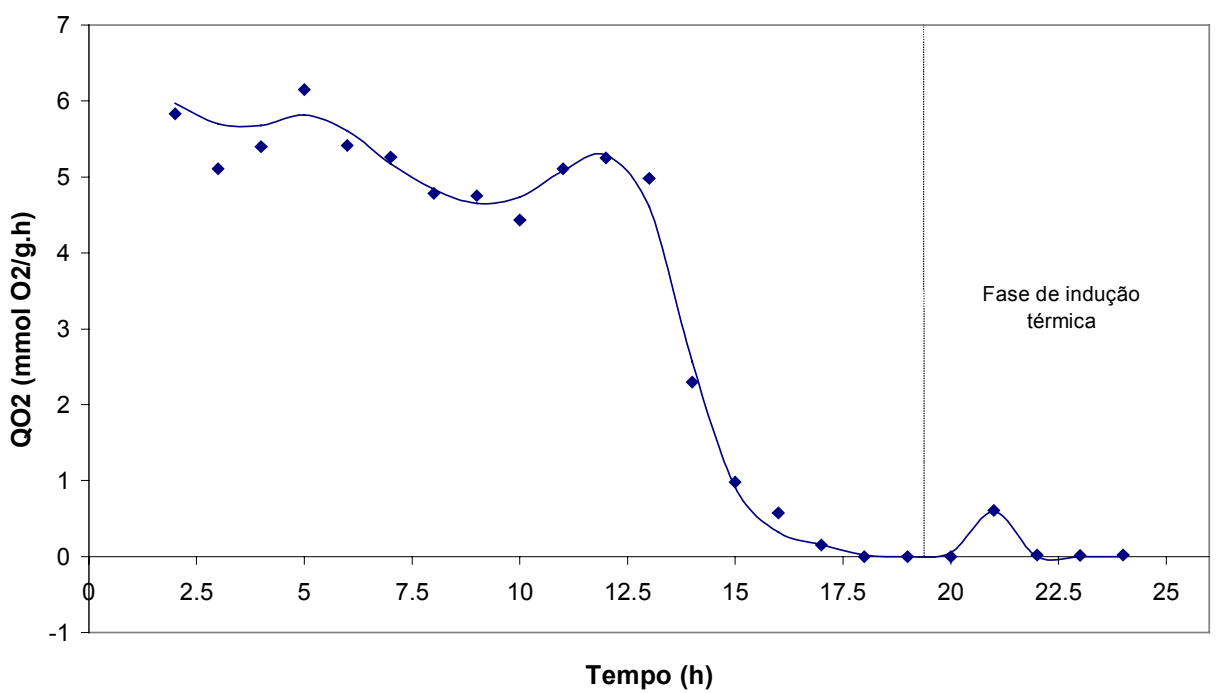

Figura 4.5.2: Velocidade específica de consumo de oxigênio em função do tempo para o ensaio da-2.

A velocidade específica de consumo de oxigênio do ensaio da-3 - Figura 4.5.3 - foi a maior obtida pelo microrganismo nestes ensaios durante a fase descontínua $(9,3 \mathrm{mmol}$ $\mathrm{g}^{-1} \mathrm{~h}^{-1}$ ), permanecendo constante na fase descontínua-alimentada em valores mais baixos $\left(3,0 \mathrm{mmol} \mathrm{g}^{-1} \mathrm{~h}^{-1}\right)$, semelhante aos encontrados nos ensaios anteriores e decaindo novamente na fase de indução para valores ainda mais baixos.

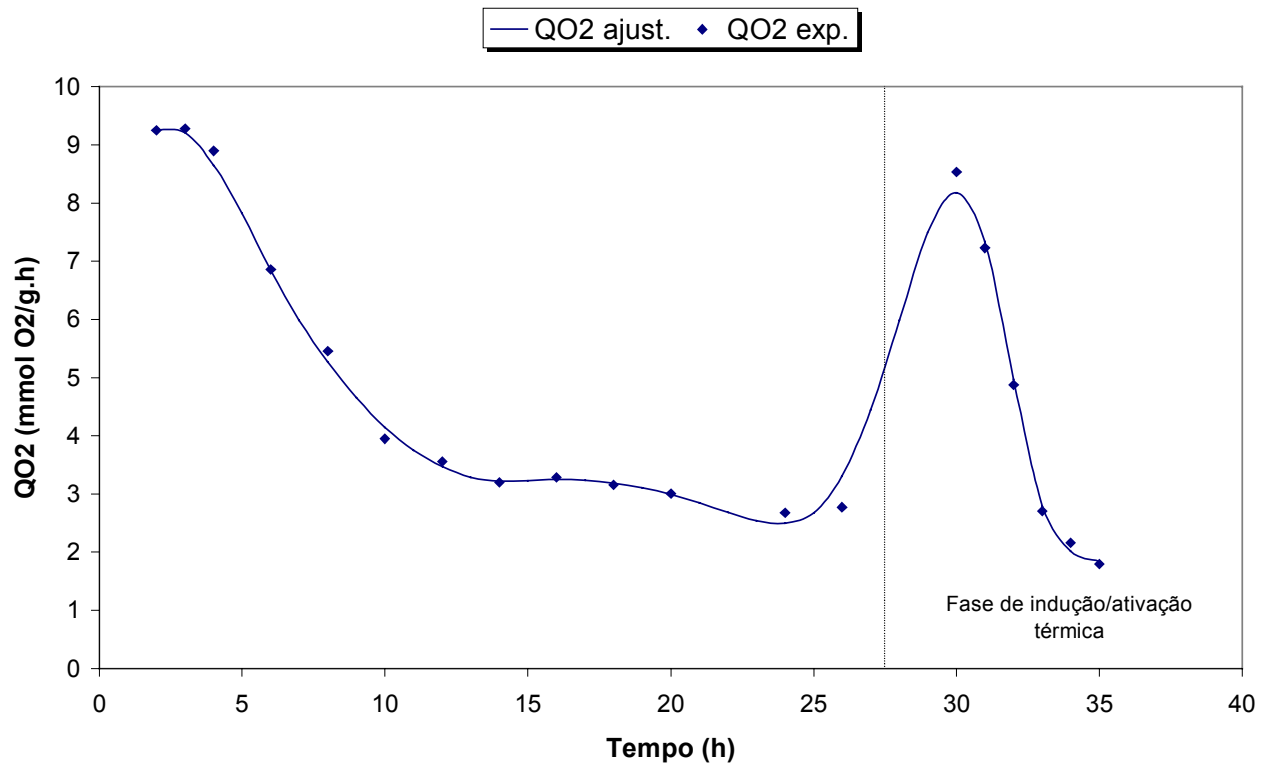

Figura 4.5.3: Velocidade específica de consumo de oxigênio em função do tempo para o ensaio da-3. 


\section{Conclusões}

1) Conforme os resultados dos ensaios descontínuos d1 e d2, o uso do aminoácido 1-prolina promoveu um aumento de massa celular (acréscimo de $185 \%$ );

2) No ensaio d9 foi obtido um aumento no fator de conversão glicose à células $\left(Y_{\mathrm{x} / \mathrm{s}}=0,54 \mathrm{~g} \mathrm{~g}^{-1}\right)$ mas um pequeno aumento na concentração celular $\left(X_{\mathrm{f}}=5,90 \mathrm{~g} \mathrm{~L}^{-1}\right)$ em relação ao ensaio d8 $\left(\mathrm{X}_{\mathrm{f}}=5,25 \mathrm{~g} \mathrm{~L}^{-1}\right.$ e $\left.\mathrm{Y}_{\mathrm{x} / \mathrm{s}}=0,37 \mathrm{~g} \mathrm{~g}^{-1}\right)$ também promovido pela adição de 1-prolina. Tais valores foram maiores que os alcançados nos demais ensaios descontínuos, provavelmente devido ao uso do primeiro lote de células;

3) Acredita-se que a diferença no desempenho do crescimento celular entre o primeiro e o segundo conjunto de ensaios em biorreator deve-se à diferença entre os lotes utilizados, isto é, é possível que os microrganismos do segundo lote contenham algum problema na estrutura celular. Os resultados dos ensaios d5 e d6 validam esta hipótese, visto que mesmo com a adição de 1-prolina no meio de cultivo do d6, objetivando-se um aumento da massa celular deste em relação ao d5, este efeito não foi observado. Há uma diferença significativa entre os resultados destes ensaios quanto ao fator de conversão substrato a células (0,48 e 0,29 $\mathrm{g} \mathrm{g}^{-1}$ para o ensaio d5 e d6, respectivamente), à velocidade específica máxima de crescimento $\left(0,53\right.$ e $0,26 \mathrm{~h}^{-1}$, respectivamente) e à produtividade em células (de 0,30 para 0,13 $\mathrm{g} \mathrm{L}^{-1} \mathrm{~h}^{-1}$, respectivamente ).

4) Em ensaio descontínuo alimentado com vazão exponencial de alimentação (da3) foram alcançados $9,2 \mathrm{~g} \mathrm{~L}^{-1}$ de concentração celular com fator de conversão de glicose à células $\left(\mathrm{Y}_{\mathrm{x} / \mathrm{s}}\right)$ de $0,36 \mathrm{~g} \mathrm{~g}^{-1}$. Este ensaio descontínuo alimentado pertence ao segundo lote de 
células (o qual não apresentou crescimento satisfatório nos ensaios descontínuos), razão pela qual optou-se por uma estratégia de adição de nutrientes através de uma alimentação contínua. Apesar das concentrações dos reagentes na solução de alimentação dos ensaios descontínuosalimentados terem sido variadas com a intenção de favorecer um melhor crescimento celular e a síntese do hGH, esta última não foi detectada;

5) Seria conveniente a troca da cepa atual por uma outra que não fosse auxotrófica, o que facilitaria a escolha de um meio de cultivo mais adequado, que pudesse fornecer os nutrientes necessários para o crescimento e para a síntese do hGH. 


\section{Anexo I}

Segue abaixo a relação, em ordem cronológica, dos ensaios efetuados em biorreator de forma descontínua e descontínua-alimentada. Portanto:

\begin{tabular}{|c|c|}
\hline Ensaios & Data de Realização \\
\hline $\mathrm{d} 1$ & Set/2000 \\
\hline $\mathrm{d} 2$ & Set/2000 \\
\hline $\mathrm{d} 3$ & Nov/2000 \\
\hline $\mathrm{d} 4$ & Nov/2000 \\
\hline $\mathrm{d} 5$ & Nov/1999 \\
\hline $\mathrm{d} 6$ & Jan/2001 \\
\hline $\mathrm{d} 7$ & Nov/1999 \\
\hline $\mathrm{d} 8$ & Mar/2000 \\
\hline $\mathrm{d} 9$ & Fev/2000 \\
\hline $\mathrm{d} 10$ & Fev/2000 \\
\hline $\mathrm{da}-1$ & Abr/2000 \\
\hline $\mathrm{da}-2$ & Mar/2001 \\
\hline & \\
\hline & \\
\hline & \\
\hline & \\
\hline & \\
\hline & \\
\hline & \\
\hline & \\
\hline & \\
\hline & \\
\hline & \\
\hline
\end{tabular}




\section{Bibliografia}

AMERICAN TYPE CULTURE COLLECTION (ATCC). Catálogo bacteria [on line]. Manassas, VA, ATCC, 2001. Disponível em: <http://www.atcc.org> [arquivo capturado em 29 de março de 2001].

ARISTIDOU, A.A. ; SAN, K. ; BENNETT, G.N. Modification of central metabolic pathway in Escherichia coli to reduce acetate accumulation by heterologous expression of the Bacillus subtilis acetolactate synthase gene. Biotechnology and Bioengineering, v. 44, n. 8, p. 944-51, 1994.

ASTURIAS, J. A. Cloning and high level expression of Cynodon dactylon (Bermuda grass) pollen profilin (Cyn d 12) in Escherichia coli: purification and characterization of the allergen. Clinical and Experimental Allergy, v. 27, n. 11, p. 1307-13, 1997.

AXE, D.D. ; BAILEY, J.E. Transport of acetate through the energized cytoplasmic membrane of Escherichia coli. Biotechnology and Bioengineering, v. 47, n. 1, p. $8-19,1995$.

BAILEY, J. E. ; OLLIS, D. F. Biochemical Engineering Fundamentals. New York, McGraw-Hill, 1986.

BAUER, K. A. ; BEM-BASSAT, A. ; DAWSON, M. ; PUENTE, V. T. ; NEWAY, J. O. Improvement expression of human interleukin-2 in high-cell-density fermentor cultures of Escherichia coli K-12 by a phosphotranscetylase mutant. Applied and Environmental Microbiology, v. 56, n. 5, p. 1296-1302, 1990. 
BAUER, S. ; SHILOACH, J. Maximal exponential growth rate and yield of Escherichia coli obtainable in a bench scale fermentor. Biotechnology and Bioengineering, v. 16, n. 7, p. 933-41, 1974.

BERMEJO, L.L. ; WELKER, N.E. ; PAPOUTSAKIS, E.T. Expression of Clostridium acetobutilicum ATCC 824 genes in Escherichia coli for acetone production and acetate detoxification. Applied and Environmental Microbiology, v. 64, n. 3, p. 1079-85, 1998.

BROWNLIE, L. ; STEPHENSON, J. R. ; COLE, J. A. Effects of growth rate on plasmid maintenance by Escherichia coli HB101(pAT153). Journal of General Microbiology, v. 136, p. 2471-80, 1990.

BYLUND, F. ; CASTAN, A. ; MIKKOLA, R. ; VEIDE, A. ; LARSSON, G. Influence of scale-up on the quality of recombinant human growth hormone. Biotechnology and Bioengineering, v. 69, n. 2, p. 119-28, 2000.

CALWELL, C.R. ; TURANO, F.J. ; McMAHON, M.B. Identification of two citosolic ascorbato peroxidase cDNA from soybean leaves and characterization of their products by functional expression in E. coli. Planta, v.204, n. 1, p. 120-6, 1998.

CHANG, C.N. ; REY, M. ; BOCHNER, B. ; HEYNEKER, H. ; GRAY, G. High level secretion of human growth hormone by Escherichia coli. Gene, v. 55 , p. 189-96, 1987.

CHANG, D. E.; JUNG, H. C.; RHEE, J. S.; PAN, J. G. Homofermentative production of D- or L- lactate in metabolically engineered Escherichia coli RR1. Applied and Environmental Microbiology, v. 65, n. 4, p. 1384-9, 1999. 
CROWL, R. Expression of human interferon genes in E. coli with lambda $\mathrm{P}_{\mathrm{L}}$ promoter . Methods in Enzymology, v. 119, p.376-83, 1986.

De VOS, A.M. ; ULTSCH, M. ; KOSSIAKOFF, A.A. Human growth hormone and extracelular domain of its receptor: crystal structure of the complex. Science, v. 255, p. 306-12, 1992.

DONOVAN, R.S. ; ROBINSON, C.W. ; GLICK, B.R. Review: Optimization inducer and culture conditions for expression of foreign proteins under control of the lac promoter. Journal of Industrial Microbiology, v. 16, p. 145-54, 1996.

ECAMILLA-TREVIÑO, L.L. ; VIADER-SALVADÓ, J.M. ; BARRERA-SALDAÑA, H.A. ; GUERRERO-OLAZARÁN, M. Biosynthesis and secretion of recombinant human growth hormone in Pichia pastoris. Biotechnology Letters, v. 22, n. 2, p. 10914, 2000.

FASS, R.; VAN DE WALLE, M.; SHILOACH, A.; JOSLYN, A.; KAUFMAN, J.; SHILOACH, J. Use of high density cultures of Escherichia coli for high level production of Pseudomonas aeruginosa exotoxin A. Applied Microbiology Biotechnology, v.36, n. 1, p. 65-9, 1991.

FRIEDS, K.; REARDON, K. F. Parameters influencing the productivity of recombinant $E$. coli cultivations. Advances in Biochemical Engineering/Biotechnology, v. 48, p.5377, 1993.

GALKIN, A.; KULAKOVA, L. Synthesis of optically active aminoacids from 'alpha'cetoacids with Escherichia coli cells expressing heterologous genes. Applied and Environmental Microbiology, v. 63, n. 12, p. 4651-56, 1997. 
GRAY, C. T. ; WIMPENNY, I. W. T. ; MOSSMANN, M. R. Regulation of metabolism in facultative bacteria. Effects of aerobiosis and nutrition on the formation of Krebs cycle enzymes in Escherichia coli. Biochimica et Biophysica Acta, v. 117, p. 33-41, 1966.

GSCHAEDLER, A. ; BOUDRANT, J . Aminoacid utilization during batch and continuous cultures of Escherichia coli on a semi-synthetic medium. Journal of Biotechnology, v. 37, n. 3, p. 235-51, 1994.

GOMBERT, A.K. Produção de troponina C em Escherichia coli: estudo da indução por lactose e obtenção de alta concentração celular. São Paulo, 1996, 134 p.

Dissertação (Mestrado) - Escola Politécnica, Universidade de São Paulo

GUPTA, J.C. ; JAISANI, M. ; PANDEY, G. ; MURKHERJEE, K. J. Enhancing recombinant protein yields in Escherichia coli using the T7 system under the control of heat inducible $\lambda$-P $\mathrm{P}_{\mathrm{L}}$ promoter. Journal of Biotechnology, v. 68, n. 2/3, p. 125-34, 1999.

HARCUM, S.W. ; RAMIREZ, D.M. ; BENTLEY, W.E. Optimal nutrient feed policies for heterologous protein production. Applied Biochemistry and Biotechnology, v. 34, p. 161-73, 1992.

HAUGHT, C.; DAVIS, G.D. Recombinant production and purification of novel antisense antimicrobial peptide in Escherichia coli. Biotechnology and Bioengineering, v. 57, n. 1, p. 55-61, 1998.

HEINZLE, E. ; DUNN, I. J. Methods and instruments in fermentation gas analysis. In: REHM, H. J. ; REED, G. Biotechnology: a multi-volume comprehensive treatise. 2. ed. Weinheim, VCH, 1991. v. 4. 
HORTON, H. R. Principles of Biochemistry. 2. ed. Upper Saddle River, 1996.

INGRAHAM, J. L. ; MAALOE, O. ; NEIDHARDT, F. C. Growth of Bacterial Cell. Sunderland, Sinauer, 1983.

JANG, W.C. ; KIM, S.I. ; LEE, S.Y. Purification and characterization of recombinant bovine growth hormone produced in Escherichia coli. Biotechnology Letters, v. 20, n. 3, p. 269-73, 1998.

JENSEN, E. B. ; CARLSEN, S. Production of recombinant human growth hormone in Escherichia coli: expression of different precursors and physiology effects of glucose, acetate and salts. Biotechnology and Bioengineering, v. 36, n. 1, p. 1-11, 1990.

\section{KILIKIAN, B.V. Desenvolvimento de Processo de Produção de Proteína}

Recombinante. São Paulo, 1998. 103 p. . Tese (Livre-docência) - Escola Politécnica, Universidade de São Paulo.

KILIKIAN, B.V. ; SUÁREZ, I.D. ; LIRIA, C.W. ; GOMBERT, A. K. Process strategies to improve heterologous protein production in Escherichia coli under lactose or IPTG induction. Process Biochemistry, v.35, n. 9, p. 1019-25, 2000.

KOSTYO, J.L. ; ISAKSSON, O. Growth hormone and the regulation of somatic growth. International Reviews of Physiology, v. 13, p. 255-74, 1977.

KNAPPE, J. Anaerobic dissimulation of piruvate. In. NEIDHARDT, F.C. ed. Escherichia coli and Salmonella typhimurium: cellular and molecular biology. Washington, American Society for Microbiology, v. 1, 1987.

LEE,C. ; SUN, W.J. ; BURGESS, B. W. ; JUNKER, B. H. ; REDDY, J. ; BUCKLAND, B. C. ; GREASHAM, R. L. Process optimization for large-scale production of TGF- $\alpha$ - 
PE40 in recombinant Escherichia coli: effect of medium composition and induction timing on protein expression. Journal of Industrial Microbiology \& Biotechnology, v. 18, n. 4, p. 260-6, 1997.

LEE, S.J. ; KIM, I.C. High level secretion of recombinant staphilokinase into periplasm of Escherichia coli. Biotechnology Letters, v. 20, n. 2, p. 113-6, 1998.

LEHNINGER, A. L. Biochemistry. New York, Worth Publishers, Inc.,1993.

LI, S. ;LI, F. ; WU, W. Expression in Escherichia coli and purification of human thrombopoietin. Biotechnology and Applied Biochemistry, v. 26, n. 1, p. 15-7, 1997.

LI, Y.; JIAN, C.; MAO, Y.Y.; LUN, S.; KOO, Y. Effects of additives and fed-batch culture strategies on the production of glutathione by recombinant Escherichia coli. Process Biochemistry, v. 33, n. 7, p. 709-14, 1998.

LIM, H.K. ; JUNG, K.H. Improvement of heterologous protein productivity by controlling post-induction specific growth rate in recombinant Escherichia coli under the control of the $\mathrm{P}_{\mathrm{L}}$ promoter. Biotechnology Progress, v. 14, n. 3, p. 548-53, 1998.

LIN,E.C.C. ; LYNCH, A.S. Regulation of Gene Expression in Escherichia coli. Austin, R. G. Landes , 1996.

LIN, M.T. ; KUO, T.J. ; LIN, C.T. Molecular cloning of a cDNA encoding copper/zinc superoxide dismutase from papaya fruit and overexpression in Escherichia coli . Journal of Agricultural and Food Chemistry, v. 46, n. 1, p. 344-8, 1998.

LIRIA, C. W. Processo descontínuo alimentado no cultivo de Escherichia coli BL21(DE3)pLysS para a produção da proteína recombinante troponina C. São 
Paulo, 1995. 129 p.. Dissertação (Mestrado) - Escola Politécnica, Universidade de São Paulo.

LOVE, C. A. ; LILLEY, P. E. ; DIXON, N. E. Stable high-copy-number bacteriophage $\lambda$ promoter vectors for overproduction of proteins in Escherichia coli. Gene, v. 176, p. 49-53, 1996.

LULI, G. W. ; STROHL, W. R. Comparison of growth, acetate production, and acetate inhibition of Escherichia coli strains in batch and fed-batch fermentations. Applied and Environmental Microbiology, v. 56, n. 4, p. 1004-11, 1990.

MOAT, A .G. ; FOSTER, J.W. Microbial Physiology. New York, John Wiley, 1995.

NAKAI, T. ; TONOUCHI, N. Expression and characterization of sucrose syntase from mung bean seedling in Escherichia coli. Bioscience, Biotechnology and Biochemistry, v. 61, n. 9, p. 1500-3, 1997.

OLSSON, L. ; HAHN-HAGERDAHL, B. Kinetics of ethanol production by recombinant Escherichia coli KO11. Biotechnology and Bioengineering, v. 45, n. 4, p. 356-65, 1995.

PANDA, A. K. ; KHAN, R. H. ; APPA RAO, K. B. C. ; TOTEY, S. M. Kinetics of inclusion body production in batch and high cell density fed-batch culture of Escherichia coli expressing ovine growth hormone. Journal of Biotechnology, v. 75, n. 2/3, p. 161-72, 1999.

RAMIREZ, D. M. ; BENTLEY, W. E. Enhancement of recombinant protein synthesis and stability via coordinated amino acid addition. Biotechnology and Bioengineering, v. 41, n. 5, p. 557-65, 1993. 
ROTHEN, S.A. ; SAUER, M. ; SONNLEITNER, B. ; WITHOLT, B. Growth characteristics of Escherichia coli HB101 [pGEc47] on defined medium. Biochemistry and Bioengineering, v. 58, n. 1, p. 92-100, 1998.

SAKAKIBARA, R. ; UEMURA, M. Human placental fructose-6-phosphate, 2klinase/fructose,2,6-bisphsphatase: its isozymic form, expression and characterization. Bioscience, Biotechnology and Biochemistry, v. 61, n. 11, p. 1949-52, 1997.

SCHMIDT, M. ; BABU, K.R. ; KHANNA, N. ; MARTEN, S. ; RINAS, U. Temperatureinduced production of recombinant human insulin in high cell density cultures of recombinant Escherichia coli. Journal of Biotechnology, v. 68, n. 1, p. 71-83, 1999.

SHIN, C.S. ; HONG, M.S. ; KIM, D. Y. ; LEE, J. ; PARK, Y. H. Growth associated synthesis of recombinant human glucagon and human growth hormone in high-celldensity cultures of Escherichia coli. Applied Microbiology and Biotechnology, v.49, n. 4, p. 364-70, 1998.

SHIN, N.K. ; KIM, D.Y. ; SHIN, C. S. ; HONG, M. S. ; LEE, J. ; SHIN, H. C. High level production of human growth hormone in Escherichia coli by a simple recombinant process. Journal of Biotechnology, v. 62, n. 2, p. 143-51, 1998.

STRYER, L. Bioquímica. Rio de Janeiro, Guanabara Koogan, 1995.

SUAREZ, I.D. Cultivo de Escherichia coli recombinante: Desenvolvimento de Estratégia para o Crescimento e Indução à Síntese de Troponina C. São Paulo, 1997. 181 p.. Dissertação (Mestrado) - Escola Politécnica, Universidade de São Paulo. 
SUAREZ, I.D. ; LIRIA, C.W. ; KILIKIAN, B.V. Effect of yeast extract on Escherichia coli growth and acetic acid production. World Journal of Microbiology \& Biotechnology, v. 14, n. 3, p. 331-5, 1998.

SUAREZ, I.D. ; KILIKIAN, B.V. Acetic acid accumulation in aerobic growth of recombinant Escherichia coli. Process Biochemistry, v. 35, n. 9, p. 1051-5, 2000.

UCHIDA, H. ; NAITO, N. ; ASADA, N. ; WADA, M. ; IKEDA, M. ; KOBAYASHI, H. ; ASANAGI, M. ; MORI, K. ; FUGITA, Y. ; KONDA, K. ; KUSUHARA, N. ; KAMIOKA, T. ; NAKASHIMA, K. ; HONJO, M. Secretion of authentic 20 KDa human growth hormone (20 K hGH) in Escherichia coli and properties of the purified product. Journal of Biotechnology, v. 55, n. 2, p. 101-12, 1997.

UI, S. ; OKAGIMA, Y. Molecular generation of Escherichia coli strain producing only the meso-isomer of 2,3-butanediol. Journal of Fermentation and Bioengineering, v. 84, n. 3, p. 185-9, 1997.

VOET, D. ; VOET, J.G. Biochemistry. New York, John Wiley, 1995.

WEUSTER-BOTZ, D. ; PRAMATAROVA, V. ; SPASSOV, G. ; WANDREY, C. Use a genetic algorithm in the development of a synthetic growth medium for Arthrobacter simplex with high hidrocortisone delta l-dehidrogenase activity. Journal of Chemical Technology and Biotechnology, v. 64, n. 4, p. 386-392, 1995.

WHITE, D. The Physiology and Biochemistry of Prokaryotes. New York, Oxford University, 1995. 
WONG, H.H. ; KIM, Y. C. ; LEE, S. Y. ; CHANG, H. N. Effect of post-induction nutrient feeding strategies on the production of bioadhesive protein in Escherichia coli . Biotechnology and Bioengineering, v. 60, n. 3, p. 271-6, 1998.

YEE, L. ; BLANCH, H.W. Defined media optimization for growth of recombinant Escherichia coli X90. Biotechnology and Bioengineering, v. 41, n. 2, p. 221-30, 1993. 


\section{APÊNDICE A}

Aqui estão colocadas as tabelas com os valores experimentais de cada ensaio realizado em incubador rotativo e em biorreator. Nelas constam os valores de concentração celular, concentração de glicose (com seus respectivos valores alisados pelo Logicieu du Lissage) e as velocidades específicas de crescimento $\left(\mu_{\mathrm{x}}\right)$ e de consumo de glicose $\left(\mu_{\mathrm{s}}\right)$. Também constam, em cada tabela de dados dos ensaios em biorreator, dados de concentração de acetato produzido (e seu valor ajustado) bem como sua velocidade de formação.

Tabela A1: Valores experimentais do ensaio S1.

\begin{tabular}{|c|c|c|c|c|}
\hline Tempo (h) & \multicolumn{1}{c}{$\mathbf{X}(\mathbf{g} / \mathbf{L})$} & $\mathbf{X}$ lis. & \multicolumn{1}{c|}{$\mathbf{~ ( g / L )}$} & $\mathbf{G}$ lis. \\
\hline 0 & 0,35 & 0,21 & 2,2 & 2,2 \\
\hline 1 & 0,20 & 0,23 & 2,2 & 2,2 \\
\hline 2 & 0,27 & 0,28 & 2,1 & 2,1 \\
\hline 3 & 0,46 & 0,46 & 2,0 & 2,0 \\
\hline 4 & 0,75 & 0,75 & 1,8 & 1,7 \\
\hline 5 & 1,08 & 1,02 & 1,2 & 1,3 \\
\hline 6 & 1,07 & 1,12 & 1,1 & 1,0 \\
\hline 7 & 1,08 & 1,14 & 0,8 & 0,8 \\
\hline 8 & 1,27 & 1,24 & 0,6 & 0,6 \\
\hline 9 & 1,45 & 1,40 & 0,2 & 0,2 \\
\hline 10 & 1,44 & 1,45 & 0,0 & 0,0 \\
\hline 11 & 1,35 & 1,35 & 0,0 & 0,0 \\
\hline 12 & 1,22 & 1,29 & 0,0 & 0,0 \\
\hline 13 & 1,35 & 1,35 & 0,0 & 0,0 \\
\hline 14 & 1,45 & 1,43 & 0,0 & 0,0 \\
\hline
\end{tabular}


Tabela A2: Valores experimentais do ensaio S2.

\begin{tabular}{|c|c|c|c|c|}
\hline Tempo (h) & \multicolumn{1}{c}{$\mathbf{X}(\mathbf{g} / \mathbf{L})$} & $\mathbf{X}$ lis. & \multicolumn{1}{c|}{$\mathbf{G}(\mathbf{g} / \mathbf{L})$} & G lis. \\
\hline 0 & 0,24 & 0,26 & 2,3 & 2,3 \\
\hline 1 & 0,27 & 0,28 & 2,3 & 2,2 \\
\hline 2 & 0,37 & 0,33 & 2,0 & 2,0 \\
\hline 3 & 0,36 & 0,48 & 1,7 & 1,7 \\
\hline 4 & 0,79 & 0,79 & 1,3 & 1,2 \\
\hline 5 & 1,20 & 1,18 & 0,7 & 0,7 \\
\hline 6 & 1,37 & 1,41 & 0,2 & 0,2 \\
\hline 7 & 1,47 & 1,47 & 0,1 & 0,1 \\
\hline 8 & 1,48 & 1,48 & 0,2 & 0,2 \\
\hline 9 & 1,51 & 1,49 & 0,2 & 0,2 \\
\hline 10 & 1,50 & 1,50 & 0,0 & 0,1 \\
\hline 11 & 1,45 & 1,48 & 0,0 & 0,0 \\
\hline 12 & 1,52 & 1,49 & 0,0 & 0,0 \\
\hline
\end{tabular}

Tabela A3: Valores experimentais do ensaio S3.

\begin{tabular}{|c|c|c|c|c|}
\hline Tempo (h) & \multicolumn{1}{c}{$\mathbf{X}(\mathbf{g} / \mathbf{L})$} & $\mathbf{X}$ lis. & $\mathbf{G}$ (g/L) & G lis. \\
\hline 0 & 0,13 & 0,22 & 12,3 & 12,6 \\
\hline 1 & 0,24 & 0,25 & 12,7 & 12,5 \\
\hline 2 & 0,39 & 0,36 & 12,3 & 12,1 \\
\hline 3 & 0,57 & 0,57 & 11,3 & 11,1 \\
\hline 4 & 0,91 & 0,86 & 9,0 & 9,8 \\
\hline 5 & 1,02 & 1,14 & 10,1 & 9,4 \\
\hline 6 & 1,52 & 1,45 & 9,3 & 9,4 \\
\hline 7 & 1,66 & 1,68 & 9,3 & 9,0 \\
\hline 8 & 1,69 & 1,74 & 8,2 & 8,3 \\
\hline 9 & 1,80 & 1,71 & 7,8 & 7,7 \\
\hline 10 & 1,53 & 1,62 & 7,4 & 7,4 \\
\hline 11 & 1,63 & 1,71 & 7,4 & 7,0 \\
\hline 12 & 2,09 & 1,95 & 5,6 & 5,6 \\
\hline 13 & 1,96 & 2,04 & 4,9 & 4,8 \\
\hline 14 & 2,04 & 2,04 & & \\
\hline
\end{tabular}


Tabela A4: Valores experimentais do ensaio S4.

\begin{tabular}{|c|c|c|c|c|}
\hline Tempo (h) & \multicolumn{1}{c}{$\mathbf{X}(\mathbf{g} / \mathbf{L})$} & \multicolumn{1}{c}{$\mathbf{X}$ lis } & \multicolumn{1}{c|}{$\mathbf{~ ( g / L ) ~}$} & G lis \\
\hline 4 & 1,07 & 1,09 & 10,5 & 10,0 \\
\hline 6 & 1,50 & 1,50 & 9,5 & 9,5 \\
\hline 8 & 1,89 & 1,89 & 7,9 & 7,9 \\
\hline 10 & 1,66 & 1,69 & 7,9 & 7,9 \\
\hline 12 & 2,06 & 2,06 & 5,5 & 5,5 \\
\hline 14 & 2,10 & 2,10 & 5,1 & 5,1 \\
\hline
\end{tabular}

Tabela A5: Valores experimentais do ensaio S5.

\begin{tabular}{|r|r|r|r|r|}
\hline \multicolumn{1}{|c}{ Tempo (h) } & \multicolumn{1}{c}{$\mathbf{X}(\mathbf{g} / \mathbf{L})$} & \multicolumn{1}{c}{$\mathbf{X}$ lis } & \multicolumn{1}{c|}{$\mathbf{G}(\mathbf{g} / \mathbf{L})$} & \multicolumn{1}{c|}{$\mathbf{~ l i s}$} \\
\hline 4 & 0,74 & 0,74 & 11,2 & 10,0 \\
\hline 6 & 0,99 & 0,99 & 10,5 & 9,8 \\
\hline 8 & 1,32 & 1,32 & 9,5 & 9,5 \\
\hline 10 & 1,46 & 1,46 & 8,7 & 8,7 \\
\hline 12 & 1,39 & 1,53 & 8,9 & 8,1 \\
\hline 14 & 1,65 & 1,65 & 7,7 & 7,7 \\
\hline
\end{tabular}

Tabela A6: Valores experimentais do ensaio S6.

\begin{tabular}{|r|r|r|r|r|}
\hline \multicolumn{1}{|l}{ Tempo (h) } & \multicolumn{1}{c}{$\mathbf{X}(\mathbf{g} / \mathbf{L})$} & \multicolumn{1}{c|}{$\mathbf{X}$ lis } & \multicolumn{1}{c|}{$\mathbf{G}(\mathbf{g} / \mathbf{L})$} & \multicolumn{1}{c|}{$\mathbf{G}$ lis } \\
\hline 4 & 0,71 & 0,71 & 11,0 & 10,0 \\
\hline 6 & 1,57 & 1,60 & 9,8 & 9,8 \\
\hline 8 & 2,26 & 2,26 & 6,9 & 6,9 \\
\hline 10 & 2,61 & 2,61 & 3,6 & 3,6 \\
\hline 12 & 2,85 & 2,80 & 2,2 & 2,2 \\
\hline
\end{tabular}

Tabela A7: Valores experimentais do ensaio S7.

\begin{tabular}{|r|r|r|r|r|}
\hline \multicolumn{1}{|c}{ Tempo (h) } & \multicolumn{1}{c}{$\mathbf{X}(\mathbf{g} / \mathbf{L})$} & \multicolumn{1}{c|}{$\mathbf{X}$ lis } & \multicolumn{1}{c|}{$\mathbf{G}(\mathbf{g} / \mathbf{L})$} & \multicolumn{1}{c|}{$\mathbf{G}$ lis } \\
\hline 4 & 0,78 & 0,77 & 11,8 & 10,0 \\
\hline 6 & 1,52 & 1,52 & 10,9 & 9,9 \\
\hline 8 & 2,22 & 2,22 & 6,9 & 6,9 \\
\hline 10 & 2,61 & 2,61 & 3,9 & 3,9 \\
\hline 12 & 2,78 & 2,76 & 2,4 & 2,4 \\
\hline
\end{tabular}


Tabela A8: Valores experimentais do ensaio S8.

\begin{tabular}{|c|c|c|c|c|c|c|}
\hline Tempo (h) & $\mathbf{X}(\mathbf{g} / \mathbf{L})$ & $\mathbf{X}$ lis. & $\mathbf{G}(\mathbf{g} / \mathbf{L})$ & $\mathbf{G}$ lis. & $\boldsymbol{\mu}_{\mathbf{x}}$ & $\boldsymbol{\mu}_{\mathbf{s}}$ \\
\hline 0 & 0,02 & 0.08 & 10,7 & 10,0 & 0,00 & 0,00 \\
\hline 1 & & 0.10 & 10,3 & 10,0 & 0,38 & 0,23 \\
\hline 2 & 0,21 & 0.16 & 9,9 & 10,0 & 0,55 & 0,20 \\
\hline 3 & 0,26 & 0.31 & & 10,0 & 0,73 & 0,00 \\
\hline 4 & 0,64 & 0.61 & 10,0 & 10,0 & 0,59 & 0,08 \\
\hline 5 & 1,04 & 1.00 & 9,7 & 9,8 & 0,40 & 0,42 \\
\hline 6 & 1,40 & 1.42 & 9,0 & 8,7 & 0,31 & 1,34 \\
\hline 7 & 1,86 & 1.85 & 6,1 & 6,5 & 0,21 & 1,12 \\
\hline 8 & 2,15 & 2.15 & 5,1 & 4,9 & 0,10 & 0,50 \\
\hline 9 & 2,17 & 2.30 & & 4,3 & 0,03 & 0,18 \\
\hline 10 & 2,12 & 2.33 & 5,4 & 3,9 & 0,00 & 0,12 \\
\hline 11 & 2,01 & 2.33 & 5,0 & 3,5 & 0,00 & 0,31 \\
\hline 12 & 2,26 & 2.35 & 2,6 & 2,6 & 0,01 & 0,36 \\
\hline 13 & 2,39 & 2.39 & 1,8 & 1,7 & 0,02 & 0,47 \\
\hline 14 & 2,38 & 2.43 & 0,0 & 0,6 & 0,02 & 0,37 \\
\hline 15 & 2,49 & 2.49 & 0,0 & 0,0 & 0,03 & 0,00 \\
\hline 16 & 2,61 & 2.57 & 0,0 & 0,0 & 0,03 & 0,00 \\
\hline 17 & 2,68 & 2.65 & 0,0 & 0,0 & 0,03 & 0,00 \\
\hline 18 & 2,80 & 2.72 & 0,0 & 0,0 & 0,02 & 0,00 \\
\hline 19 & 2,82 & 2.77 & 0,0 & 0,0 & 0,02 & 0,00 \\
\hline
\end{tabular}

Tabela A9: Valores experimentais do ensaio S9.

\begin{tabular}{|c|c|c|c|c|c|c|}
\hline Tempo (h) & \multicolumn{1}{c}{$\mathbf{X}(\mathbf{g} / \mathbf{L})$} & $\mathbf{X}$ lis. & \multicolumn{1}{c}{$\mathbf{G}(\mathbf{g} / \mathbf{L})$} & \multicolumn{1}{c|}{$\mathbf{G}$ lis. } & \multicolumn{1}{c|}{$\boldsymbol{\mu}_{\mathbf{x}}$} & $\boldsymbol{\mu}_{\mathbf{s}}$ \\
\hline 0 & 0.06 & 0.04 & 10,1 & 10,2 & 0,00 & 0,00 \\
\hline 2 & 0.12 & 0.20 & 10,1 & 10,1 & 0,78 & 0,86 \\
\hline 4 & 0.65 & 0.63 & 9,4 & 9,4 & 0,41 & 0,77 \\
\hline 6 & 1.21 & 1.24 & 8,1 & 8,0 & 0,27 & 0,72 \\
\hline 8 & 1.91 & 1.87 & 6,1 & 6,0 & 0,14 & 0,60 \\
\hline 10 & 2.16 & 2.24 & 3,7 & 3,8 & 0,06 & 0,44 \\
\hline 12 & 2.42 & 2.42 & 2,6 & 2,0 & 0,03 & 0,38 \\
\hline 14 & 2.59 & 2.52 & 0,0 & 0,4 & 0,00 & 0,21 \\
\hline 16 & 2.42 & 2.53 & 0,0 & 0,0 & 0,00 & 0,00 \\
\hline 18 & 2.68 & 2.56 & 0,0 & 0,0 & 0,00 & 0,00 \\
\hline 20 & & 2.88 & 0,0 & 0,0 & 0,00 & 0,00 \\
\hline
\end{tabular}


Tabela A10: Valores experimentais do ensaio S10.

\begin{tabular}{|c|c|c|c|c|c|c|}
\hline Tempo (h) & \multicolumn{1}{c}{$\mathbf{X}(\mathbf{g} / \mathbf{L})$} & \multicolumn{1}{c}{$\mathbf{X}$ lis. } & \multicolumn{1}{c}{$\mathbf{G}(\mathbf{g} / \mathbf{L})$} & \multicolumn{1}{c|}{$\mathbf{G}$ lis. } & \multicolumn{1}{c|}{$\boldsymbol{\mu}_{\mathbf{x}}$} & $\boldsymbol{\mu}_{\mathbf{s}}$ \\
\hline 0 & 0,05 & 0.06 & 10,0 & 10,0 & 0,00 & 0,00 \\
\hline 1 & 0,07 & 0.07 & 10,1 & 9,9 & 0,20 & 6,26 \\
\hline 2 & 0,09 & 0.10 & 9,2 & 9,2 & 0,52 & 8,26 \\
\hline 3 & 0,16 & 0.19 & 7,9 & 8,5 & 0,78 & 3,09 \\
\hline 4 & 0,45 & 0.40 & 8,7 & 8,1 & 0,67 & 0,83 \\
\hline 5 & 0,65 & 0.74 & 7,8 & 7,8 & 0,57 & 0,27 \\
\hline 6 & 1,21 & 1.18 & 7,6 & 7,5 & 0,33 & 0,37 \\
\hline 7 & 1,43 & 1.50 & 7,2 & 6,8 & 0,18 & 0,72 \\
\hline 8 & 1,78 & 1.73 & 4,3 & 5,6 & 0,10 & 0,67 \\
\hline 9 & 1,80 & 1.87 & 5,0 & 4,5 & 0,06 & 0,55 \\
\hline 10 & 1,95 & 1.97 & 3,3 & 3,5 & 0,05 & 0,54 \\
\hline 11 & 2,14 & 2.07 & 2,8 & 2,3 & 0,05 & 0,57 \\
\hline 12 & 1,88 & 2.17 & 0,7 & 1,1 & 0,05 & 0,53 \\
\hline 13 & 2,27 & 2.27 & 0,0 & 0,2 & 0,05 & 0,26 \\
\hline 14 & 2,40 & 2.37 & 0,0 & 0,0 & 0,03 & 0,02 \\
\hline 15 & 2,36 & 2.40 & 0,0 & 0,0 & 0,00 & 0,00 \\
\hline 16 & 2,40 & 2.40 & 0,0 & 0,0 & 0,00 & 0,00 \\
\hline 17 & 2,40 & 2.39 & 0,0 & 0,0 & 0,00 & 0,00 \\
\hline 18 & 2,25 & 2.40 & 0,0 & 0,0 & 0,00 & 0,00 \\
\hline 19 & 2,41 & 2.41 & 0,0 & 0,0 & 0,00 & 0,00 \\
\hline 20 & 2,42 & 2.42 & 0,0 & 0,0 & 0,00 & 0,00 \\
\hline
\end{tabular}


Aqui são mostradas as Tabelas dos ensaios descontínuos realizados em biorreator.

Tabela A12: Valores experimentais do ensaio d2.

\begin{tabular}{|c|c|c|c|c|c|c|c|c|c|}
\hline Tempo (h) & $X(g / L)$ & X lis. & $\overline{G(g / L)}$ & G lis. & $\mu_{x}$ & $\overline{\mu_{\mathrm{s}}}$ & $\overline{A c}(\mathrm{mg} / \mathrm{L})$ & Acetato & $\overline{\mu A c}$ \\
\hline 0 & 0,35 & 0,33 & $\overline{10,1}$ & 10,1 & 0,00 & 0,00 & $\overline{0,0}$ & 53,2 & $\overline{1,27}$ \\
\hline 1 & & 0,34 & & 10,1 & 0,09 & 0,00 & & 55,8 & 13,64 \\
\hline 2 & 0,33 & 0,40 & 10,1 & 10,1 & 0,18 & 0,01 & 79,0 & 62,6 & 21,74 \\
\hline 3 & & 0,48 & & 10,1 & 0,22 & 0,02 & & 71,9 & 18,83 \\
\hline 4 & 0,60 & 0,60 & $\overline{10,1}$ & 10,1 & 0,22 & 0,04 & 80,3 & 79,6 & 9,96 \\
\hline 5 & & 0,74 & & 10,1 & 0,17 & 0,06 & & 84,0 & 4,06 \\
\hline 6 & 0,90 & 0,85 & 10,1 & 10,0 & 0,11 & 0,08 & 82,0 & 86,3 & 2,16 \\
\hline 7 & & 0,92 & & 9,9 & 0,06 & 0,10 & & 88,6 & 3,42 \\
\hline 8 & 0,89 & 0,96 & 9,8 & 9,8 & 0,04 & 0,11 & 83,0 & 93,4 & 6,49 \\
\hline 9 & & 1,00 & & 9,7 & 0,05 & 0,12 & & 100,9 & 8,16 \\
\hline 10 & 1,05 & 1,07 & 9,6 & 9,6 & 0,08 & 0,13 & 113,7 & 109,3 & 7,33 \\
\hline 11 & & 1,17 & & 9,4 & 0,10 & 0,14 & & 116,4 & 5,01 \\
\hline 12 & 1,35 & 1,28 & 9,3 & 9,2 & 0,08 & 0,16 & 121,0 & 121,1 & 2,54 \\
\hline 13 & & 1,37 & & 9,0 & 0,06 & 0,17 & & 123,5 & 1,20 \\
\hline 14 & 1,43 & 1,44 & 8,8 & 8,8 & 0,03 & 0,17 & 124,3 & 125,1 & 1,34 \\
\hline 15 & & 1,47 & & 8,6 & 0,02 & 0,15 & & 128,3 & 3,50 \\
\hline 16 & 1,25 & 1,50 & 8,3 & 8,4 & 0,02 & 0,12 & 122,7 & 135,8 & 6,94 \\
\hline 17 & & 1,53 & & 8,2 & 0,02 & 0,09 & & 147,2 & 8,24 \\
\hline 18 & 1,57 & 1,56 & 8,3 & 8,1 & 0,02 & 0,07 & 165,6 & 158,4 & 6,49 \\
\hline 19 & & 1,59 & & 8,0 & 0,02 & 0,07 & & 166,4 & 3,67 \\
\hline 20 & 1,75 & 1,63 & 7,8 & 7,9 & 0,02 & 0,07 & 168,8 & 170,3 & 1,10 \\
\hline 21 & & 1,66 & & 7,8 & 0,02 & 0,07 & & 170,8 & $-0,35$ \\
\hline 22 & 1,56 & 1,69 & 7,7 & 7,6 & 0,02 & 0,06 & 165,4 & 169,8 & $-0,65$ \\
\hline 23 & & 1,72 & & 7,5 & 0,02 & 0,06 & & 168,8 & $-0,44$ \\
\hline 24 & 1,76 & 1,77 & 7,4 & 7,4 & 0,03 & 0,07 & 168,8 & 168,3 & $-0,15$ \\
\hline 25 & & 1,83 & & 7,3 & 0,03 & 0,07 & & 168,0 & $-0,20$ \\
\hline 26 & 1,90 & 1,88 & 7,3 & 7,2 & 0,02 & 0,07 & 166,1 & 167,3 & $-0,58$ \\
\hline 27 & & 1,91 & & 7,0 & 0,01 & 0,07 & & 166,0 & $-0,75$ \\
\hline 28 & 1,92 & 1,92 & 6,9 & 6,9 & 0,00 & 0,07 & 152,3 & 164,6 & $-0,64$ \\
\hline 29 & & 1,90 & & 6,8 & $-0,01$ & 0,07 & & 163,5 & $-0,59$ \\
\hline 30 & 1,70 & 1,87 & 6,7 & 6,6 & $-0,02$ & 0,08 & 162,4 & 162,2 & $-0,97$ \\
\hline 31 & & 1,83 & & 6,5 & $-0,02$ & 0,09 & & 159,6 & $-2,21$ \\
\hline 32 & 1,80 & 1,80 & 6,3 & 6,3 & $-0,01$ & 0,13 & 156,4 & 154,0 & $-4,64$ \\
\hline
\end{tabular}


Tabela A13: Valores experimentais do ensaio d3.

\begin{tabular}{|c|c|c|c|c|c|c|}
\hline Tempo (h) & $X(g / L)$ & $X$ lis. & $G(g / L)$ & G lis. & $\mu_{x}$ & $\mu_{\mathrm{s}}$ \\
\hline 0 & 0,02 & 0,02 & 10,2 & 10,1 & 0,00 & $\overline{0,34}$ \\
\hline 2 & 0,06 & 0,06 & 9,9 & 9,9 & 0,73 & 1,76 \\
\hline 4 & 0,25 & 0,28 & 9,6 & 9,6 & 0,70 & 0,79 \\
\hline 6 & 0,85 & 0,81 & 9,0 & 9,1 & 0,37 & 0,40 \\
\hline 8 & 1,34 & 1,32 & 8,3 & 8,3 & 0,14 & 0,35 \\
\hline 10 & 1,54 & 1,58 & 7,2 & 7,3 & 0,07 & 0,29 \\
\hline 12 & 1,83 & 1,79 & 6,7 & 6,5 & 0,05 & 0,23 \\
\hline 14 & & 1,92 & & 5,7 & 0,03 & 0,20 \\
\hline 16 & 1,93 & 2,00 & 4,8 & 4,9 & 0,02 & 0,20 \\
\hline 18 & 2,08 & 2,05 & 4,0 & 4,0 & 0,00 & 0,21 \\
\hline 20 & & 2,09 & & 3,2 & 0,00 & 0,22 \\
\hline 22 & 2,04 & 2,17 & 2,4 & 2,3 & 0,02 & 0,21 \\
\hline 24 & 2,29 & 2,26 & 1,3 & 1,4 & 0,05 & 0,18 \\
\hline 26 & 2,46 & 2,41 & 0,7 & 0,7 & $-0,02$ & 0,13 \\
\hline 28 & 2,15 & 2,50 & 0,1 & 0,0 & 0,00 & 0,14 \\
\hline 30 & 2,53 & 2,46 & 0,0 & 0,6 & 0,01 & 0,00 \\
\hline 32 & 2,25 & 2,28 & 4,3 & 4,0 & $-0,04$ & 0,00 \\
\hline 34 & 1,98 & 2,07 & 2,5 & 3,3 & $-0,03$ & 0,41 \\
\hline 36 & 2,11 & 2,10 & 0,9 & 1,1 & 0,05 & 0,48 \\
\hline 38 & 2,44 & 2,44 & 0,0 & 0,0 & 0,08 & 0,05 \\
\hline
\end{tabular}

Tabela A14: Valores experimentais do ensaio d4.

\begin{tabular}{|c|c|c|c|c|c|c|}
\hline Tempo (h) & \multicolumn{1}{c}{$\mathbf{X}(\mathbf{g} / \mathbf{L})$} & \multicolumn{1}{c}{$\mathbf{X}$ lis. } & \multicolumn{1}{c}{$\mathbf{G}(\mathbf{g} / \mathbf{L})$} & $\mathbf{G}$ lis. & $\boldsymbol{\mu}_{\mathbf{x}}$ & $\boldsymbol{\mu}_{\mathbf{s}}$ \\
\hline 0 & 0,13 & 0,13 & 10,06 & 10,06 & 0,000 & 0,360 \\
\hline 2 & 0,21 & 0,24 & 9,93 & 9,88 & 0,480 & 0,558 \\
\hline 4 & 0,57 & 0,55 & 9,60 & 9,55 & 0,346 & 0,339 \\
\hline 6 & 1,00 & 1,07 & 9,51 & 9,16 & 0,321 & 0,186 \\
\hline 8 & 1,77 & 1,75 & 8,49 & 8,71 & 0,119 & 0,159 \\
\hline 10 & 1,80 & 1,84 & 7,87 & 8,10 & $-0,014$ & 0,194 \\
\hline 12 & 2,23 & 2,18 & 7,43 & 7,43 & 0,081 & 0,178 \\
\hline 14 & & 2,29 & & 6,78 & 0,061 & 0,142 \\
\hline 16 & 2,27 & 2,32 & 6,34 & 6,19 & 0,008 & 0,120 \\
\hline 18 & 2,31 & 2,27 & 5,64 & 5,66 & $-0,035$ & 0,108 \\
\hline 20 & & 2,26 & & 5,10 & $-0,055$ & 0,171 \\
\hline 22 & 2,31 & 2,28 & 4,77 & 4,22 & $-0,049$ & 0,267 \\
\hline 24 & 2,19 & 2,27 & 3,18 & 3,49 & $-0,004$ & 0,085 \\
\hline 26 & 2,28 & 2,25 & 3,57 & 3,29 & $-0,007$ & 0,118 \\
\hline 28 & 2,09 & 2,24 & 2,35 & 2,31 & 0,020 & 0,421 \\
\hline 30 & 2,40 & 2,30 & 1,23 & 1,89 & 0,020 & 0,000 \\
\hline 32 & 2,26 & 2,16 & 5,12 & 4,26 & $-0,050$ & 0,000 \\
\hline 34 & 1,93 & 2,08 & 4,97 & 5,28 & $-0,039$ & 0,081 \\
\hline
\end{tabular}




\begin{tabular}{|l|l|l|l|l|l|l|}
\hline 36 & 2,06 & 1,96 & 4,23 & 4,42 & 0,013 & 0,303 \\
\hline 38 & 1,93 & 1,84 & 3,89 & 3,84 & $-0,154$ & 0,062 \\
\hline
\end{tabular}

Tabela A15: Valores experimentais do ensaio d5.

\begin{tabular}{|c|c|c|c|c|c|c|c|c|c|}
\hline Tempo (h) & $X(g / L)$ & $\mathrm{X}$ lis. & $\overline{G(g / L)}$ & G lis. & $\mu_{x}$ & $\mu_{s}$ & Ac (mg/L) & Acetato & $\mu \mathrm{Ac}$ \\
\hline 0 & 0,01 & 0,21 & 10,0 & 10,0 & 0,00 & 0,00 & 163,1 & 163,1 & 191,97 \\
\hline 1 & 0,25 & 0,25 & 10,0 & 10,0 & 0,75 & 0,38 & 229,2 & 236,3 & 399,04 \\
\hline 2 & 0,40 & 0,41 & 9,8 & 9,6 & 0,64 & 1,29 & 363,6 & 358,8 & 319,64 \\
\hline 3 & 0,78 & 0,78 & 8,4 & 8,6 & 0,50 & 1,38 & 474,3 & 511,9 & 222,23 \\
\hline 4 & 1,18 & 1,22 & 7,5 & 7,6 & 0,24 & 0,36 & 729,7 & 696,5 & 153,89 \\
\hline 5 & 1,36 & 1,47 & 7,4 & 7,4 & 0,16 & 0,00 & 797,7 & 839,7 & 53,64 \\
\hline 6 & 1,61 & 1,62 & 7,8 & 7,6 & 0,15 & 0,02 & 905,8 & 833,6 & $-51,05$ \\
\hline 7 & 1,85 & 1,84 & 7,3 & 7,3 & 0,15 & 0,30 & 662,7 & 795,6 & 41,31 \\
\hline 8 & 2,17 & 2,13 & 6,7 & 6,7 & 0,13 & 0,32 & 1063,6 & 957,2 & 92,54 \\
\hline 9 & 2,41 & 2,45 & 5,8 & 5,8 & 0,11 & 0,39 & 968,6 & 1154,8 & 84,80 \\
\hline 10 & 2,72 & 2,73 & 4,8 & 4,9 & 0,13 & 0,35 & 1307,0 & 1434,0 & 140,57 \\
\hline 11 & 3,10 & 3,06 & 3,9 & 4,0 & 0,09 & 0,18 & 1942,1 & 1968,5 & 216,32 \\
\hline 12 & 3,31 & 3,44 & 3,5 & 3,3 & 0,10 & 0,16 & 2543,9 & 2417,6 & 12,02 \\
\hline 13 & 3,81 & 3,80 & 2,7 & 2,6 & 0,11 & 0,22 & 1776,6 & 2046,9 & $-174,71$ \\
\hline 14 & 4,14 & 4,10 & 1,9 & 1,9 & 0,07 & 0,15 & 1384,5 & 1415,9 & $-109,59$ \\
\hline 15 & 4,39 & 4,39 & 1,4 & 1,3 & 0,06 & 0,13 & 1043,8 & 1199,1 & $-8,27$ \\
\hline 16 & 4,69 & 4,74 & 0,7 & 0,7 & 0,08 & 0,14 & 1598,0 & 1183,9 & $-15,68$ \\
\hline 17 & 5,11 & 5,02 & 0,0 & 0,0 & 0,03 & 0,06 & 921,6 & 976,8 & $-67,76$ \\
\hline 18 & 5,02 & 5,09 & 0,0 & 0,0 & $-0,03$ & 0,00 & 564,1 & 586,7 & $-75,52$ \\
\hline 19 & 4,84 & 5,07 & 0,0 & 0,0 & 0,01 & 0,00 & 344,4 & 265,6 & $-48,87$ \\
\hline 20 & 5,16 & 5,07 & 0,0 & 0,0 & 0,02 & 0,00 & 0,0 & 83,8 & 0,00 \\
\hline 21 & 5,03 & 5,10 & 0,0 & 0,0 & $-0,02$ & 0,00 & 0,0 & 4,6 & 0,00 \\
\hline 22 & 4,98 & 5,09 & 0,0 & 0,0 & 0,01 & 0,00 & 0,0 & 0,0 & 0,00 \\
\hline 23 & 5,12 & 5,05 & 0,0 & 0,0 & $-0,01$ & 0,00 & 0,0 & 0,0 & 0,00 \\
\hline
\end{tabular}


Tabela A16: Valores experimentais do ensaio d6.

\begin{tabular}{|c|c|c|c|c|c|c|}
\hline \multicolumn{1}{|c}{ Tempo (h) } & \multicolumn{1}{c}{$\mathbf{X}(\mathbf{g} / \mathbf{L})$} & \multicolumn{1}{c}{$\mathbf{X}$ lis. } & \multicolumn{1}{c}{$\mathbf{G}(\mathbf{g} / \mathbf{L})$} & G lis. & $\boldsymbol{\mu}_{\mathbf{x}}$ & $\boldsymbol{\mu}_{\mathbf{s}}$ \\
\hline 0 & 0,61 & 0,64 & 8,1 & 8,1 & 0,00 & 0,14 \\
\hline 1 & & 0,69 & & 8,0 & 0,09 & 0,22 \\
\hline 2 & 0,76 & 0,77 & 7,8 & 7,8 & 0,13 & 0,27 \\
\hline 3 & & 0,89 & & 7,6 & 0,16 & 0,30 \\
\hline 4 & 1,13 & 1,06 & 7,3 & 7,3 & 0,19 & 0,32 \\
\hline 5 & & 1,29 & & 6,9 & 0,19 & 0,31 \\
\hline 6 & 1,50 & 1,56 & 6,5 & 6,5 & 0,18 & 0,28 \\
\hline 7 & & 1,85 & & 6,0 & 0,16 & 0,23 \\
\hline 8 & 2,10 & 2,14 & 5,4 & 5,6 & 0,13 & 0,18 \\
\hline 9 & & 2,40 & & 5,3 & 0,10 & 0,13 \\
\hline 10 & 2,60 & 2,59 & 5,1 & 5,0 & 0,06 & 0,10 \\
\hline 11 & & 2,72 & & 4,7 & 0,03 & 0,08 \\
\hline 12 & & 2,78 & & 4,5 & 0,01 & 0,08 \\
\hline 13 & & 2,80 & & 4,3 & 0,00 & 0,09 \\
\hline 14 & 2,71 & 2,78 & 4,0 & 4,0 & $-0,01$ & 0,10 \\
\hline 15 & & 2,76 & & 3,7 & $-0,01$ & 0,11 \\
\hline 16 & 2,68 & 2,75 & 3,4 & 3,4 & 0,00 & 0,11 \\
\hline 17 & & 2,77 & & 3,1 & 0,01 & 0,10 \\
\hline 18 & 2,80 & 2,81 & 2,7 & 2,9 & 0,01 & 0,07 \\
\hline 19 & & 2,84 & & 2,7 & 0,01 & 0,04 \\
\hline 20 & 2,88 & 2,86 & 2,7 & 2,6 & 0,00 & 0,03 \\
\hline 21 & & 2,84 & & 2,5 & $-0,01$ & 0,04 \\
\hline 22 & 2,71 & 2,78 & 2,4 & 2,4 & $-0,03$ & 0,08 \\
\hline
\end{tabular}


Tabela A17: Valores experimentais do ensaio d7.

\begin{tabular}{|c|c|c|c|c|c|c|c|c|c|}
\hline Tempo (h) & $X(g / L)$ & $X$ lis. & $\overline{G(g / L)}$ & G lis. & $\mu_{x}$ & $\mu_{s}$ & Ac (mg/L) & Acetato & $\mu \mathrm{Ac}$ \\
\hline 0 & 0,18 & 0,25 & 10,3 & 10,0 & 0,00 & 0,00 & 152,3 & 173,5 & 210,46 \\
\hline 1 & 0,29 & 0,29 & 10,0 & 9,9 & 0,23 & 0,78 & & 228,5 & 191,44 \\
\hline 2 & 0,39 & 0,40 & 9,6 & 9,6 & 0,38 & 0,74 & 285,9 & 285,5 & 147,23 \\
\hline 3 & 0,61 & 0,61 & 9,4 & 9,3 & 0,45 & 0,63 & & 346,3 & 108,68 \\
\hline 4 & 0,90 & 0,97 & 8,8 & 8,9 & 0,48 & 0,52 & 411,6 & 415,9 & 78,71 \\
\hline 5 & 1,49 & 1,45 & 8,6 & 8,3 & 0,30 & 0,41 & & 495,4 & 56,80 \\
\hline 6 & 1,74 & 1,81 & 7,5 & 7,6 & 0,17 & 0,47 & 604,2 & 580,1 & 47,27 \\
\hline 7 & 2,13 & 2,08 & 6,8 & 6,6 & 0,12 & 0,52 & & 671,2 & 46,75 \\
\hline 8 & 2,25 & 2,31 & 5,6 & 5,6 & 0,10 & 0,41 & 743,8 & 778,3 & 50,36 \\
\hline 9 & 2,52 & 2,51 & 4,7 & 4,7 & 0,07 & 0,32 & & 900,9 & 50,09 \\
\hline 10 & 2,68 & 2,68 & 3,9 & 3,9 & 0,05 & 0,30 & 1054,0 & 1024,3 & 44,33 \\
\hline 11 & 2,82 & 2,82 & 3,1 & 3,1 & 0,05 & 0,28 & & 1133,7 & 34,93 \\
\hline 12 & 2,96 & 2,95 & 2,3 & 2,3 & 0,04 & 0,27 & 1210,8 & 1217,9 & 23,66 \\
\hline 13 & 2,89 & 3,04 & 1,5 & 1,5 & 0,03 & 0,26 & & 1274,6 & 16,07 \\
\hline 14 & 3,02 & 3,12 & 0,8 & 0,8 & 0,02 & 0,23 & 1210,8 & 1312,5 & 8,44 \\
\hline 15 & 3,40 & 3,18 & 0,2 & 0,2 & 0,02 & 0,12 & & 1299,9 & $-21,15$ \\
\hline 16 & 3,22 & 3,22 & 0,0 & 0,0 & 0,01 & 0,00 & 1330,5 & 1152,7 & $-69,26$ \\
\hline 17 & 3,17 & 3,23 & 0,0 & 0,0 & 0,00 & 0,00 & & 865,3 & $-102,14$ \\
\hline 18 & 3,13 & 3,24 & 0,0 & 0,0 & 0,00 & 0,00 & 332,0 & 539,8 & $-98,34$ \\
\hline 19 & 3,25 & 3,25 & 0,0 & 0,0 & 0,01 & 0,00 & & 279,1 & $-63,81$ \\
\hline 20 & 2,62 & 3,28 & 0,0 & 0,0 & 0,01 & 0,00 & 223,6 & 165,4 & $-6,22$ \\
\hline 21 & 3,33 & 3,33 & 0,0 & 0,0 & 0,02 & 0,00 & 251,7 & 258,8 & 63,56 \\
\hline
\end{tabular}


Tabela A18: Valores experimentais do ensaio d8.

\begin{tabular}{|c|c|c|c|c|c|c|c|c|c|}
\hline Tempo (h) & $X(g / L)$ & $\mathrm{X}$ lis. & $G(g / L)$ & G lis. & $\mu_{x}$ & $\mu_{s}$ & Ac (mg/L) & Acetato & $\mu A c$ \\
\hline 0 & 0,52 & 0,58 & 12,7 & 12,4 & 0,00 & 0,00 & 103,3 & 100,8 & 0,00 \\
\hline 1 & 0,68 & 0,69 & 12,2 & 12,2 & 0,28 & 0,41 & 101,4 & 116,9 & 53,97 \\
\hline 2 & 0,98 & 0,99 & 11,7 & 11,7 & 0,43 & 0,65 & 174,5 & 177,2 & 83,13 \\
\hline 3 & 1,54 & 1,53 & 10,6 & 10,9 & 0,40 & 0,64 & 267,2 & 261,5 & 45,64 \\
\hline 4 & 2,12 & 2,10 & 9,7 & 9,9 & 0,23 & 0,51 & 297,7 & 313,8 & 17,97 \\
\hline 5 & 2,38 & 2,50 & 8,8 & 8,7 & 0,14 & 0,55 & 196,0 & 340,7 & 6,02 \\
\hline 6 & 2,84 & 2,84 & 7,4 & 7,1 & 0,13 & 0,59 & 249,3 & 344,0 & $-2,59$ \\
\hline 7 & 3,24 & 3,23 & 5,0 & 5,5 & 0,12 & 0,48 & 371,4 & 329,6 & $-5,74$ \\
\hline 8 & 3,80 & 3,57 & 4,0 & 4,2 & 0,08 & 0,25 & 274,9 & 317,7 & 0,47 \\
\hline 9 & 3,94 & 3,80 & 3,7 & 3,6 & 0,05 & 0,09 & 305,0 & 331,3 & 4,98 \\
\hline 10 & 3,90 & 3,99 & 3,4 & 3,4 & 0,04 & 0,06 & 380,5 & 348,0 & 2,62 \\
\hline 11 & 4,16 & 4,16 & 3,1 & 3,1 & 0,04 & 0,06 & 279,3 & 346,8 & $-3,44$ \\
\hline 12 & 4,32 & 4,35 & 2,9 & 2,9 & 0,05 & 0,06 & 301,9 & 321,9 & $-7,37$ \\
\hline 13 & 4,56 & 4,55 & 2,6 & 2,6 & 0,04 & 0,08 & 296,9 & 297,8 & $-1,73$ \\
\hline 14 & 4,71 & 4,71 & 1,7 & 2,1 & 0,03 & 0,09 & 267,0 & 313,7 & 8,35 \\
\hline 15 & 4,84 & 4,84 & 1,6 & 1,7 & 0,03 & 0,08 & 263,6 & 367,7 & 12,72 \\
\hline 16 & 4,96 & 4,98 & 1,5 & 1,4 & 0,03 & 0,07 & 443,2 & 428,4 & 11,25 \\
\hline 17 & 5,33 & 5,15 & 1,1 & 1,1 & 0,03 & 0,05 & 443,7 & 476,5 & 7,82 \\
\hline 18 & 5,24 & 5,29 & 0,6 & 0,8 & 0,02 & 0,04 & 534,2 & 533,2 & 17,52 \\
\hline 19 & 5,43 & 5,35 & 0,6 & 0,6 & 0,01 & 0,06 & 723,6 & 723,9 & 61,12 \\
\hline 20 & 5,26 & 5,36 & 0,0 & 0,0 & 0,01 & 0,19 & & & 163,17 \\
\hline
\end{tabular}


Tabela A19: Valores experimentais do ensaio d9.

\begin{tabular}{|c|c|c|c|c|c|c|c|c|c|}
\hline Tempo (h) & $X(g / L)$ & $\mathrm{X}$ lis. & $\overline{G(g / L)}$ & G lis. & $\mu_{x}$ & $\mu_{s}$ & Ac (mg/L) & Acetato & $\mu \mathrm{Ac}$ \\
\hline 0 & 0,31 & 0,39 & 10,4 & 10,4 & 0,00 & 0,00 & 108,3 & $\overline{108,3}$ & 0,00 \\
\hline 1 & 0,47 & 0,48 & 10,4 & 10,3 & 0,36 & 0,23 & 126,2 & 132,9 & 108,08 \\
\hline 2 & 0,80 & 0,86 & 10,1 & 10,1 & 0,77 & 0,42 & 203,9 & 198,5 & 82,30 \\
\hline 3 & 1,81 & 1,74 & 9,7 & 9,5 & 0,58 & 0,52 & 149,3 & 258,2 & 24,06 \\
\hline 4 & 2,81 & 2,78 & 8,3 & 8,4 & 0,37 & 0,48 & 288,4 & 275,8 & $-2,27$ \\
\hline 5 & 3,63 & 3,77 & 7,1 & 7,0 & 0,26 & 0,34 & 161,1 & 260,6 & $-3,62$ \\
\hline 6 & 4,66 & 4,63 & 5,9 & 5,8 & 0,15 & 0,23 & 178,7 & 262,1 & 4,11 \\
\hline 7 & 5,09 & 5,11 & 4,8 & 4,8 & 0,06 & 0,21 & 313,7 & 293,3 & 7,31 \\
\hline 8 & 5,36 & 5,28 & 3,7 & 3,7 & 0,02 & 0,20 & 317,9 & 330,3 & 6,21 \\
\hline 9 & 5,05 & 5,35 & 2,7 & 2,7 & 0,01 & 0,18 & 356,5 & 354,7 & 2,75 \\
\hline 10 & 5,45 & 5,45 & 1,8 & 1,7 & 0,03 & 0,16 & 359,3 & 361,4 & 0,21 \\
\hline 11 & 5,84 & 5,60 & 0,9 & 0,9 & 0,03 & 0,14 & 358,4 & 355,9 & $-2,32$ \\
\hline 12 & 5,99 & 5,72 & 0,0 & 0,3 & 0,01 & 0,07 & 329,9 & 339,0 & $-2,91$ \\
\hline 13 & 5,65 & 5,75 & 0,0 & 0,0 & 0,00 & 0,00 & 203,7 & 325,9 & $-1,59$ \\
\hline 14 & 5,75 & 5,75 & 0,0 & 0,0 & 0,00 & 0,00 & 314,8 & 298,0 & $-10,50$ \\
\hline 15 & 5,90 & 5,75 & 0,0 & 0,0 & 0,00 & 0,00 & 178,9 & 206,8 & $-18,33$ \\
\hline 16 & 5,58 & 5,75 & 0,0 & 0,0 & 0,00 & 0,00 & 145,5 & 144,8 & 4,76 \\
\hline 17 & & 5,72 & 0,0 & 0,0 & 0,00 & 0,00 & & & \\
\hline
\end{tabular}


Tabela A20: Valores experimentais do ensaio d10.

\begin{tabular}{|c|c|c|c|c|c|c|c|c|c|}
\hline Tempo (h) & $\overline{X(g / L)}$ & $\mathrm{X}$ lis. & $G(g / L)$ & G lis. & $\mu_{x}$ & $\mu_{s}$ & $A c(m g / L)$ & Acetato & $\mu \mathrm{Ac}$ \\
\hline$\overline{0}$ & 0,53 & 0,58 & 9,2 & 9,2 & 0,13 & 0,13 & 88,5 & 91,4 & 51,63 \\
\hline 1 & 0,75 & 0,78 & 8,9 & 9,0 & 0,42 & 0,26 & 131,0 & 136,7 & 76,82 \\
\hline 2 & 1,21 & 1,20 & 8,9 & 8,8 & 0,40 & 0,20 & 197,3 & 188,5 & 24,36 \\
\hline 3 & 1,65 & 1,63 & 8,3 & 8,5 & 0,22 & 0,16 & 174,7 & 190,9 & $-11,16$ \\
\hline 4 & 1,87 & 1,89 & 8,2 & 8,3 & 0,09 & 0,15 & 98,1 & 164,0 & $-15,48$ \\
\hline 5 & 2,02 & 2,02 & 8,3 & 8,0 & 0,05 & 0,14 & 138,7 & 140,2 & $-7,08$ \\
\hline 6 & 1,85 & 2,12 & 8,0 & 7,7 & 0,04 & 0,11 & 140,9 & 140,8 & 8,24 \\
\hline 7 & 2,17 & 2,21 & 7,5 & 7,5 & 0,04 & 0,13 & 174,2 & 164,7 & 11,24 \\
\hline 8 & 2,48 & 2,31 & 7,2 & 7,2 & 0,04 & 0,13 & 116,3 & 181,3 & 3,11 \\
\hline 9 & 2,31 & 2,40 & 6,9 & 6,9 & 0,03 & 0,14 & 177,1 & 180,1 & $-3,18$ \\
\hline 10 & 2,57 & 2,48 & 6,5 & 6,5 & 0,03 & 0,15 & 171,4 & 177,9 & 3,66 \\
\hline 11 & 2,55 & 2,55 & 6,3 & 6,1 & 0,02 & 0,16 & 197,0 & 190,5 & 3,33 \\
\hline 12 & 2,61 & 2,61 & 5,9 & 5,7 & 0,02 & 0,17 & 184,1 & 194,8 & 1,45 \\
\hline 13 & 2,45 & 2,69 & 5,2 & 5,3 & 0,04 & 0,15 & 203,8 & 202,6 & 4,84 \\
\hline 14 & 2,77 & 2,96 & 5,0 & 4,9 & 0,17 & 0,12 & 218,9 & 216,4 & 4,69 \\
\hline 15 & 3,74 & 3,47 & 4,6 & 4,5 & 0,11 & 0,11 & 235,0 & 244,3 & 14,59 \\
\hline 16 & 3,36 & 3,63 & 4,1 & 4,1 & 0,00 & 0,12 & 323,1 & 293,8 & 8,25 \\
\hline 17 & 3,80 & 3,56 & 3,8 & 3,7 & 0,00 & 0,12 & 271,3 & 306,4 & 2,07 \\
\hline 18 & 3,15 & 3,50 & 3,2 & 3,3 & 0,00 & 0,12 & 244,1 & 318,7 & 4,37 \\
\hline 19 & 3,51 & 3,50 & 2,8 & 2,7 & 0,00 & 0,18 & 325,2 & 318,8 & $-9,16$ \\
\hline 20 & 2,88 & 3,51 & 2,2 & 2,2 & 0,00 & 0,11 & 182,5 & 210,6 & $-65,35$ \\
\hline 21 & 3,93 & 3,52 & & 1,7 & 0,01 & 0,00 & & & \\
\hline
\end{tabular}


Aqui encontram-se as Tabelas com os resultados dos ensaios descontínuos alimentados realizados em biorreator. Portanto, segue-se:

Tabela A21: Valores experimentais do ensaio da-1.

\begin{tabular}{|c|c|c|c|c|c|c|c|c|c|}
\hline Tempo (h) & $X(g / L)$ & $\mathrm{X}$ lis. & $\overline{G(g / L)}$ & G lis. & $\mu_{x}$ & $\mu_{\mathrm{s}}$ & $A c(m g / L)$ & Acetato & $\mu \mathrm{Ac}$ \\
\hline 0 & 0,16 & 0,14 & 10,0 & 10,0 & 0,16 & 1,53 & 203,3 & 121,5 & 7,13 \\
\hline 1 & 0,09 & 0,19 & 9,6 & 9,6 & 0,64 & 2,54 & 120,3 & 124,1 & 20,70 \\
\hline 2 & 0,41 & 0,39 & 9,0 & 9,0 & 0,75 & 1,72 & 142,0 & 129,9 & 19,63 \\
\hline 3 & 0,78 & 0,82 & 8,3 & 8,3 & 0,71 & 0,87 & 117,2 & 140,1 & 15,31 \\
\hline 4 & 1,53 & 1,51 & 7,6 & 7,6 & 0,50 & 0,47 & 141,7 & 153,0 & 8,06 \\
\hline 5 & 2,29 & 2,33 & 6,9 & 6,8 & 0,38 & 0,44 & 202,3 & 165,1 & 5,75 \\
\hline 6 & 3,23 & 3,19 & 5,4 & 5,5 & 0,24 & 0,45 & 120,1 & 180,4 & 5,32 \\
\hline 7 & 3,75 & 3,76 & 4,0 & 4,1 & 0,10 & 0,37 & 222,6 & 198,5 & 5,08 \\
\hline 8 & 3,84 & 4,04 & 2,9 & 2,4 & 0,06 & 0,53 & 122,2 & 217,3 & 4,41 \\
\hline 9 & 4,25 & 4,19 & 0,0 & 0,4 & 0,01 & 0,33 & 247,4 & 236,4 & 5,27 \\
\hline 10 & 4,02 & 4,21 & 0,0 & 0,0 & 0,02 & 0,15 & 349,7 & 260,9 & 6,30 \\
\hline 11 & 4,46 & 4,38 & 0,0 & 1,6 & 0,05 & 0,00 & 234,8 & 290,7 & 8,34 \\
\hline 12 & 4,67 & 4,76 & 8,2 & 6,3 & 0,13 & 0,00 & 311,0 & 368,9 & 28,28 \\
\hline 13 & 5,72 & 5,75 & 0,0 & 2,6 & 0,24 & 0,87 & 543,7 & 526,0 & 24,80 \\
\hline 14 & 7,26 & 7,11 & 0,0 & 0,0 & 0,15 & 0,15 & 579,7 & 556,2 & $-16,53$ \\
\hline 15 & 7,60 & 7,96 & 0,0 & 0,0 & 0,09 & 0,00 & 353,3 & 386,6 & $-17,15$ \\
\hline 16 & 8,77 & 8,37 & 0,0 & 0,0 & 0,00 & 0,06 & 405,9 & 411,0 & 25,63 \\
\hline 17 & 7,89 & 8,01 & 0,0 & 1,6 & $-0,06$ & 0,00 & 726,3 & 687,8 & 30,07 \\
\hline 18 & 7,61 & 7,67 & 9,8 & 6,5 & $-0,01$ & 0,00 & 766,9 & 827,9 & 6,12 \\
\hline 19 & 7,94 & 7,87 & 0,0 & 2,7 & 0,04 & 0,65 & 654,7 & 838,8 & 0,15 \\
\hline 20 & 7,97 & 8,10 & 0,0 & 0,0 & 0,00 & 0,14 & 987,6 & 784,9 & $-17,96$ \\
\hline 21 & 0,70 & 7,86 & 0,0 & 0,0 & $-0,05$ & 0,00 & 524,1 & 593,0 & $-24,00$ \\
\hline 22 & 5,00 & 7,37 & 0,0 & 0,2 & $-0,07$ & 0,00 & 494,3 & 502,5 & 6,02 \\
\hline 23 & 6,91 & 7,07 & 0,0 & 0,1 & $-0,01$ & 0,03 & 782,3 & 580,3 & 4,41 \\
\hline 24 & 6,74 & 7,17 & 0,0 & 0,0 & 0,03 & 0,00 & 411,6 & 552,5 & $-8,49$ \\
\hline 25 & 7,41 & 7,48 & 0,0 & 0,0 & 0,07 & 0,00 & 606,9 & 504,6 & $-2,66$ \\
\hline 26 & 8,42 & 8,57 & 0,0 & 0,0 & 0,21 & 0,00 & 511,5 & 505,4 & 1,28 \\
\hline 27 & 10,90 & 10,54 & 0,0 & 0,0 & 0,15 & 0,00 & 480,7 & 513,4 & 0,25 \\
\hline 28 & 9,73 & 9,79 & 0,0 & 0,0 & $-0,46$ & 0,00 & 515,0 & 514,9 & 0,62 \\
\hline
\end{tabular}


Tabela A22: Valores experimentais do ensaio da-2.

\begin{tabular}{|c|c|c|c|c|c|c|c|c|c|}
\hline Tempo (h) & $X(g / L)$ & $\mathrm{X}$ lis. & $\overline{G(g / L)}$ & G lis. & $\mu_{x}$ & $\mu_{s}$ & Ac (mg/L) & Acetato & $\mu \mathrm{Ac}$ \\
\hline 0 & 0,18 & 0,18 & 10,0 & 10,0 & 0,00 & 1,64 & 74,0 & 74,0 & 0,00 \\
\hline 1 & 0,24 & 0,26 & 9,7 & 9,7 & 0,60 & 1,28 & 82,4 & 81,7 & 63,54 \\
\hline 2 & 0,49 & 0,51 & 9,4 & 9,3 & 0,69 & 0,95 & 101,9 & 99,6 & 32,78 \\
\hline 3 & 0,97 & 0,94 & 8,5 & 8,7 & 0,52 & 0,76 & 101,1 & 112,6 & 10,83 \\
\hline 4 & 1,44 & 1,45 & 7,9 & 7,9 & 0,36 & 0,58 & 107,6 & 124,9 & 11,48 \\
\hline 5 & 1,96 & 1,97 & 7,2 & 7,1 & 0,26 & 0,42 & 145,1 & 142,0 & 7,22 \\
\hline 6 & 2,47 & 2,45 & 6,3 & 6,3 & 0,17 & 0,31 & 143,1 & 155,6 & 6,38 \\
\hline 7 & 2,66 & 2,80 & 5,6 & 5,6 & 0,10 & 0,26 & 184,1 & 167,4 & 1,32 \\
\hline 8 & 2,98 & 2,99 & 5,0 & 4,8 & 0,05 & 0,24 & 146,5 & 169,2 & 2,04 \\
\hline 9 & 3,09 & 3,09 & 4,1 & 4,1 & 0,02 & 0,22 & 195,6 & 183,2 & 7,05 \\
\hline 10 & 3,13 & 3,12 & 3,5 & 3,5 & 0,00 & 0,23 & 186,0 & 220,1 & 17,68 \\
\hline 11 & 3,01 & 3,13 & 2,8 & 2,7 & 0,00 & 0,26 & 287,3 & 280,5 & 17,99 \\
\hline 12 & 2,89 & 3,13 & 2,3 & 1,9 & 0,00 & 0,25 & 317,0 & 320,1 & 7,32 \\
\hline 13 & 3,14 & 3,14 & 1,5 & 1,2 & 0,00 & 0,15 & 310,5 & 326,8 & $-2,22$ \\
\hline 14 & 3,14 & 3,13 & 1,1 & 1,1 & 0,00 & 0,00 & 320,6 & 305,4 & $-11,11$ \\
\hline 15 & 2,95 & 3,10 & 11,6 & 11,3 & $-0,01$ & 0,10 & 240,7 & 276,4 & $-3,10$ \\
\hline 16 & 2,76 & 3,07 & 10,8 & 11,0 & 0,00 & 0,12 & 311,4 & 317,6 & 35,00 \\
\hline 17 & 2,90 & 3,07 & 10,7 & 10,6 & 0,00 & 0,16 & 463,0 & 451,2 & 48,40 \\
\hline 18 & 3,03 & 3,08 & 9,8 & 10,0 & 0,00 & 0,22 & 572,9 & 549,1 & 12,57 \\
\hline 19 & 3,04 & 3,09 & 9,2 & 9,2 & 0,00 & 0,24 & 506,3 & 540,2 & $-11,13$ \\
\hline 20 & 3,02 & 3,09 & 8,5 & 8,5 & 0,00 & 0,25 & 240,7 & 508,5 & $-6,95$ \\
\hline 21 & 3,11 & 3,09 & 8,5 & 7,7 & 0,00 & 0,27 & 503,3 & 508,1 & 7,31 \\
\hline 22 & 3,05 & 3,11 & 6,8 & 6,8 & 0,01 & 0,29 & 562,4 & 547,9 & 17,64 \\
\hline 23 & 4,39 & 3,17 & & 5,8 & 0,02 & 0,31 & 593,7 & 625,1 & 34,36 \\
\hline 24 & 3,20 & 3,21 & 4,8 & 4,9 & 0,01 & 0,29 & 799,5 & 800,1 & 81,83 \\
\hline 25 & 3,23 & 3,22 & 4,0 & 4,0 & 0,00 & 0,26 & & & \\
\hline 26 & 3,20 & 3,22 & 3,2 & 3,2 & 0,00 & 0,22 & & & \\
\hline
\end{tabular}


Tabela A23: Valores experimentais do ensaio da-3.

\begin{tabular}{|c|c|c|c|c|c|c|c|c|c|}
\hline Tempo (h) & $X(g / L)$ & $\mathrm{X}$ lis. & $G(g / L)$ & G lis. & $\mu_{x}$ & $\mu_{s}$ & Ac (mg/L) & Acetato & $\mu \mathrm{Ac}$ \\
\hline 0| & 0,72 & 0,71 & 4,6 & 5,0 & 0,00 & 0,00 & 0,0 & 0,0 & 0,00 \\
\hline 1 & 0,76 & 0,72 & 5,1 & 5,0 & 0,05 & 0,03 & 0,0 & 0,0 & 0,00 \\
\hline 2 & 0,72 & 0,79 & 4,6 & 5,0 & 0,14 & 0,02 & 0,0 & 0,0 & 0,00 \\
\hline 3 & 0,98 & 0,99 & 5,1 & 5,0 & 0,32 & 0,06 & 0,0 & 0,0 & 0,00 \\
\hline 4 & 1,43 & 1,42 & 4,9 & 4,9 & 0,37 & 0,10 & 0,0 & 0,0 & 0,00 \\
\hline 5 & & 1,98 & & 4,7 & 0,29 & 0,12 & & 0,0 & 0,00 \\
\hline 6 & 2,57 & 2,53 & 4,4 & 4,4 & 0,20 & 0,12 & 0,0 & 0,0 & 0,00 \\
\hline 7 & & 2,97 & & 4,1 & 0,12 & 0,12 & & 0,0 & 0,00 \\
\hline 8 & 3,23 & 3,24 & 3,7 & 3,7 & 0,06 & 0,11 & 0,0 & 0,0 & 0,00 \\
\hline 9 & & 3,35 & & 3,3 & 0,02 & 0,10 & & 0,0 & 0,00 \\
\hline 10 & 3,23 & 3,38 & 3,0 & 3,0 & 0,00 & 0,10 & 0,0 & 0,0 & 0,00 \\
\hline 11 & & 3,39 & & 2,7 & 0,00 & 0,09 & & 0,0 & 0,00 \\
\hline 12 & 3,24 & 3,40 & 2,6 & 2,4 & 0,00 & 0,10 & 0,0 & 0,0 & 0,00 \\
\hline 13 & & 3,42 & & 2,0 & 0,01 & 0,12 & & 0,0 & 0,00 \\
\hline 14 & 3,60 & 3,44 & 2,4 & 1,5 & 0,01 & 0,14 & 0,0 & 0,0 & 0,00 \\
\hline 15 & & 3,48 & & 1,0 & 0,02 & 0,15 & & 0,0 & 0,00 \\
\hline 16 & 3,51 & 3,59 & 0,5 & 0,5 & 0,04 & 0,13 & 0,0 & 0,0 & 0,00 \\
\hline 17 & & 3,82 & & 0,1 & 0,08 & 0,07 & & 0,0 & 0,00 \\
\hline 18 & 4,04 & 4,20 & 0,0 & 0,0 & 0,11 & 0,00 & 0,0 & 0,0 & 0,00 \\
\hline 19 & & 4,73 & & 0,3 & 0,12 & $-0,09$ & & 0,0 & 0,00 \\
\hline 20 & 5,46 & 5,33 & 1,7 & 0,8 & 0,11 & $-0,10$ & 0,0 & 0,0 & 0,00 \\
\hline 21 & & 5,93 & & 1,4 & 0,10 & $-0,10$ & & 0,0 & 0,00 \\
\hline 22 & & 6,49 & 2,0 & 2,0 & 0,08 & $-0,08$ & 0,0 & 0,0 & 0,00 \\
\hline 23 & & 7,03 & & 2,5 & 0,08 & $-0,06$ & & 0,0 & 0,00 \\
\hline 24 & 7,04 & 7,60 & 2,9 & 2,9 & 0,08 & $-0,05$ & 0,0 & 0,0 & 0,00 \\
\hline 25 & & 8,20 & & 3,3 & 0,07 & $-0,05$ & & 0,0 & 0,00 \\
\hline 26 & 8,56 & 8,73 & 3,7 & 3,7 & 0,05 & $-0,04$ & 0,0 & 0,0 & 0,00 \\
\hline 27 & & 9,06 & & 4,0 & 0,02 & $-0,03$ & & 0,0 & 0,00 \\
\hline 28 & 9,20 & 9,16 & 4,3 & 4,3 & 0,00 & $-0,02$ & 0,0 & 0,0 & 0,00 \\
\hline 29 & & 9,14 & & 4,3 & 0,00 & 0,00 & & 0,0 & 0,50 \\
\hline 30 & 9,18 & 9,13 & 4,1 & 4,1 & 0,00 & 0,13 & 7,9 & 7,7 & $-0,15$ \\
\hline 31 & & 9,14 & & 1,7 & 0,00 & 0,28 & 2,9 & 4,0 & $-0,49$ \\
\hline 32 & 8,61 & 9,09 & 0,2 & 0,0 & $-0,01$ & 0,00 & 0,0 & 0,0 & 0,00 \\
\hline 33 & 9,21 & 9,04 & 0,0 & 0,0 & 0,00 & 0,00 & 0,0 & 0,0 & 0,00 \\
\hline 34 & 8,71 & 9,02 & 0,0 & 0,0 & 0,00 & 0,00 & 0,0 & 0,0 & 0,00 \\
\hline 35 & 9,15 & 9,06 & 0,0 & 0,0 & 0,00 & 0,00 & 0,0 & 0,0 & 0,00 \\
\hline 36 & 8,90 & 9,02 & 0,0 & 0,0 & $-0,02$ & $-0,02$ & 0,0 & 0,0 & 0,00 \\
\hline
\end{tabular}




\section{APÊNDICE B}

Estão listadas neste apêndice os valores de $\mathrm{Q}_{2}$ e OD referentes as Figuras dos ensaios d9 e d10 - valores de OD - e dos ensaios descontínuos alimentados - valores de Qo2 - . Portanto, segue-se as Tabelas:

Tabela B1: Valores de tensão de oxigênio dissolvido para os ensaios d3 e d4 e para os ensaios d9 e d10.

\begin{tabular}{|r|r|r|}
\hline \multicolumn{1}{|r|}{ Tempo (h) } & OD (d3) & OD (d4) \\
\hline 0 & 99.8 & \multicolumn{1}{c|}{100} \\
\hline 2 & 98.5 & 100 \\
\hline 4 & 96.5 & 99.4 \\
\hline 6 & 92.5 & 96.7 \\
\hline 8 & 89.8 & 95.8 \\
\hline 10 & 93.1 & 88.9 \\
\hline 12 & 94.9 & 90 \\
\hline 14 & 93.6 & 90 \\
\hline 16 & 94.3 & 90 \\
\hline 18 & 94.6 & 90.4 \\
\hline 20 & 95.1 & 91.6 \\
\hline 22 & 95.3 & 92.3 \\
\hline 24 & 95.6 & 95.4 \\
\hline 26 & 95.8 & 95.1 \\
\hline 28 & 95.9 & 95.8 \\
\hline 30 & 96.1 & 95.6 \\
\hline 32 & 109.5 & 95.5 \\
\hline 34 & 99 & 102.3 \\
\hline 36 & 94.7 & 100 \\
\hline 38 & 102.9 & 100.9 \\
\hline 40 & & 101.5 \\
\hline & & \\
\hline
\end{tabular}

\begin{tabular}{|r|r|r|}
\hline Tempo (h) & OD(d9) & OD(d10) \\
\hline 0 & 94.1 & 100 \\
\hline 1 & 88.1 & 100 \\
\hline 2 & 80 & 100 \\
\hline 3 & 70.3 & 99.5 \\
\hline 4 & 60.5 & 93.5 \\
\hline 5 & 55 & 87.7 \\
\hline 6 & 59 & 89.9 \\
\hline 7 & 59.4 & 91.7 \\
\hline 8 & 57.1 & 92.2 \\
\hline 9 & 55.5 & 94.4 \\
\hline 10 & 60.7 & 95.6 \\
\hline 11 & 61.8 & 96.2 \\
\hline 12 & 63.1 & 96.9 \\
\hline 13 & 61.8 & 101.6 \\
\hline 14 & 56.4 & 102 \\
\hline 15 & 54.8 & 103.2 \\
\hline 16 & 53.4 & 105 \\
\hline
\end{tabular}


Listados abaixo estão os valores de QO2 para os ensaios descontínuos

alimentados: para os ensaios da-1, da-2 e da-3.

\begin{tabular}{|c|c|c|c|c|c|c|}
\hline Tempo (h) & $\begin{array}{c}\text { da-1 } \\
\text { QO2 ajust. }\end{array}$ & QO2 exp. & $\begin{array}{c}\text { da-2 } \\
\text { QO2 ajust. }\end{array}$ & QO2 exp. & $\begin{array}{c}\text { da-3 } \\
\text { QO2 ajust. }\end{array}$ & QO2 exp. \\
\hline 0 & 0,00 & 0,00 & 0,00 & 5,69 & 0,00 & 0,00 \\
\hline 1 & 0,00 & 0,00 & 6,08 & 6,58 & 6,59 & 7,18 \\
\hline 2 & 0,14 & 0,00 & 5,97 & 5,83 & 9,27 & 9,25 \\
\hline 3 & 0,82 & 0,75 & 5,70 & 5,11 & 9,21 & 9,28 \\
\hline 4 & 2,60 & 2,56 & 5,68 & 5,40 & 8,65 & 8,90 \\
\hline 5 & 4,77 & 4,85 & 5,81 & 6,15 & 7,82 & \\
\hline 6 & 3,65 & 3,28 & 5,60 & 5,41 & 6,84 & 6,86 \\
\hline 7 & 1,47 & 0,95 & 5,17 & 5,26 & 5,99 & \\
\hline 8 & 0,30 & 0,49 & 4,84 & 4,78 & 5,27 & 5,46 \\
\hline 9 & 0,09 & 0,08 & 4,65 & 4,75 & 4,65 & \\
\hline 10 & 0,20 & 0,09 & 4,74 & 4,43 & 4,15 & 3,95 \\
\hline 11 & 0,86 & 0,00 & 5,08 & 5,11 & 3,75 & \\
\hline 12 & 1,98 & 2,27 & 5,29 & 5,25 & 3,47 & 3,56 \\
\hline 13 & 0,31 & 0,50 & 4,60 & 4,98 & 3,29 & \\
\hline 14 & 0,38 & & 2,56 & 2,30 & 3,22 & 3,20 \\
\hline 15 & 2,70 & 1,40 & 0,91 & 0,98 & 3,23 & \\
\hline 16 & 13,42 & 14,05 & 0,32 & 0,57 & 3,25 & 3,29 \\
\hline 17 & 16,03 & 16,06 & 0,16 & 0,15 & 3,23 & \\
\hline 18 & 16,89 & 16,74 & 0,03 & 0,00 & 3,19 & 3,16 \\
\hline 19 & 16,01 & 16,11 & 0,00 & 0,00 & 3,10 & \\
\hline 20 & 10,36 & 5,90 & 0,05 & 0,00 & 2,99 & 3,00 \\
\hline 21 & 4,92 & 6,47 & 0,59 & 0,61 & 2,84 & \\
\hline 22 & 3,97 & 3,62 & 0,00 & 0,02 & 2,68 & \\
\hline 23 & 5,19 & 5,20 & 0,00 & 0,02 & 2,54 & \\
\hline 24 & 5,90 & 5,88 & 0,00 & 0,02 & 2,49 & 2,68 \\
\hline 25 & 5,27 & 5,18 & 0,00 & 0,00 & 2,68 & \\
\hline 26 & 3,89 & 4,00 & & & 3,31 & 2,77 \\
\hline 27 & 2,38 & 2,35 & & & 4,45 & \\
\hline 28 & 2,60 & 2,58 & & & 5,99 & \\
\hline 29 & & & & & 7,50 & \\
\hline 30 & & & & & 8,18 & 8,53 \\
\hline 31 & & & & & 7,34 & 7,23 \\
\hline 32 & & & & & 4,97 & 4,88 \\
\hline 33 & & & & & 2,80 & 2,71 \\
\hline 34 & & & & & 2,02 & 2,16 \\
\hline 35 & & & & & 1,84 & 1,79 \\
\hline 36 & & & & & 1,58 & 1,57 \\
\hline
\end{tabular}

Legenda: QO2 lis.: valores ajustados da velocidade específica de respiração, $m m \mathrm{~g}^{-1} \mathrm{~h}^{-1}$ 
QO2 exp.: valores experimentais da velocidade específica de respiração, $\mathrm{mmol} \mathrm{g}^{-1} \mathrm{~h}^{-1}$. 


\section{APÊNDICE C}

Neste apêndice está detalhado o genótipo do microrganismo Escherichia coli RR1 que foi utilizado no presente trabalho. Cada gene corresponde a uma função determinada, descrita na lista abaixo:

$\mathbf{F}^{-}$: um plasmídeo auto-transmissível de baixo número de cópias. Os fatores $\mathrm{F}^{-}$ carregam porções do cromossomo de E. coli, mais notavelmente um operon lac e proAB;

supE44: cepas que carregam um supressor de RNAt da coloração amarelada resultante da inserção de glutamina, responsável pelo crescimento de alguns vetores de fagos;

lac Y1:lactose permease inativada;

ara-14: conjunto de genes envolvidos no catabolismo do carboidrato L-arabinose. Na sua inativação, o microrganismo não pode formar xilulose-5-fosfato pela Via de Pentoses-fosfato;

galK2: galactose permease inativada;

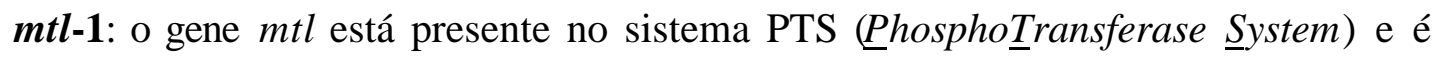
ligado ao consumo (transporte) de manitol pelo microrganismo;

leuB6: gene utilizado para marcação de cepas, responsável pela transcrição da proteína $\beta$-isopropilmalato desidrogenase;

proA2: gene utilizado para marcação de cepas, responsável pela transcrição da proteína $\gamma$-glutamil semialdeído desidrogenase;

Fonte: 
$\Delta\left(\mathbf{m c r C}-\mathbf{m}_{\mathbf{r r}}\right)$ : deleção de 6 genes $\left(m c r C, m c r B, h s d S, h s d M, h s d R, m_{r r}\right)$. Os genes mcr estão envolvidos em sistemas que afetam sistemas de restrição específicas por metilcitosina. As mutações no gene $h s d R$ inativam as restrições mas não a metilação protetora, enquanto mutações no gene $h s d S$ inativam ambos. O gene $m_{r r}$ está ligado a um sistema de restrição que requer metilação de citosina e adenina;

$\boldsymbol{r e c} A^{+}$: proteína dependente da atividade da ATPase; promove a quebra proteolítica de repressores e catalisa a formação da fita de DNA (e sua conformação espacial) e também a troca com RNA;

rpsL20: subunidade de uma pequena proteína ribossomal (ribossomal protein small);

thi-1: gene envolvido na marcação do microrganismo E. coli RR1; faz parte do sistema de síntese de tiamina no ambiente intracelular;

lambda $^{-}$: indica que a cepa RR1 é receptora de fagos lambda ou que não possue resistência à inserção de fagos lambda em seu interior. 


\section{ERRATA}

\begin{tabular}{|c|c|c|c|}
\hline Página & Localização & onde se lê & leia \\
\hline 5 & $13^{a}$ linha & ... sob forma de inclusão... & ... sob forma de corpos de inclusão ... \\
\hline 9 & $7^{\mathrm{a}}$ linha & ... que sintetiza xilose-5 fosfato... & ... que sintetiza xilulose 5-fosfato... \\
\hline 11 & $10^{\mathrm{a}}$ linha & $\ldots$ promotor $\lambda \mathrm{p}_{\mathrm{L}} \mathrm{p}_{\mathrm{R}} \ldots$ & $\ldots$ promotor $\lambda \mathrm{p}_{\mathrm{L}} \ldots$ \\
\hline 13 & $14^{\mathrm{a}}$ linha & ...que são endereçadas ao... & ... que são secretadas ao ... \\
\hline \multirow{2}{*}{15} & $5^{\mathrm{a}}$ linha & $\left(15 \mathrm{~g} \mathrm{~L}^{-1}\right)$ & $\left(65 \mathrm{~g} \mathrm{~L}^{-1}\right)$ \\
\hline & $12^{\mathrm{a}}$ linha & ... e, posteriormente, alimentar... & ...e uma alimentação... \\
\hline 28 & $16^{\mathrm{a}}$ linha & $\ldots$ da empresa $\mathrm{WHO}, \ldots$ & $\ldots$ da WHO $(\mathrm{OMS}), \ldots$ \\
\hline \multirow{4}{*}{30} & $\begin{array}{l}1^{\circ} \text { parágrafo, } \\
1^{\mathrm{a}} \text { linha }\end{array}$ & ... no biorreator em... & ... no biorreator foi Ar em... \\
\hline & $2^{\mathrm{a}}$ linha & ...a fração molar de $\mathrm{O}_{2}$ foi... & $\begin{array}{l}\text {... a fração molar de } \mathrm{O}_{2} \text { na entrada do } \\
\text { biorreator foi } 0,21 \ldots\end{array}$ \\
\hline & $6^{\mathrm{a}}$ linha & Esta é um ... & Esta equação provém de um ... \\
\hline & $7^{\mathrm{a}}$ linha & inerte, a mesma massa... & $\begin{array}{c}\text { inerte, considera-se que a mesma } \\
\text { massa... }\end{array}$ \\
\hline 33 & Equação (5) & {$[H A c]=\frac{C_{T} * 10^{p K_{a}-p H}}{1+10^{p K_{a}-p H}}$} & $\begin{array}{c}{[H A c]=\frac{C_{T} * 10^{p K_{a}-p H-\log (1-\alpha)}}{1+10^{p K_{a}-p H-\log (1-\alpha)}}} \\
\alpha: \text { grau de ionização do ácido. }\end{array}$ \\
\hline 43 & $19^{a}$ linha & S10 & S8 \\
\hline \multirow{2}{*}{45} & $4^{\mathrm{a}}$ linha & ...no mesmo instante... & ...em instante anterior ao... \\
\hline & $9^{\mathrm{a}}$ linha & ...foi praticamente a mesma... & ...foi maior que... \\
\hline 51 & $1^{\mathrm{a}}$ linha & ...consumo de base... & ... consumo de $\mathrm{NH}_{4} \mathrm{OH} 25 \% \ldots$ \\
\hline 52 & $14^{\mathrm{a}}$ linha & (choque realizado... & (elevação de temperatura em... \\
\hline
\end{tabular}




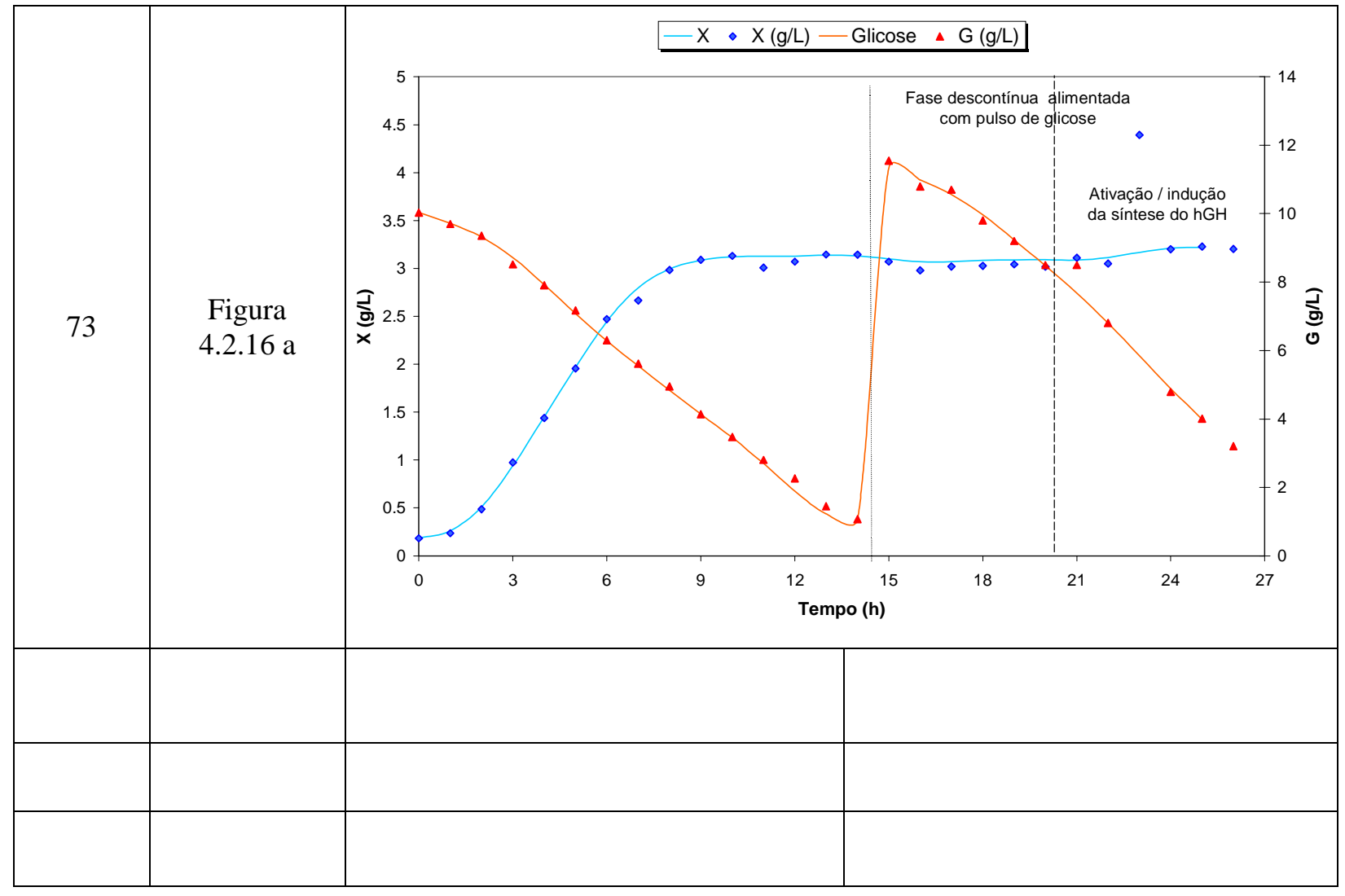

